RE-IMAGINING THE MUSEUM

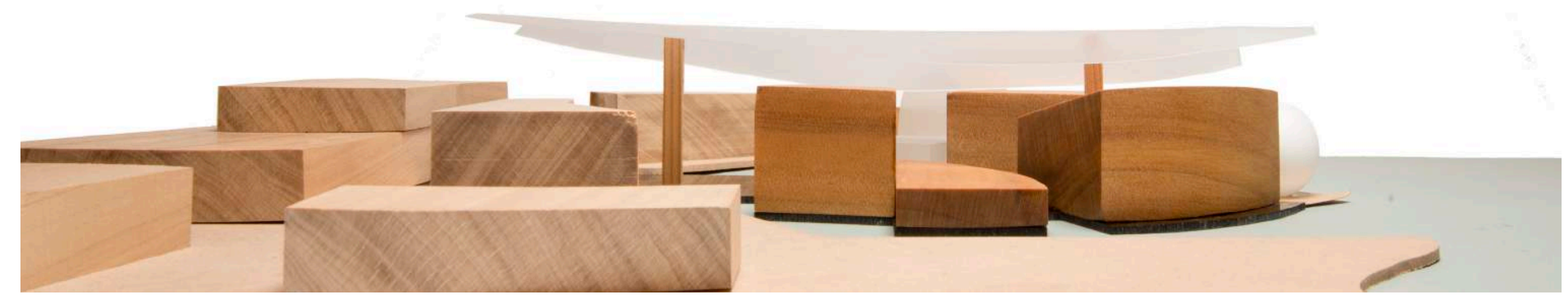





\section{RE-IMAGINING THE MUSEUM}

by

Laura Marsh

Thesis submitted to the Victoria University of Wellington

in partial fulfilment of the requirements for the degree of Master of Interior Architecture.

Victoria University of Wellington, 2015

School of Architecture 


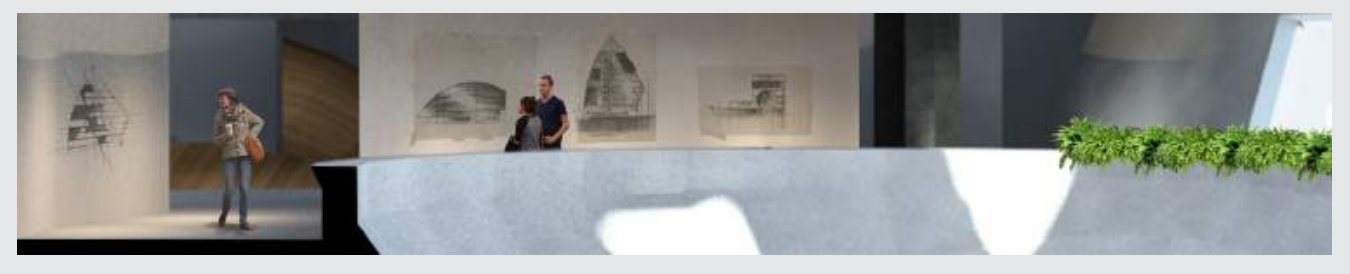


"Whatever form it takes, interior space will almost always provoke a greater emotional response than the outside of a building does"-(Goldberger 111) 



\section{ABSTRACT}

Twentieth-century museums have become more than displays of art and history. Unlike their nineteenth century origins, museums today are a centre of culture, education and entertainment.

Designing a circulation system that connects the transitions between exhibits is like forming a riddle for a visitor to enter, experience, solve and remember.

The museum reflects every asset, flaw, scar, crease, emotion, and sole of whom has time to stand and observe. For one to observe, one has to navigate. Seeking the key principles into designing a successful circulation between architecture and visitor will allow a large-scale building to be read effortlessly and seamlessly like a well-written novel.

In the late 1980's a design brief was revealed to the public requesting proposals for a National Museum of New Zealand. 10 years later the doors opened to Te Papa Tongarewa on Wellington's waterfront. Among the submitted proposals, was a concept design by Ian Athfield and Frank Gehry. Their proposal did not make it past the conceptual stage, thus offering the opportunity to explore its potential interiority and circulation.
This thesis engages with the great museums that initiated $21^{\text {st }}$ Century architecture such as the Guggenheim of Bilbao, the Jewish Museum of Berlin and most importantly, investigation into the design of Te Papa Tongarewa to analyse their method of circulation. For these museums both encapsulate the heritage of their location as well as defining future possibilities for museum architecture.

This thesis re-imagines the possibilities of the National Museum of New Zealand. This will be investigated through the tools of circulation and the experiential qualities that the architecture initiates as our bodies and the way we move are in continuous dialogue with our architecture.

This thesis investigates the importance and functionality of atrium designs, as well as the influence it has on the structures circulatory system. Exploring the potential of an Athfield / Gehry design will inspire an alternate reality to what could have been. 

ACKNOWLEDGMENTS

Through five years of study I have been taken on an eventful and unexpected journey that has been, above all, successful. I owe my achievements to those who have been by my side to offer their words of wisdom and support. For if it wasn't for them, I would not have succeeded.

To my fellow colleagues who shared the late nights on campus and the endless supply of coffee Wellington has to offer, for you have made the stress and anxiety of study an enjoyable and memorable experience.

Dr. Peter Wood whose guidance and encouragement cannot go unmentioned. Your endless amount of knowledge and attention to detail has kept me on the right path to completing a successful final product.

Lastly, I would like to express my gratitude to my family. For their love and support gave me the courage to have faith in my work and in myself. 
TABLE OF CONTENTS

$\begin{array}{ll}\text { Abstract } & \text { V } \\ \text { Acknowledgments } & \text { IX } \\ \text { Table of Contents } & \text { XI }\end{array}$

PART ONE: HISTORICAL INFLUENCES

1.1 Introduction

03

1.2 Remembering the Vision

1.2.1 The Brief

1.2.2 The Site

1.2.3 The Proposal

1.2.4 Modern Muse

1.3 Memory of Experience

1.3.1 Unique Experience

1.3.2 Economic Offerings

1.3.3 Individual Experience

1.4 Interpreting the Muse

1.4.1 Jewish Museum - Berlin

1.4.2 Guggenheim - Bilbao

1.4.3 Te Papa Tongarewa - New Zealand

1.5 To Conclude

39

53
$\mathrm{XI}$
PART TWO: REALITY OF THE INTERIOR

2.1 Syncronised Space

2.1.1 Reformation

2.1.2 Atrium

2.1.3 Vessel

2.2 Unbuilt as Reality

2.2.1 Shaping Space

2.2.2 Treasure-Box

2.2.3 Vase

2.2.4 Cannon

2.2.5 Programming

2.2.6 Deifining Circulation

2.3 The Experience

2.3.1 The Memory of the Experience

List of Figures

Bibliography

57

59

69

71

73

77

81

85

05
37 



\section{0}

HISTORICAL INFLUENCES 
A R C H ITECT URAL DE VEL OPMENT

The development of museum architecture has evolved rapidly over the past 30 years. Modern day museums are more than a place to preserve artefacts of human achievements and natural history. Museums have proceeded to become amusement parks of our past, present and future to educate and inspire the young and old as well as accommodating our human artistic contribution. A public monument, art sculpture, and a representation of social change giving the location destination architecture and the visitors a memorable experience. With this, the functional needs of preserving delicate works of our history become challenged by the architect's aesthetic representations. Limitations of exhibit design, restrict interior architectural movements but open up opportunities to orchestrate a dialogue between gallery spaces.

Vital to a modern museum is the experience of its interior. The aim of this thesis is to explore circulation systems within a complex, multi-storey hybrid architecture. The project begins with the proposed design for the National Museum of New Zealand, submitted by Ian Athfield and Frank Gehry. As this design did not proceed from its conceptual design, it then offers a 'blank canvas' to explore the interior of what could have been New Zealand's National Museum. 


\subsection{INTRODUCTION}

POSSESSION OF THE ORIGINAL

A limited amount of documentation and representation of the proposal - which only addresses the overall formation and exterior of the building - provides a most advantageous concept for an interior architect to take full control. For no component of this design (arrangement, form, access points, etc.) is complete, until it has established its interior. Realising that the experience of the interior provokes a greater emotional response than that of the exterior, the exterior is only complete once the interior succeeds in its form.

Adopting the outline of the original design brief, a museum will be designed in reference to the national identity of New Zealand (Athfield and Gehry). Three iconic museums have encouraged the research of this thesis. The directional linear circulation of the Jewish Museum of Berlin, the Guggenheim of Bilbao with a 'figure of 8 ' style, and lastly, the multi-directional circulation of Te Papa Tongarewa. Each one of these museums articulates a unique circulation system and architectural design worthy of investigation.

\section{ORIENTATING THE CIRCULATION}

Investigation of both horizontal and vertical circulatory systems will determine the path a visitor travels and experiences that they may not obtain from another architecture. The current
National Museum of New Zealand (further referred to as 'Te Papa') will heavily influence the path of this research. Te Papa's circulation system is designed and influenced by a single metaphor of biculturalism (Linzey 20). National identity and architectural symbolism are the influential ingredients needed to design a memorable architecture.

\section{S C O P E}

This thesis will focus on reviving Athfield and Gehry's proposal and develop it to be welcomed in to the twenty-first century. The idea of blessing New Zealand with a structure as iconic as Frank Gehry's Guggenheim in Bilbao is an idea that simply cannot be ignored. Design has solely focused on circulatory systems for human movement throughout a large scale building. As a focus for this project, lighting will also come in to consideration as it is an influential component and a vital ingredient to interior architecture.

Te Papa Tongarewa succeeds as a museum functionally (for art's sake) but aesthetically it seems to have a foot on either side of the fence. This is not to suggest that Te Papa needs to be redesigned as I believe that if architecture sparks a copious amount of both positive and negative critique, it is a result of statement architecture for the nation and destination architecture for the tourism industry. 

1.2

REMEMBERING THE VISION 


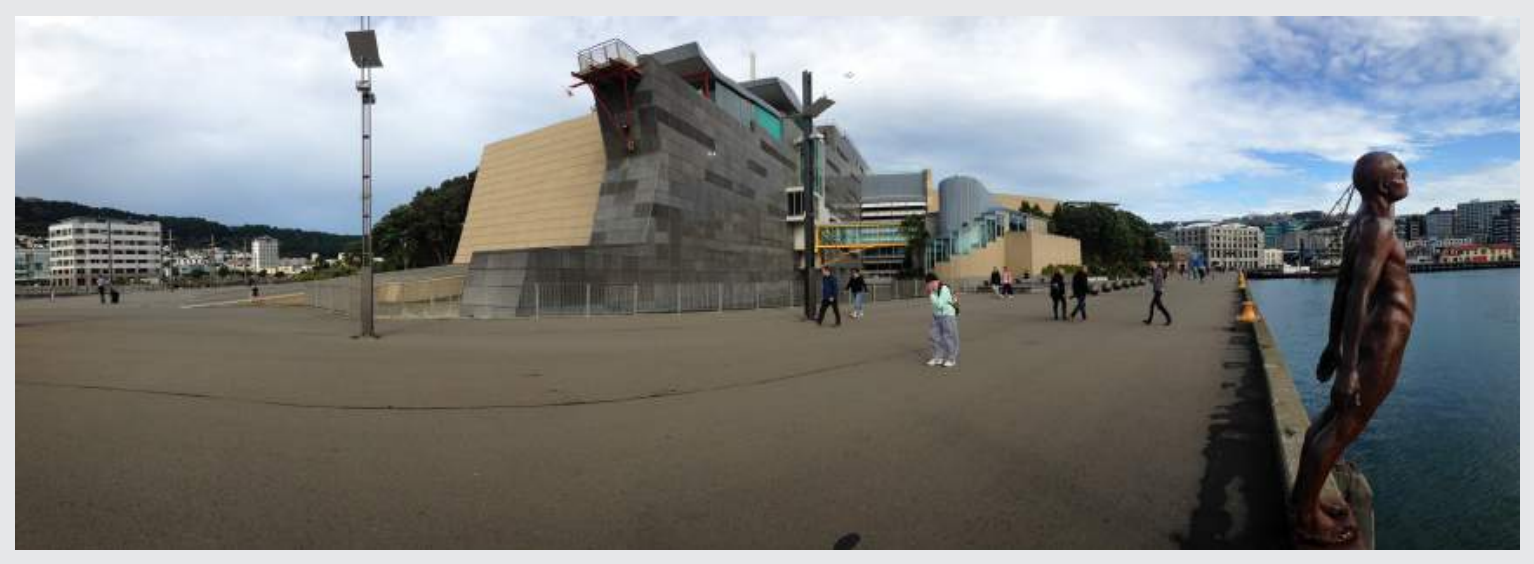

LEFT

Fig. 04: North corner of Te Papa Tongarewa and the 'Solace in the Wind Sculpture' 


\subsubsection{THE BRIEF}

\section{BACKGROUND}

In 1989 a collection of architects responded to an open invitation to conceive a conceptual design of architectural significance for the National Museum of New Zealand (Hun 14). Jasmax Architects had the most successful proposal out of thirty-eight submissions. Among those was one proposal collaboratively designed by Ian Athfield and Frank Gehry. The design brief emphasized that submissions are of a conceptual design to allow architects to focus on one of three areas - building in context, biculturalism, and national identity/symbolism (Hunt $15)$.

Confining prerequisites for submission restricted architects to four A3-sized pages of conceptual design and only half a dozen A4-sized pages of analytical description (Hunt 15). Thus providing a limited amount of information primarily focused on designing the exterior. Successful submissions moved forward to the second stage of the competition where the exterior could be further refined and the interior could begin to be established. Considering Athfield and Gehry did not surpass from their conceptual design, the interior was in the peripheral to its exterior. A space suspended in anticipation.

According to the design brief, the Board required a detailed description about the architect as well as the conceptual design. Intentions of the competition was to establish an architect and a design team, not a building (Jasmax Group 30). The architect supplied a host structure with an outline of space configuration and circulation. To finalise an interior, collaboration was made with a separate exhibition design team consisting of interior, graphic and product designers (Parkinson 61).

Conceptual challenges that confronted architects from their usual way of working, was the unfamiliar process of identifying and understanding biculturalism through design on an incomplete site. Subsequently, this resulted in what some considered an underwhelming submission of concepts (Hunt 15). 

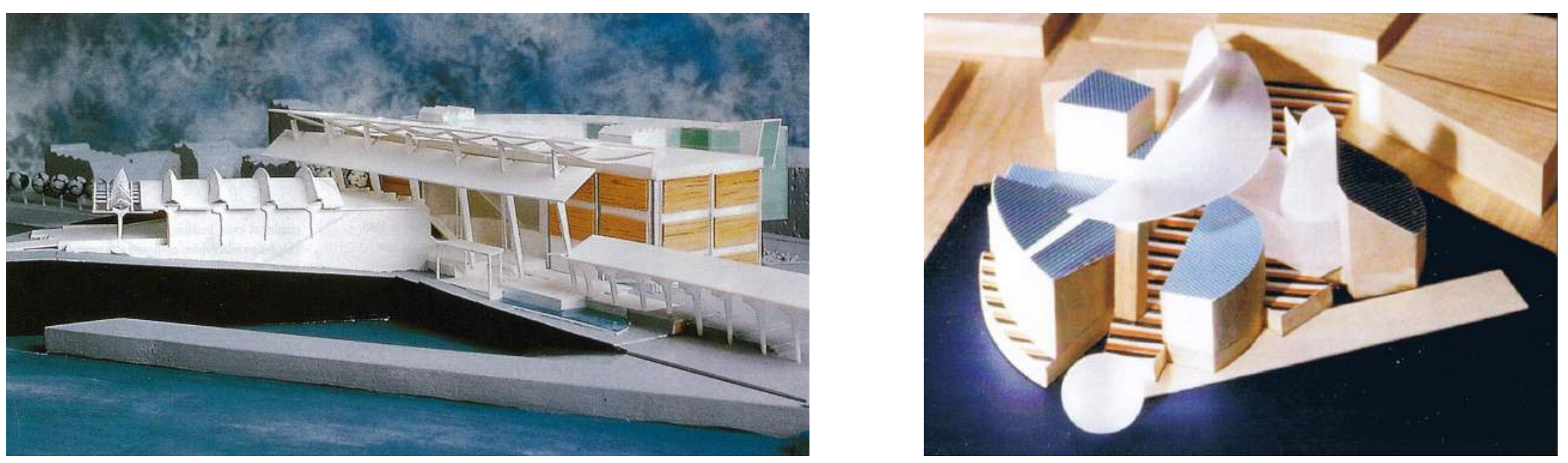

LEFT

Fig. 05: Jasmax Architects conceptual model for the National Museum of New Zealand.

ABOVE

Fig. 06: Ian Athfield and Frank Gehry conceptual model for the National Museum of New Zealand. 
THE PROPOSAL THAT PROCEEDED

Jasmax Architects proposed their design to "preserve and respect the differences in the cultures while promoting a common ground between them" (Group 32). Their design accepted and highlighted the differences between the two cultures and appropriately bound them through the structural grid.

Michael Linzey states that the "turgidly, ambiguous and nebulously stated aspiration" of the design brief was simplified by the use of a fault-line metaphor (Linzey 78-79). The metaphor signifies the relation of differences between two separate identities - tangata tiriti and tangata whenua. We are neither one people and nor are we two. This is represented within the overall gesture of the Jasmax design.

THE PROPOSAL TO BE PROCEEDED

If Athfield and Gehry's proposal was selected and further developed to become the National Museum of New Zealand, it could have marked the maturity for both careers. Athfield has since become an icon within New Zealand gaining the title Sir Ian Athfield in 2014 (Bradwell) and Frank Gehry went on to design the Guggenheim museum in Bilbao which has since been "hailed as the most important structure of its time" (Guggenheim Foundation")

\section{LOST OPPORTUNITY OF UNKNOWN Q U A L I T Y}

The outlines of the original design brief has provided this design research with a blank canvas within an architectural envelope designed by two of the most iconic architects. I aim to exploit this lost opportunity and continue the artistry crafted by Athfield and Gehry. The unknown qualities of their work provides endless opportunities to reactivate what could have been - for all we know - a mash-up of stacked, erratic forms with porthole windows.

Could this proposal have developed to be 'better' than what is? Or would the strict prerequisites of exhibition design have limited the internal qualities. Perhaps, if the metaphorical influences were focused on the internal configuration rather than working from the outside in, the critique could have been received from a different tune. 


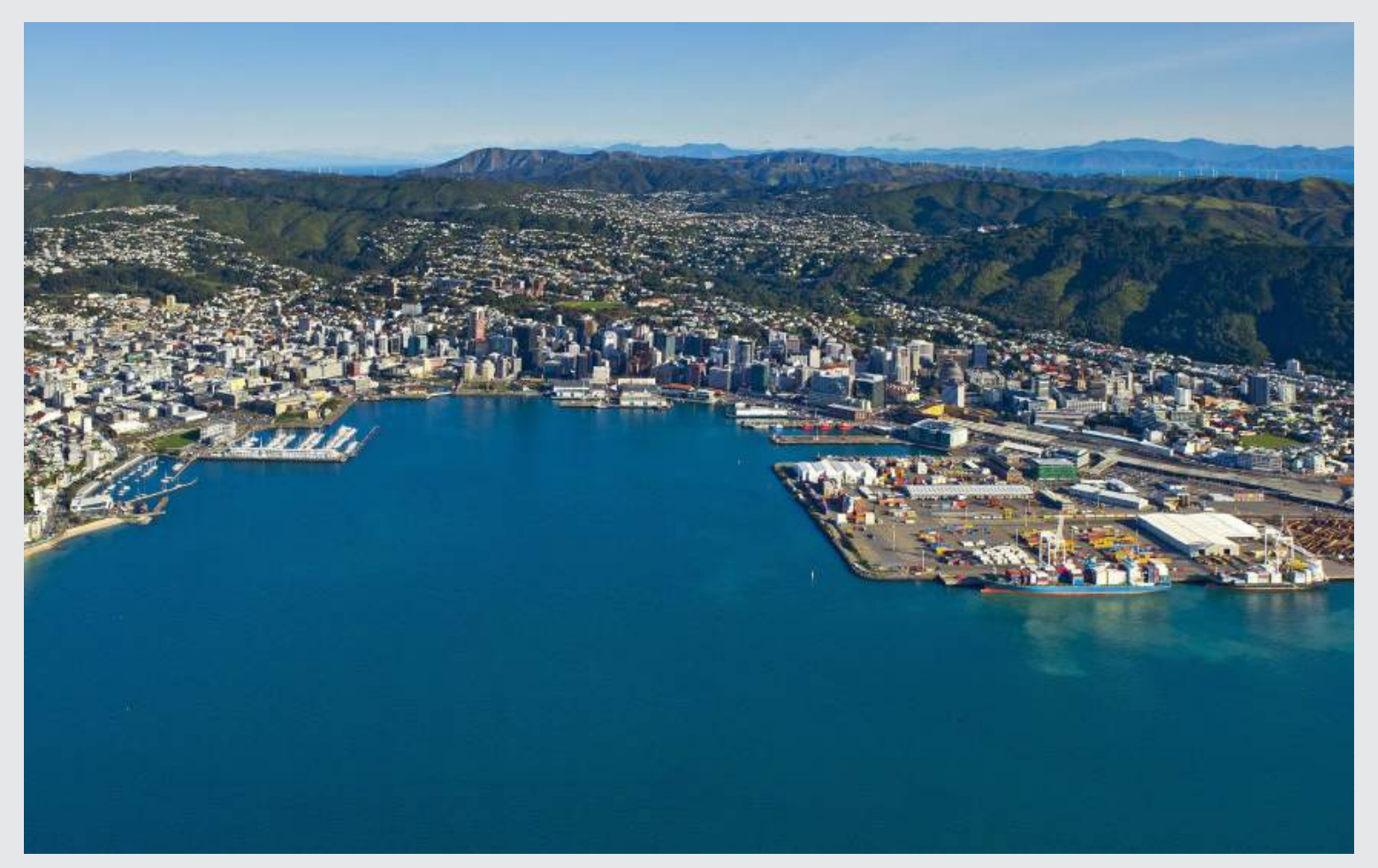

LEFT

Fig. 07: Wellington City looking south. Te Papa positioned in southwest corner

10 REMEMBERING THE VISION 


\subsubsection{THE SITE}

The site was established before the release of the design brief and will not differ for the purpose of this thesis. With the focus solely on the interiority of Athfield and Gehry's proposal, there is no need for change of location as the current is the most optimum site for such a building. The site offers the first contemporary work of art to be exhibited to its visitors - the city of Wellington. The surrounding vistas of rolling hills, cityscapes and a serene harbour, offer an ever-changing and evolving work of art crafted by man and Mother Nature.

The land was originally reclaimed for the purpose of becoming the Trans-Tasman roll-on roll-off Terminal in 1968 (Hutchison 218). Wellingtons waterfront has dramatically changed from its original shoreline discovered by the European settlers in 1840 (Kelly 01). With ideal deep waters, the harbour quickly established as a port and a city spilled out over the rolling hills. Realizing the need for more level terrain, construction began reclaiming land from the harbour. Over the course of 20 years, the city has reclaimed approximately 372 acres of land (Hutchison 220).

The National Museum of New Zealand was originally the Dominion Museum and National Art Gallery on Buckle Street. Realising its inadequacy to house the rapidly growing collections and represent the community, the decision was made to up-size and relocate (Te Papa "Our History"). Further analysis into the design and intentions of Te Papa Tongarewa are established within section 1.4.3.

To occupy this block of land, a 4-storey hotel either had to end its brief existence, or - thanks to Chris Parkin - be moved 120 meters to the other side of Cable Street. Deciding on the latter, the 3,500-tonne building was moved and settled in its new location as the Museum Hotel (Wannan).

Isolating the museum from other built forms is like placing a sculpture on display. The site delivers an optimum pedestal which can be viewed from multiple locations around Wellington City and harbour. Cable St acts as a transition point between the bustling city and the waterfront which operates at a more leisurely pace.

As well as the Buckle Street building struggling with the capacity of collections, the incentive to design a new home for the muses that represented New Zealand and its people, was the realisation that society had changed as well as our understanding of our history and national identity (Te Papa "Our History"). Nearly 25 years after the brief became public knowledge, the way in which we perceive museum architecture has progressed significantly. This has also occurred to the way in which we perceive our national identity. This presents new opportunities that Ian Athfield and Frank Gehry may not have foreseen. 


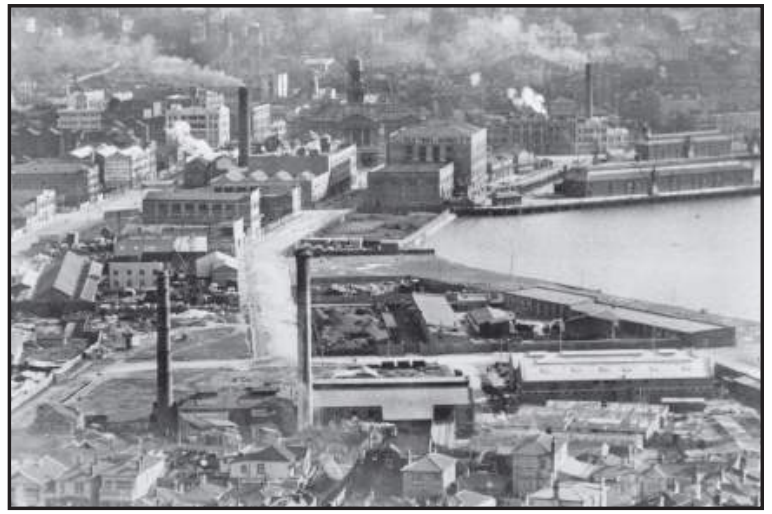

Fig. 8.1

1930 - Waitangi Park now occupies the site of

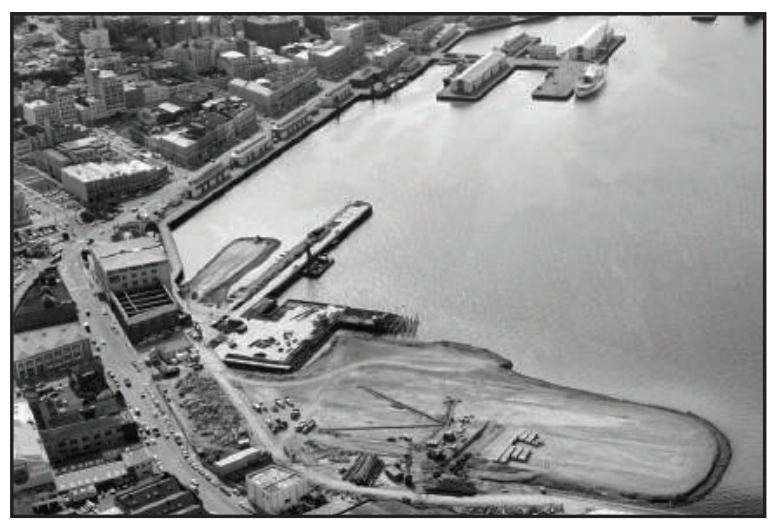

Fig. 8.2: $\quad 1968-$ Land reclamation for the Trans-Tasman

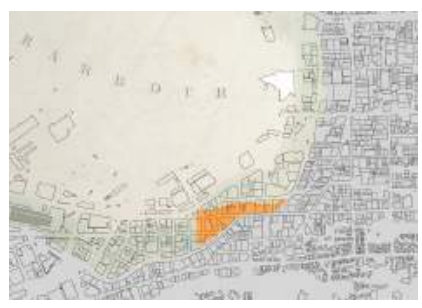

$1857-63$

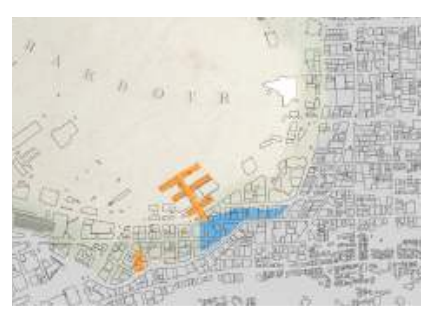

1864-65

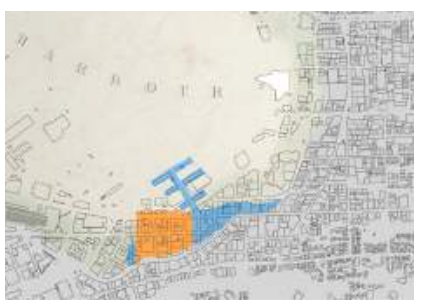

$1866-67$

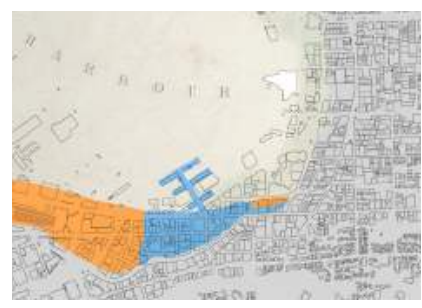

12 REMEMBERING THE VISION 


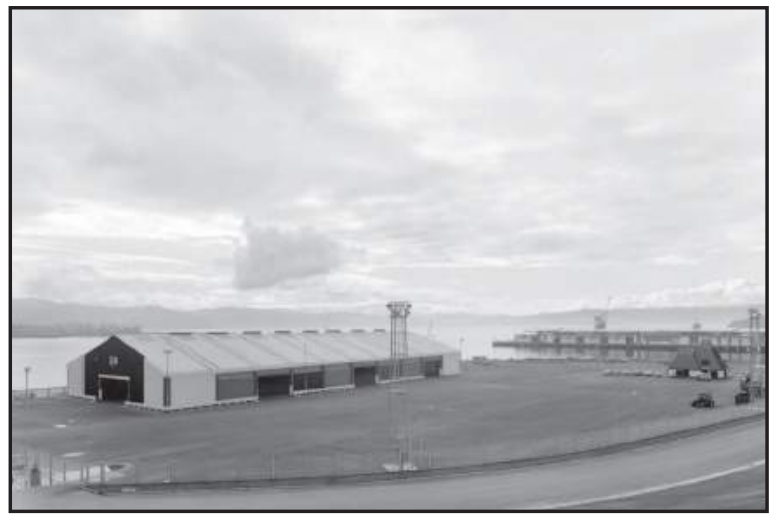

Fig. 8.3: $\quad 1984-$ Trans-Tasman Terminal
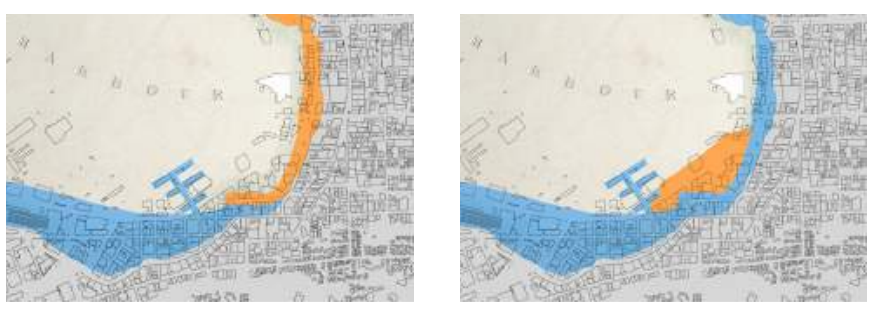

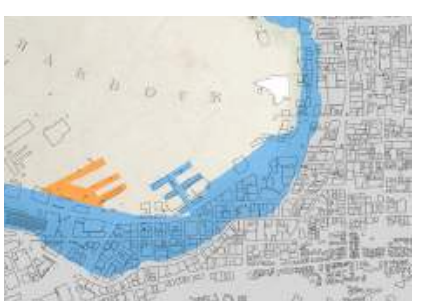

1889

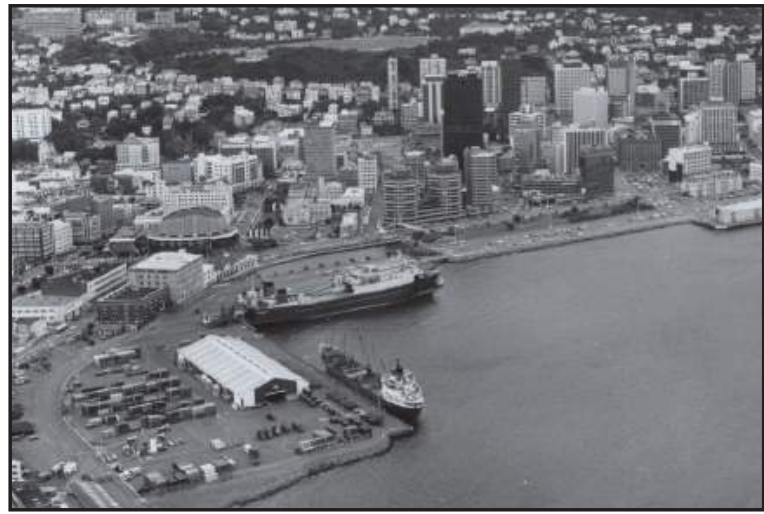

Fig. 8.4: $\begin{aligned} & 1969 \text {-Completed Trans-Tasman Terminal and } \\ & \text { shed } 26\end{aligned}$

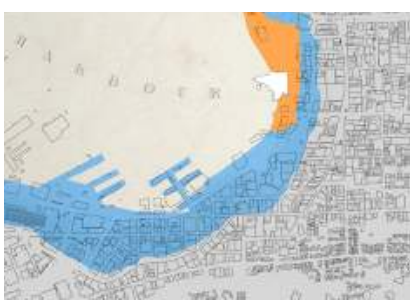

1901-04

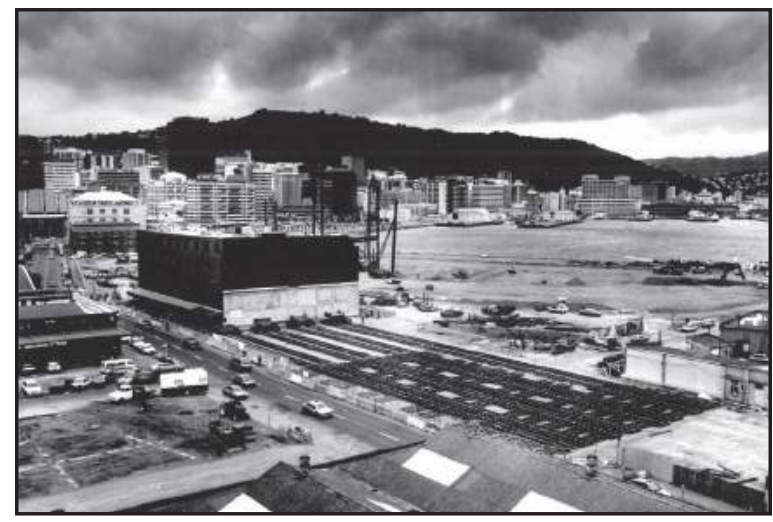

Fig. 8.5: $\begin{aligned} & 1993-\text { Museum Hotel moving } 120 \text { meters to } \\ & \text { clear the site for Te Papa Tongarewa to begin }\end{aligned}$ construction.
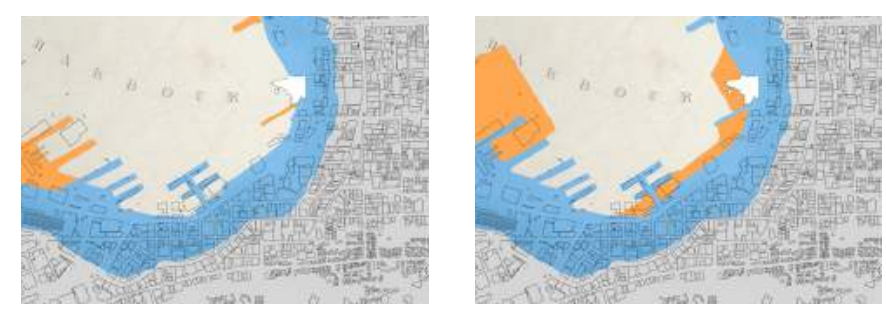

1956-Now

\begin{tabular}{l|l} 
REMEMBERING THE VISION & 13
\end{tabular} 


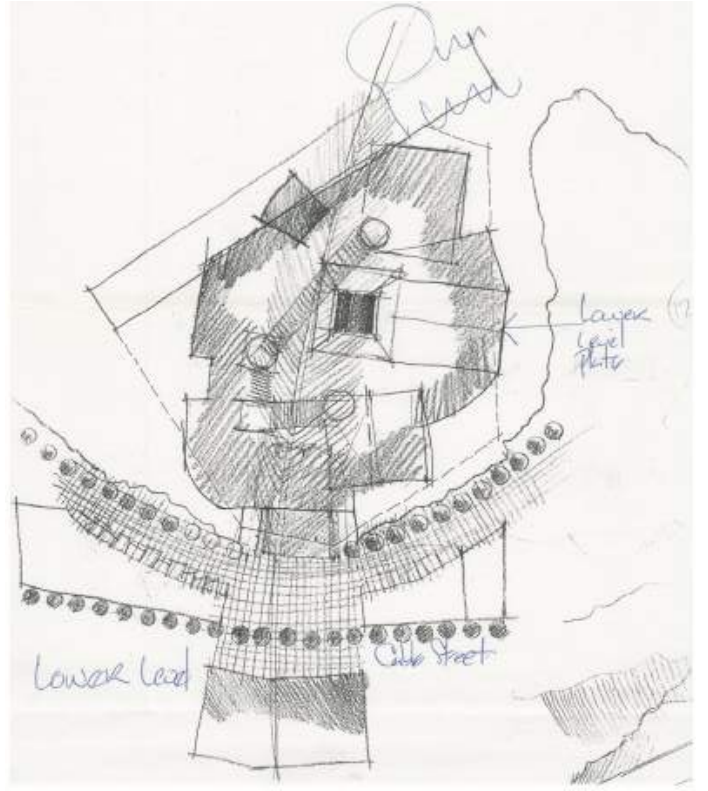

REMEMBERING THE VISION

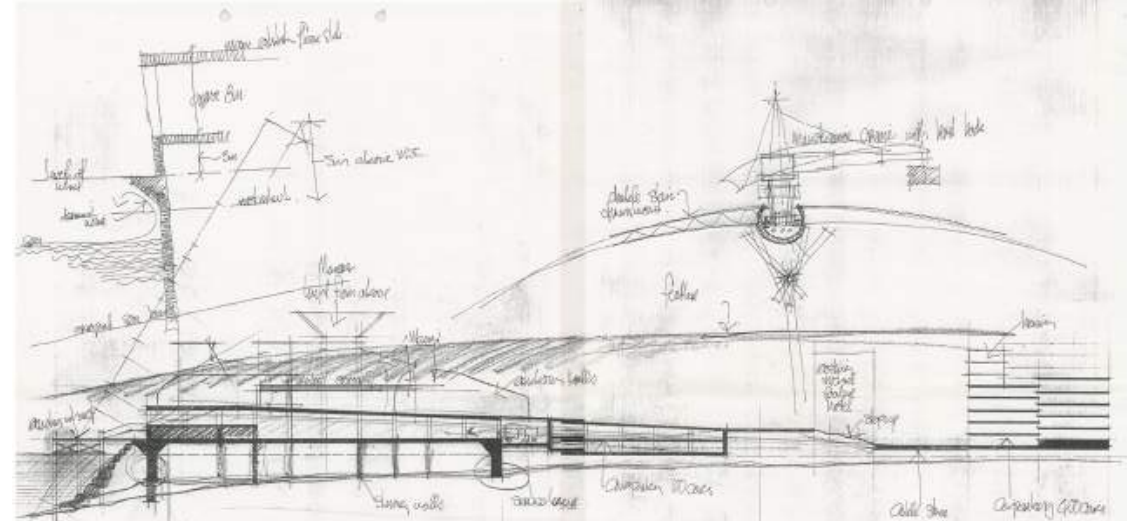

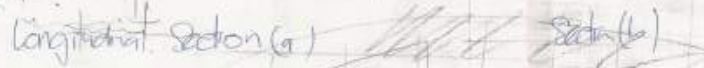

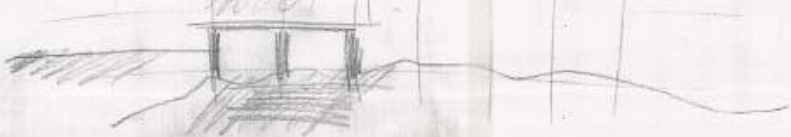

LEFT

Fig. 10: Ian Athfield and Frank Gehry proposal document. Plan drawing 01

ABOVE

Fig. 11: Ian Athfield and Frank Gehry proposal document. Longitudinal section (a)

RIGHT

Fig. 12: Ian Athfield and Frank Gehry proposal document. Section looking south 


\subsubsection{THE PROPOSAL}

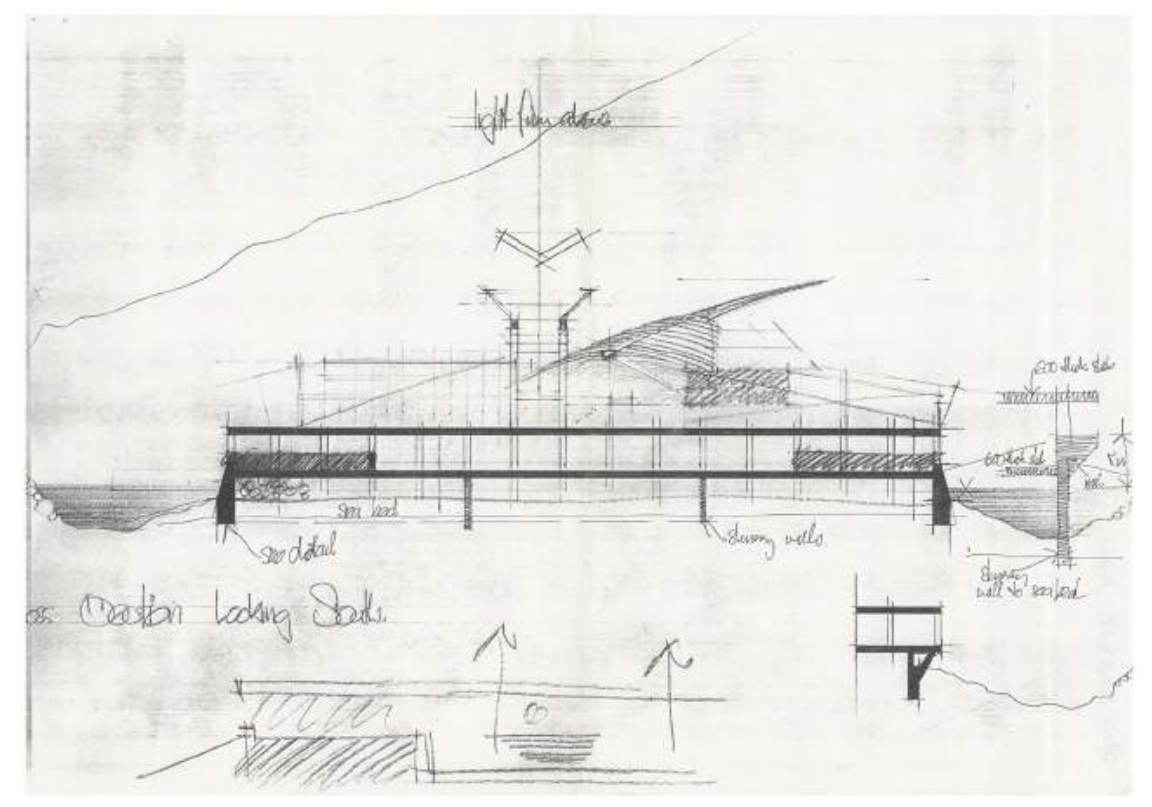

"...I have descended to share a message, to draw together and shelter our people, hold me hear; don't let me depart."- (Athfield and Gehry)

The aim of Ian Athfield and Frank Gehry's overall design was to reveal the journey of our cultural heritage from past, present and future (Athfield and Gehry). The proposed design consists of five asymmetrical voids arranged under the canopy of a large symbolic feather (see fig. 12). This was intended to signify our connections with the larger world and universe. It has been said that the laying of the feather over their design, may have been one of the reason they were disregarded at stage one of the competition (Milojevic 101)

Unfortunately, Ian Athfield passed away about a month before the commencement of this study thus leaving all information to be interpreted through his and Gehry's illustrations and models. 

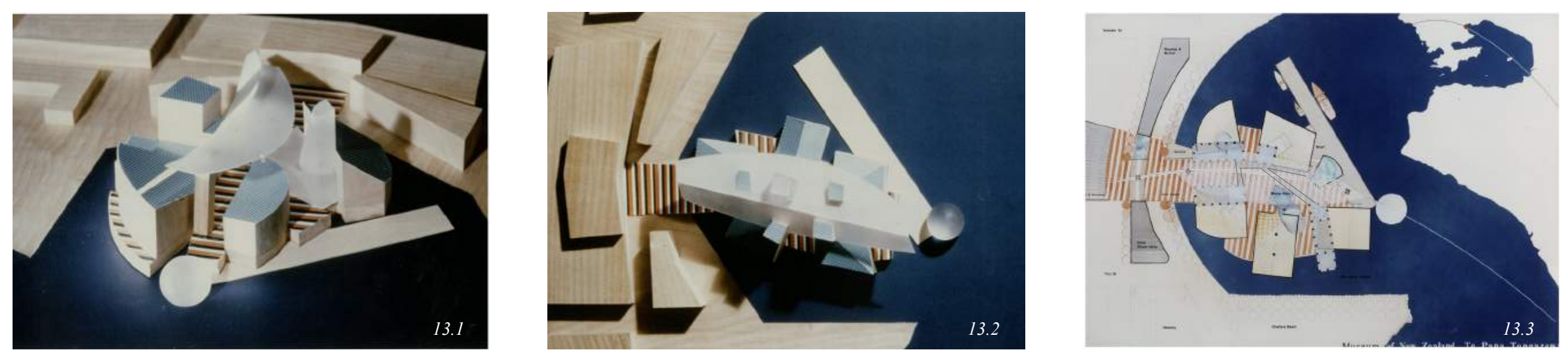

ABOVE

Fig. 13: Photo series. Ian Athfield and Frank Gehry proposal documents.

13.1: Athfield and Gehry physical model 01. Form chosen for the purpose of this research. 13.2: Athfield and Gehry physical model 02. 13.3: Athfield and Gehry plan drawing. 
THE CONCEPTUAL MODEL

The separation of structures provides identification of departments with each having a unique design. These departments consist of Art, History, Maori, Natural Environment and a unique form dedicated to the Marae Atea (Athfield \& Gehry). An inner courtyard nestles between the forms which unifies the coming together of differing identities and connects us with our natural environment. A time to appreciate the surrounding city, harbour and land.

The bridge like structure connecting each department (identified in fig. 13.3) threads together the individual identities. Interior circulation methods will stem off the central courtyard that is unique to each host structure. This could result successfully as each structure is treated as a different interior with its own unique experience, or on the other hand, could be unsuccessful and cause confusion for visitors.

The unique structure of the design has allowed Athfield and Gehry to play with the reclamation of the land. Orientating it in such a way that the structure is isolated on its own island. A historical artefact sitting upon its plinth. On the harbour side of the island is a wharf extension to be utilized for Maori Ceremonies (Athfield \& Gehry). It also symbolises the migration of the indigenous to this part of the land. A symbol similarly used within Jasmax's proposal and developed to be suggested within the final outcome. 
LEFT

Fig. 14: Re-creation of Athfield and Gehry proposal Model 01. View from Cable Stree

RIGHT (TOP)

Fig. 15: Recreation of Athfield and Gehry proposal Model 01. View from northeast.

\section{RIGHT (BOTTOM)}

Fig. 16: Recreation of Athfield and Gehry proposal Model 01. View looking down Cable Street. 

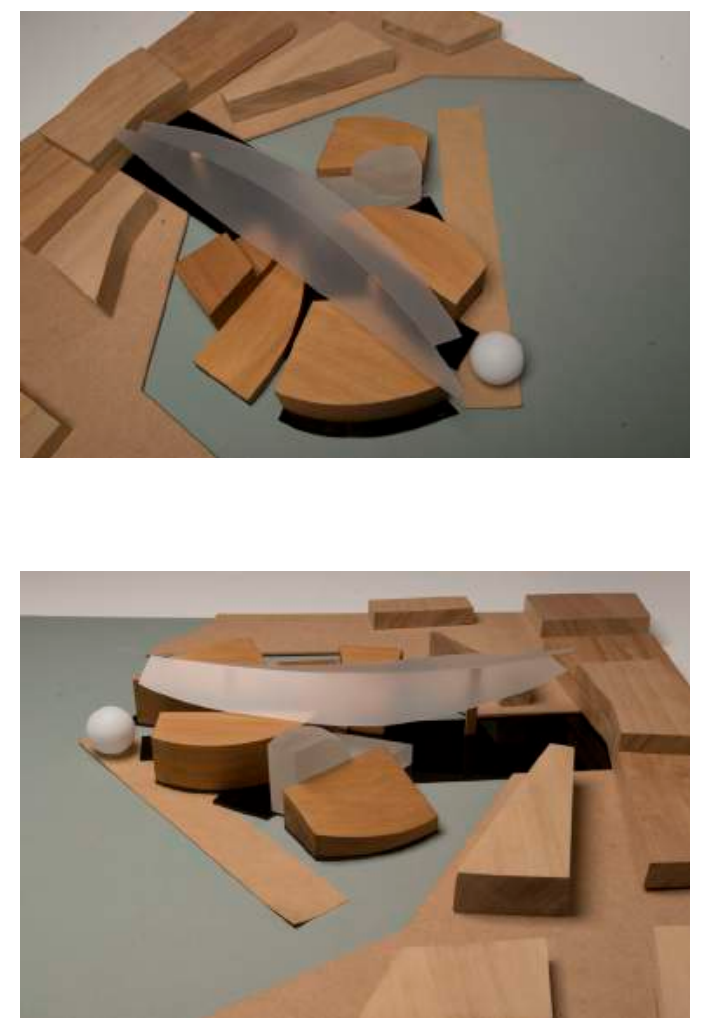

REPLICATING THE MODEL

Re-creating Athfield and Gehry's submitted model helped clarify an understanding of the physical design as well as the relationship between each individual form. The scale of the design had to be established as the only rule of measurement was comparing it to the surrounding buildings of the 1980's.

After physically interacting with the model and establishing an initial design approach, opportunities and disadvantages arise due to the configuration of forms. Each significantly different form will require a unique design, circulation and experience to maintain interest from its visitors. The bridging system of the inner courtyard will be analysed to determine whether it sufficiently connects the developed interiors. For the purpose of this research, it is proposed that the interior of this design will define the final external form. 


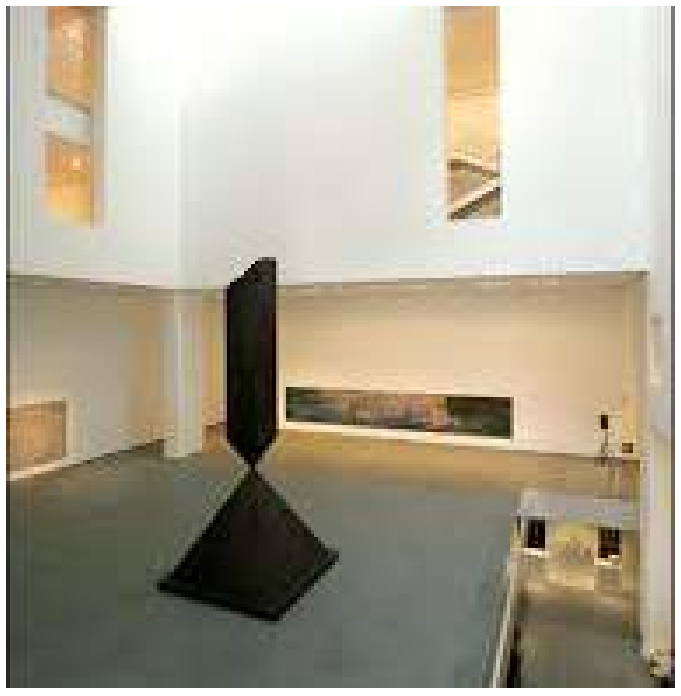

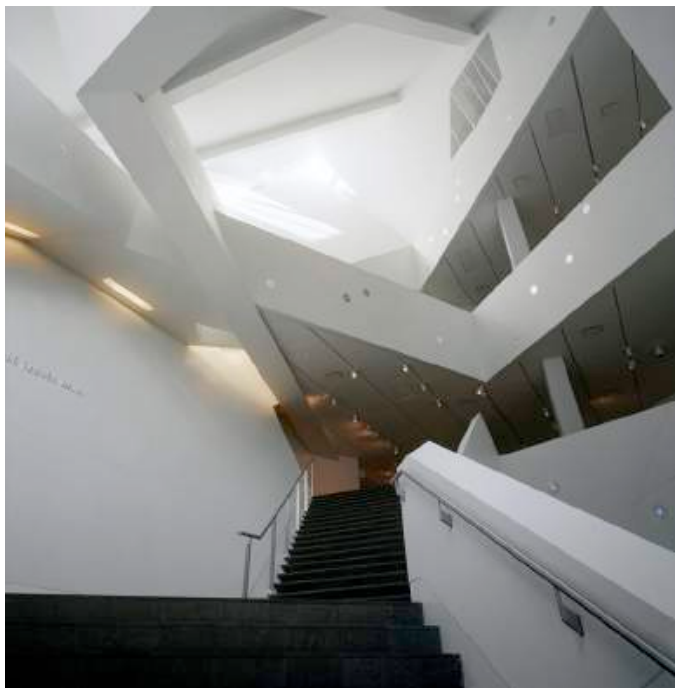

ABOVE (LEFT)

Fig. 17: Museum of Modern Art, New York City. Atrium

ABOVE (RIGHT)

Fig. 18: Art Museum, Denver. Main stairwell

RIGHT

Fig. 19: Dali Theatre and Museum, Florida. Main stairwell and atrium. 


\subsubsection{MODERN MUSE}

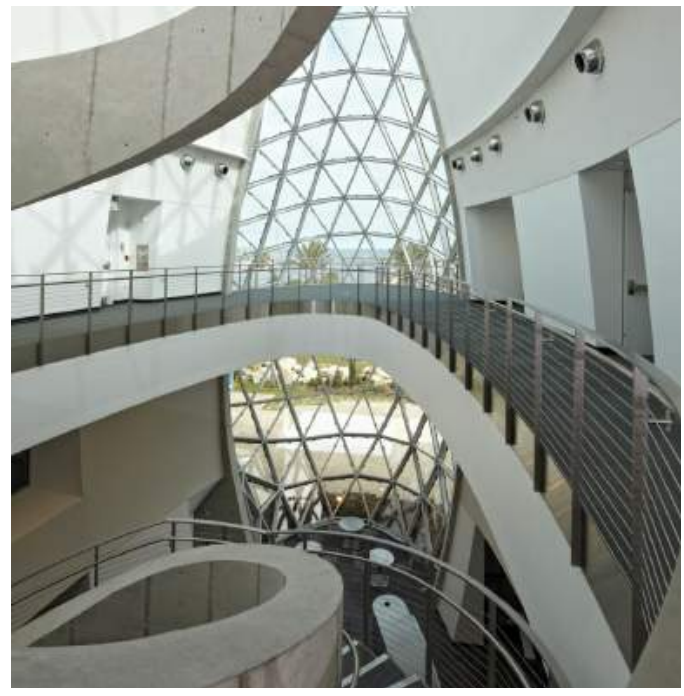

"Museum space is now recognised as a space with a history of its own, a space active in the making of meaning and, most importantly, a space open to change." - (MacLeod Reshaping Museum Space 01)

A museum's main function is to collect and preserve. Now, as well as collecting and preserving, modern museums are multi-functional structures which aim to educate the young and the old, to inspire emotion and creativity, to remember and to dream, to cause a discussion and most importantly to entertain. The grandeur of museums exhilarate visitors with an experience that is very rarely obtained from any other built form.

Museum architecture faces the challenge of desiring a long lifespan and a prediction of future events. Athfield and Gehry's design has some-what dated since its submission. We must consider however, if it had progressed to the next stage of development, would it have achieved an attempt at immortality? 


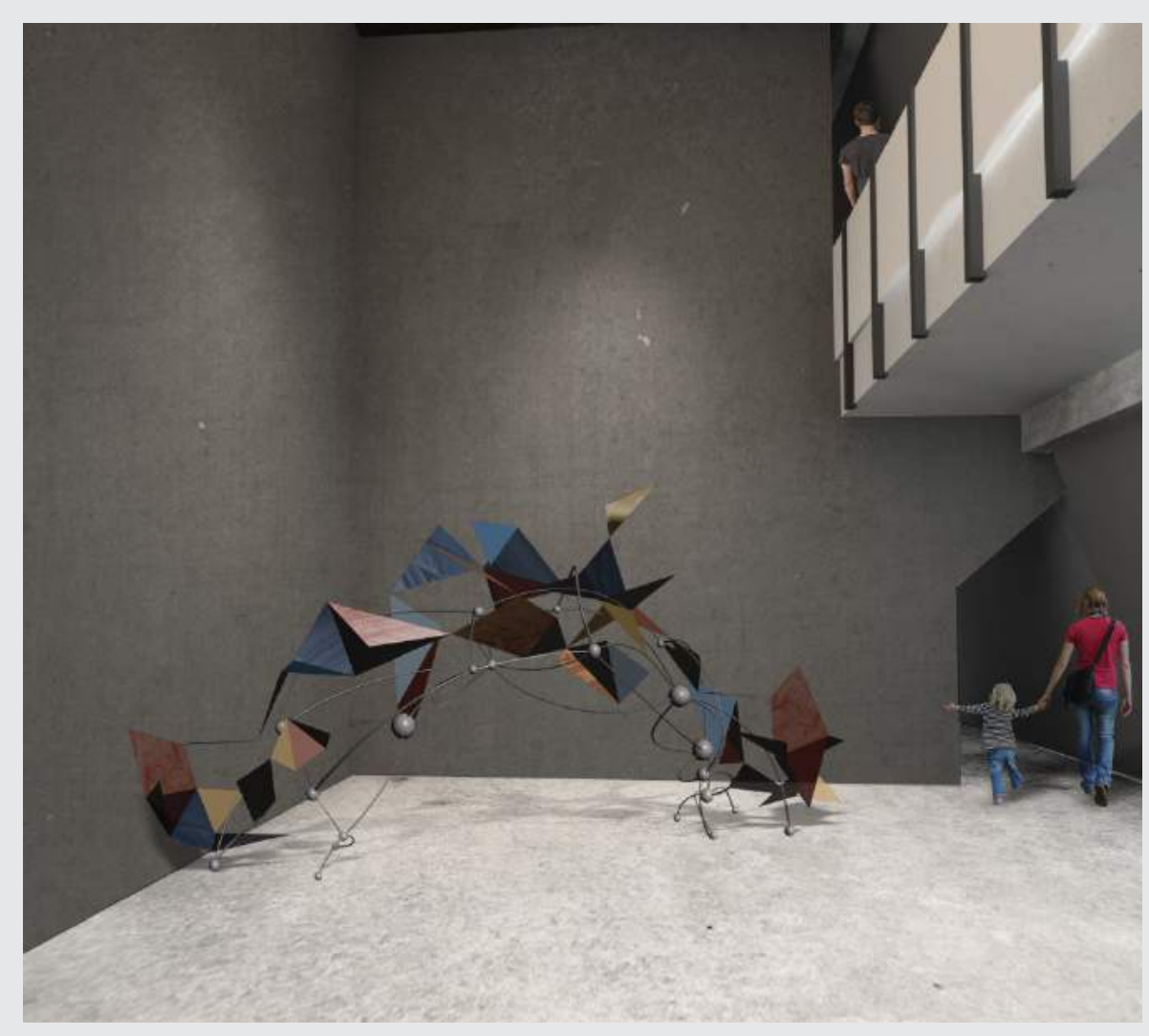

"He [she] sets the stage for a long, slow-moving performance which must be adaptable enough to accommodate unforeseen improvisations." (Rasmussen 12) 
ARCHITECTURE vs ART

Dramatic museum architecture creates an attraction for the public but also creates concern to some who question whether the architecture overshadows the art within (Shiner 31). On the other hand, most see the architecture as a performative dimension to enhance the meanings the art possesses. Architecture is both a stage and a canvas for the world of art. It is the symbolism specific to the architecture's location which creates a charismatic design and unique landmark that simultaneously achieves functionality for both the exhibit and the visitor (Macleod "Towards a Site Specific History" 10).

Museum architecture in itself is a piece of fine art. Paintings and sculptures are also under the canopy of fine art Only one factor defines the difference between the art of painting and sculpting and the art of architecture - human inhabitation (Rasmussen 10). If one was to view architecture from a great height, it simply looks like a sculptural form. Once you descend to a perspective where the architecture exceeds the horizon, the character of the structure changes as it takes on human scale and you no longer want to passively observe, but actively interact and experience the network of spaces within the monumental form.
VIRTUAL Vs REAL

The museum produces a social as well as cultural experience within a world so dominated by virtual experiences, rather than real. We rely on technology on a day to day basis to work, to learn, to socialise, confining us to a virtual reality of a second-hand experience. The museum is then heightened to an authentic temple with extraordinary real experiences to remember within an age of the virtual.

It is now expected for a new museum to be adventurous, risky and almost futuristic. What was once a passive contributor, the museum is now and active agent in the world of art. Daniel Libeskind's shards of geometric forms for the Denver Art Museum, almost defies gravity by cantilevering out over the street below. As a result of this, the internal walls are dramatically slanted for displaying artworks which has sparked a multitude of negative critiques. In my opinion, these slanted walls do implicate the work intended for a vertical display like that of the greats such as the romantics and impressionists. I see it as a dare to the contemporary artists. It challenges the perspective toward modern art. 


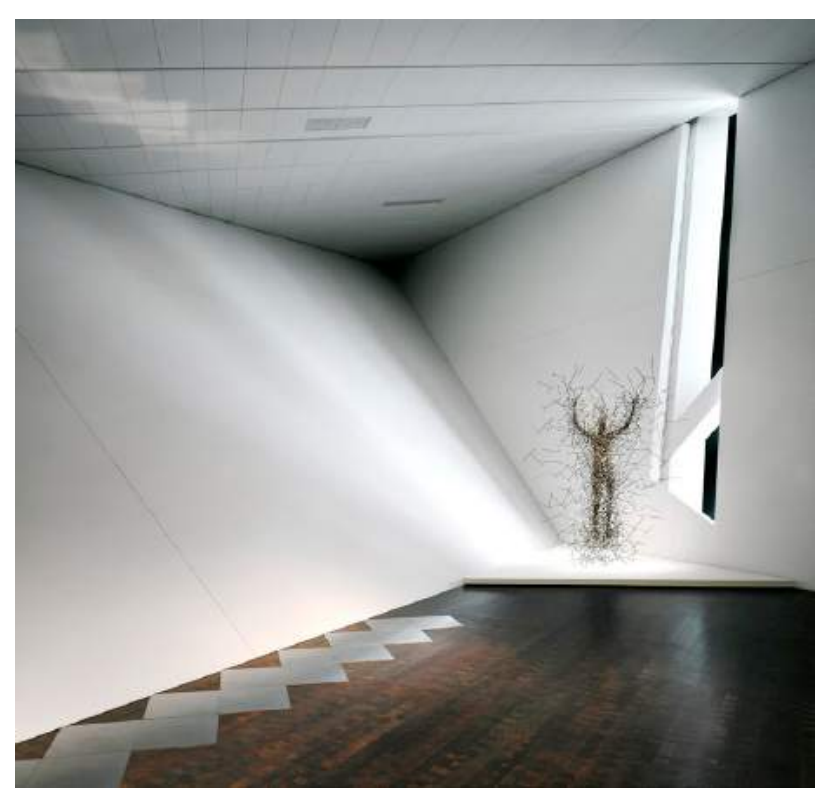

24

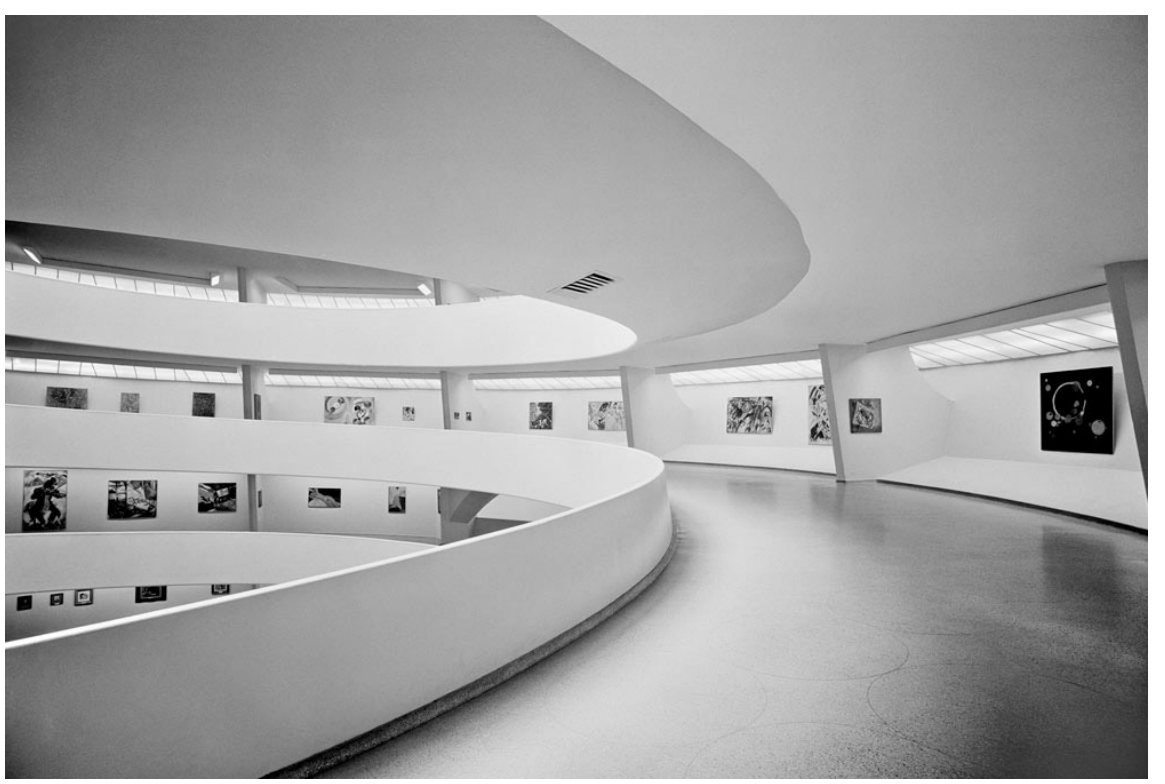

LEFT

Fig. 21: Art Museum, Denver. Daniel Libeskind. Sloping walls of gallery space.

ABOVE

Fig. 22: Guggenheim Museum, New York City. Frank Lloyd Wright. Curving walls of the continuous gallery space. 
THE EXHIBIT

Museum exhibitions can be divided into two main categories, temporary and permanent. Temporary exhibits are ever changing which attract returning visitors but do not contribute to the museums identity and meaning. Permanen exhibits on the other hand are active contributors specific to that museum (Fitzgerald 136-37).

Temporary and permanent exhibits will require differing circulations. The permanent exhibition can maintain a permanent circulation route whereas the temporary spaces will need to acquire a more malleable system depending on what subject is to be displayed. This meaning that the architecture is accommodating the art, on the other hand, if an artist is wanting to display their work within the likes of Libeskind's
Denver Museum, or Gehry's Guggenheim, it is the art that has to accommodate the architecture.

Permanent exhibitions can have more control over the architecture whereas for temporary exhibitions, the architecture has to be adaptable and malleable to inhabit any form. This results in the uninspiring "black box" design. A space of blind and mute dialogue between architecture and inhabitant - inhabitant meaning not only the visitor, but the art as well. The meandering visitor and the artist who is to display their work should have constant consideration to the architecture around them. For this to succeed, the architect too must act in consideration. Slanted, curving walls on altering axis of Gehry's Guggenheim and Libeskind's Denver Art Museum, result in individualistic interpretation between the art, the architecture, and its viewer. 


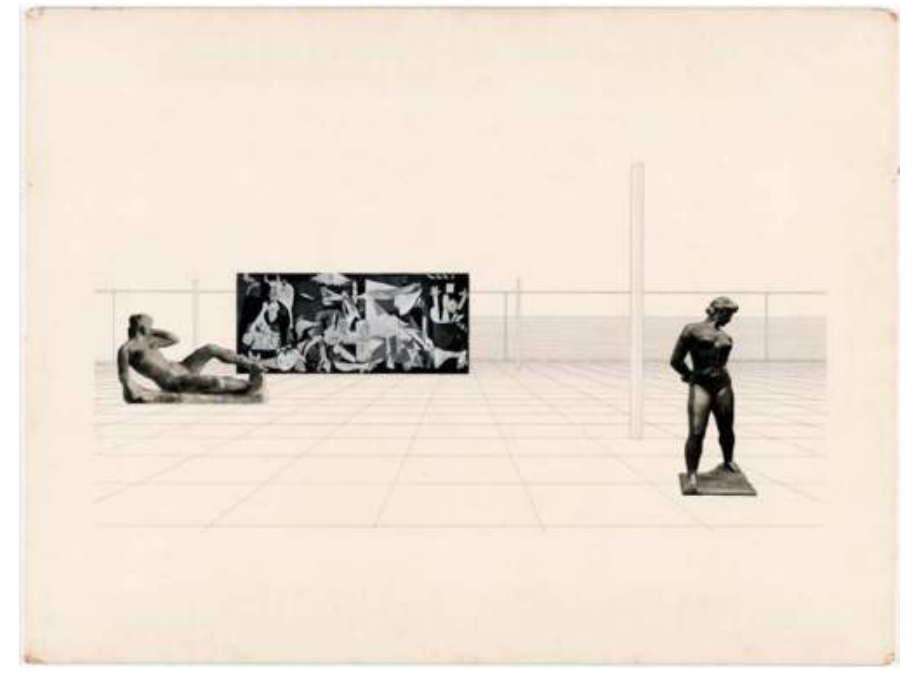

THE SPACE

Art galleries and their tendency to be of a 'black/white box' design, can result in static space, especially so with a single entry/exit point. Creating a rhythmic space will circulate the visitor around the contours of the gallery following a narrative path of the displayed works. Once there is no rhythm initiating the movement within an interior, the visitor becomes static as if to be alienated within the space (Rasmussen 134). Spaces with rhythmic qualities is further discussed in section 1.3.3. 'Individual Experience'

Mies van der Rohe displays this within his image of a small museum from 1942 (Image). Three artefacts within an implied interior of gridded lines suggest a moment of stillness through modernistic sterility. Yes the space makes you want to stand still, but yet if you do move around the space, you can't help feel that the space belongs to the art work rather than the
LEFT

Fig. 23: A Small Museum. Mies van der Rohe. (1942)

RIGHT

Fig. 24: The Turbine Hall. Tate Modern Museum,

London. 


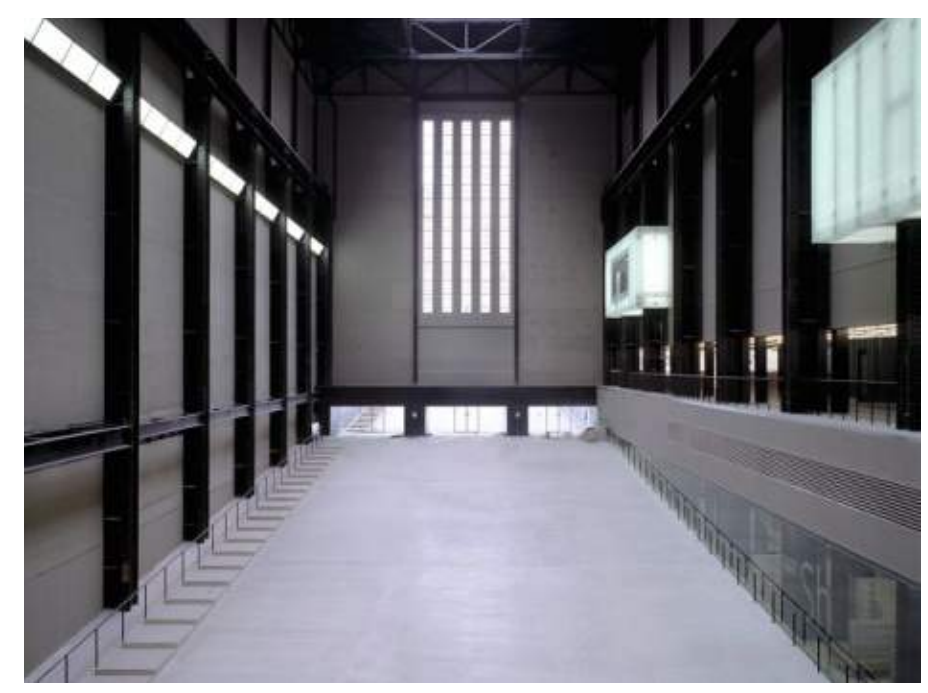

visitor. A diversity in special experiences result in a richer overall experience. Not all spaces will direct movement, smaller spaces may encourage stillness through the feeling of compression. This is all suggested, however, without reference to light. Lighting plays a significant role in circulation. If the eye cannot see into the next space, it is the light diffused from that space that will encourage curiosity and lure you to gain a visual.

The Turbine Hall of the Tate Modern Museum in London, is a space designed for giants. Repurposing it as an installation space offers an opportunity to artists that most galleries cannot - exaggeration of scale. The gallery is rhythmic in its repetitive structure, but does not offer any sense of movement, this is entirely left up to the work of the artist and how the visitors interact. For the people who view the space from the balconies above, see a performance and display of people below (Leahy 113). 

1.3

MEMORY OF EXPERIENCE 


\title{
1.3.1 A UNIQUE EXPERIENCE
}

\author{
"In a more fundamental sense, we experience satisfaction in architecture by \\ desiring it and dwelling in it, not seeking it." - (Bloomer 36)
}

The greater majority of our lives are spent in, or around buildings. Very seldom are we not interacting with a built form which has grown us accustom and sometimes oblivious to the structure surrounding us. The exterior is only an introduction that lures people to the internal world. Passing through the external envelope, the unfolding of the interior defies all expectations rendered by the exterior. This space is what conceives the surrounding spaces and is where the overall experience is centred and intensified.

Museums offer the architectural experience unattained by any other built form. From approaching at a distance, to ascending through multiple levels of exhibition spaces the visitor's mind and body is in constant awareness of their surroundings.

Architecture, art and circulation, work hand in hand to create an overall experience. The issues that arise are the overpowering nature of architecture over art (as stated earlier), and the problematic arrangement of circulation decision points (Kumar 08). Too many decision points can result in confusion for the individual. Multiply this by the amount of people to visit at a single time results in a chaotic crossing of people interrupting one another's path and distorts the rhythm between visitor and architecture. 


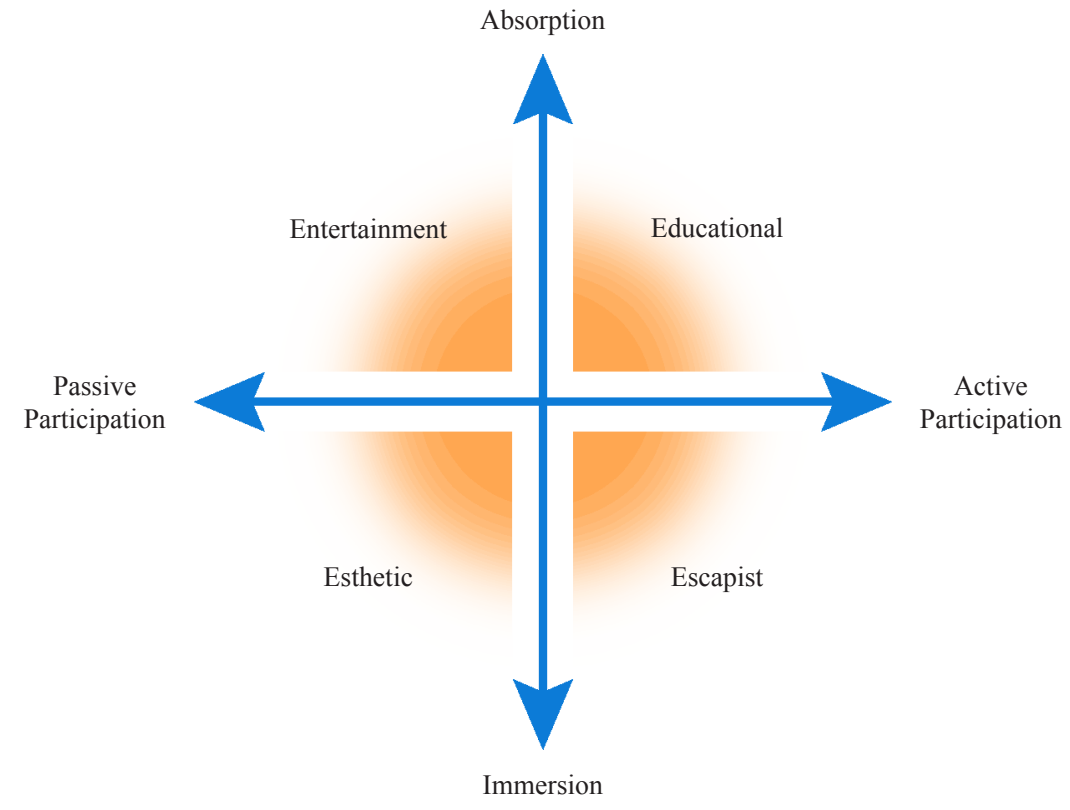

Joseph Pine and James Gilmore typology of 'experience realms' will determine an approach to circulation methods to obtain a rhythmic movement within and between spaces. A simple double axis diagram (seen in figure 26) depicts the experience engaged by establishing the level of "guest participation" and the kind of "environmental relationship" (Pine and Gilmore 45).

Pairing these dimensions identify the four "realms of experience' (Pine and Gilmore 47-55). Educational spaces are where the visitors absorb the event before them by actively engaging and influencing the outcome. Spaces for the escapist is a momentary experience that the visitor can define and control what they would not otherwise experience in everyday life. The individual is actively influences the event. Aesthetic spaces are purely visual where the visitor encounters a particular experience having little to no physical effect on the static environment. Lastly, spaces of entertainment allow the visitor to absorb the events unfolding before them while having little to no interaction with the event itself.
LEFT

Fig. 26: Joseph Pine and James Gilmore's four 'Realms of Experience' 


\subsubsection{EXPERIENCE REALM}

Architectural experiences produce economic offerings to the setting of the built form (Pine xxiv). An iconic structure can enhance the profile of its region, increase its economic investment, strengthen its tourism values and effectively, place it on the cultural map (MacLeod Reshaping Museum Space 03). This is established within Pine and Gilmore's Experience Economy. Architecture is the destination for the majority of tourists, whether it be architecture of the indigenous (temples) or hybrid architecture of today (Guggenheim of Bilbao). Tourists visit these sites to have an experience that cannot be obtained elsewhere (Lederer 117). A business (in this case a museum) must coordinate a memorable event for the visitor, and that memory is the very thing in which creates the experience (Pine 07).

The most successful architecture in this case is Frank Gehry's Guggenheim Museum (famously known as the 'Bilbao Effect'). The Guggenheim of Bilbao has expressed to the world the power of architecture (MacCannell 156). Achieving this is a result of great risk-taking and perseverance of what is uncertain.
For it is unknown if the architecture will succeed the Bilbao Effect until the architecture itself is performing.

It is believed that Te Papa Tongarewa has succeeded in this model. If compared to Frank Gehry's Guggenheim, the Bilbao Museum has an average annual visitation rate of 1 million (Guggenheim Foundation "Annual Report") whereas Te Papa Tongarewa succeeds an average of 1.3 million (Te Papa Tongarewa "Annual Report 2013/14" 05). This would imply that Te Papa Tongarewa has a successful experience economy resulting in being a destination architecture and accomplishing the Bilbao Effect. This structure is the most visited museum within Australasia making it an icon for this part of the world (Te Papa "Annual Report" 03). This is revisited in chapter 1.4.3 (Interpreting the Muse - Te Papa Tongarewa) to determine whether it is an icon because of its form or its function. 


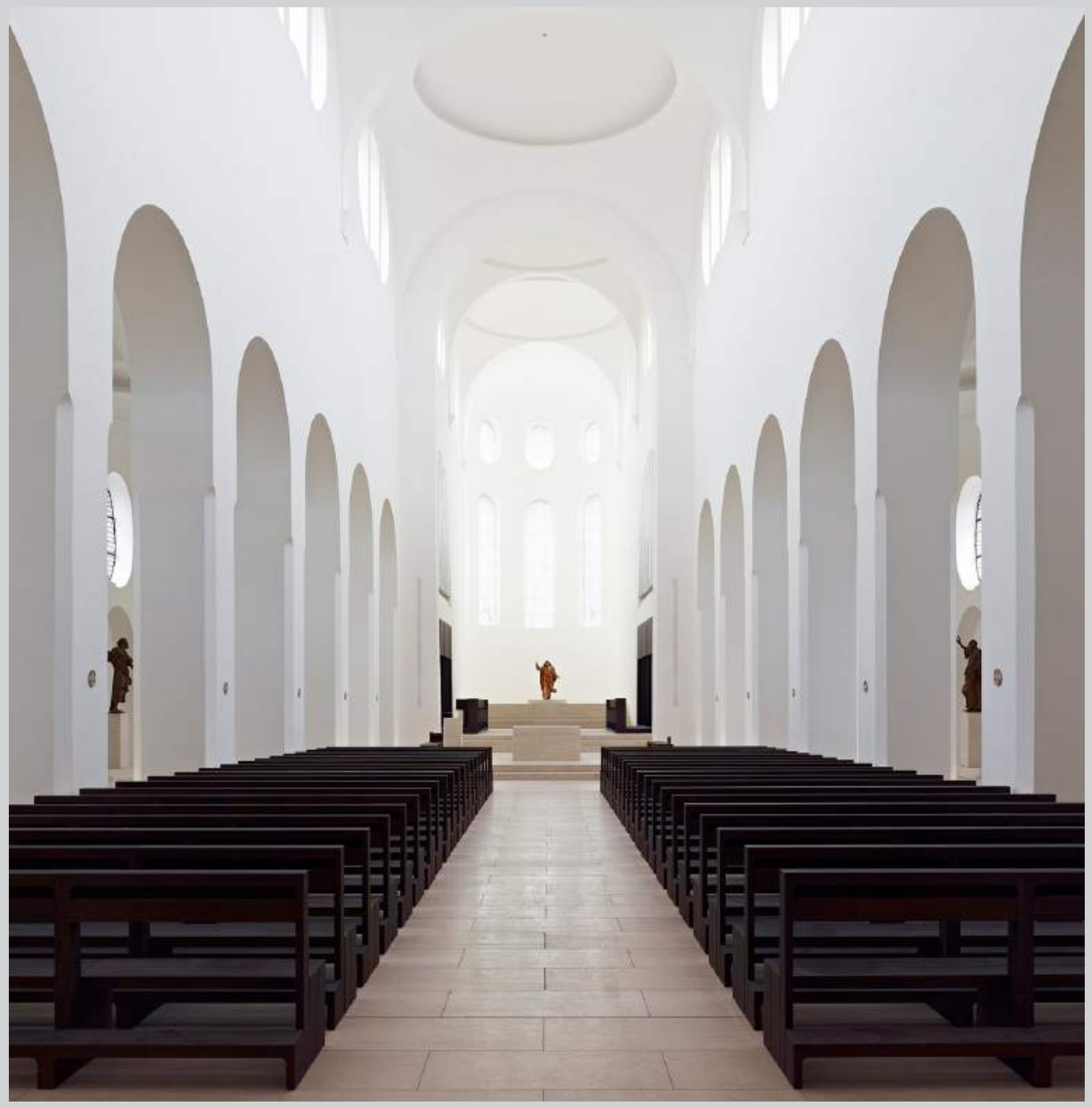

\section{MEMORY}

Architecture is remembered when it is unique and in some form or another, has affected our bodies. Generating enough relations between the built form and human form creates a rare experience worthy of documentation within our memory. There is something about rhythm which easily imprints on the mind. Remembering a beat or tone of music can spark a memory of an experience like that of a smell can remind you of a food, place or person.

The rhythmic forms of John Pawson's Moritz Church is compelling in its repetitive simplicity (fig. 27). As it practices Adolf Loose's words of 'ornamentation is crime', the configuration of forms and unification with the natural lighting encourages one to move within the space, and not move on to another. This space would have a different experiences with differing days. The natural lighting plays such a significant role creating the perception of the space to be of a divergent experience. 


\title{
1.3.3 INDIVIDUAL EXPERIENCE
}

\author{
"The manifestation of the memory of spatial events from the history of the site is idealized \\ through the abstraction of the language of the architecture, while the elements of architecture \\ become the catalysts of the process of memory" -(Abraham 113)
}

\section{R H Y T H M}

Architecture cannot establish rhythm like that of music and dance, but it is experienced in a similar manner. There are two forms of rhythm experienced within architecture. Firstly is the three-dimensional rhythm of the physical architecture. Frank Lloyd Wight's Guggenheim conducts a rhythm with the spiral movement of the central atrium. This space must be experienced for one to comprehend for an image only offers a snapshot of anticipation (Sully xxvii)

Secondly, it has to be played by the human form to achieve a motion of rhythm. Movement of visitors flowing in streams which contour the interior, listening to the footsteps and murmurs of each individual and feeling the architecture breath as it is filled with an orchestra all plays into the experience of rhythmic motion of an architectural performance.

\section{THE EXPERIENCE OF THE MUSEUM}

Where does the experience of the museum begin? Is it seeing the structure for the first time peeking behind neighbouring buildings, or is it upon walking through the grand entrance. Some people love Te Papa, some people hate it. This is what sparks conversation and debate of personal experiences. For those who have not had a personal encounter with the museum, hear this discussion and depict an image in their mind of what they imagine the museum to be. Idealised and glamorised by what others have said, I believe this is where the experience of the museum begins. 

1.4

INTERPRETING THE MUSE 


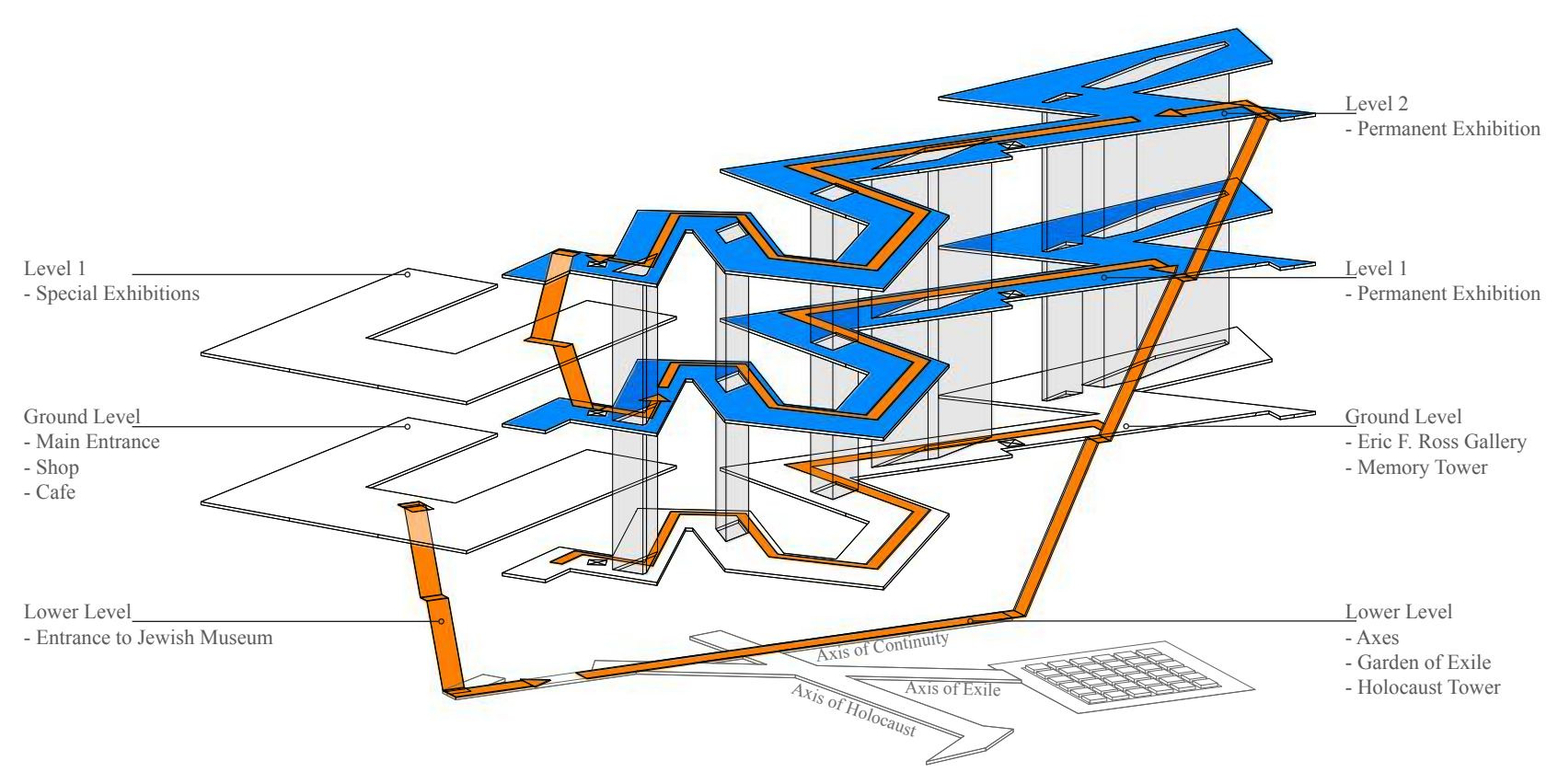

ABOVE

Fig. 28: Circulation system and space configuration of the Jewish Museum, Berlin.

RIGHT

Fig. 29: Memory Void. Jewish Museum, Berlin. 


\subsubsection{JEWISH MUSEUM - BERLIN}

DANIEL LIBESKIND - 1999

\section{B A C K G R O UN D}

Selection of an architect and design was also of a competition process for the extension of Jewish Museum in Berlin. Not long after the competition, the Berlin Wall fell which resulted the extension of the museum to be an active participant in reunifying Germany and its capital (Gorbey 02). Much like Te Papa, Libeskind aimed to acknowledge the relationship between two cultures. Two cultures which have been translated into architecture and can be interpreted as either integration, or disintegration by its visitor (Young 19). Not only has Daniel Libeskind designed a structure that both celebrates and commemorates a nation, but invites the people that were so viciously driven away, back to the city they once called home (Young 01).

One of the major design issues faced with designing the extension to the Berlin Museum, was the problematic result of highlighting the segregation between the two people once again. For the separation of two people had become suppressed and al but a buried memory. Libeskind ensures that the memory of such events are prolonged in history (Chametzky 217).

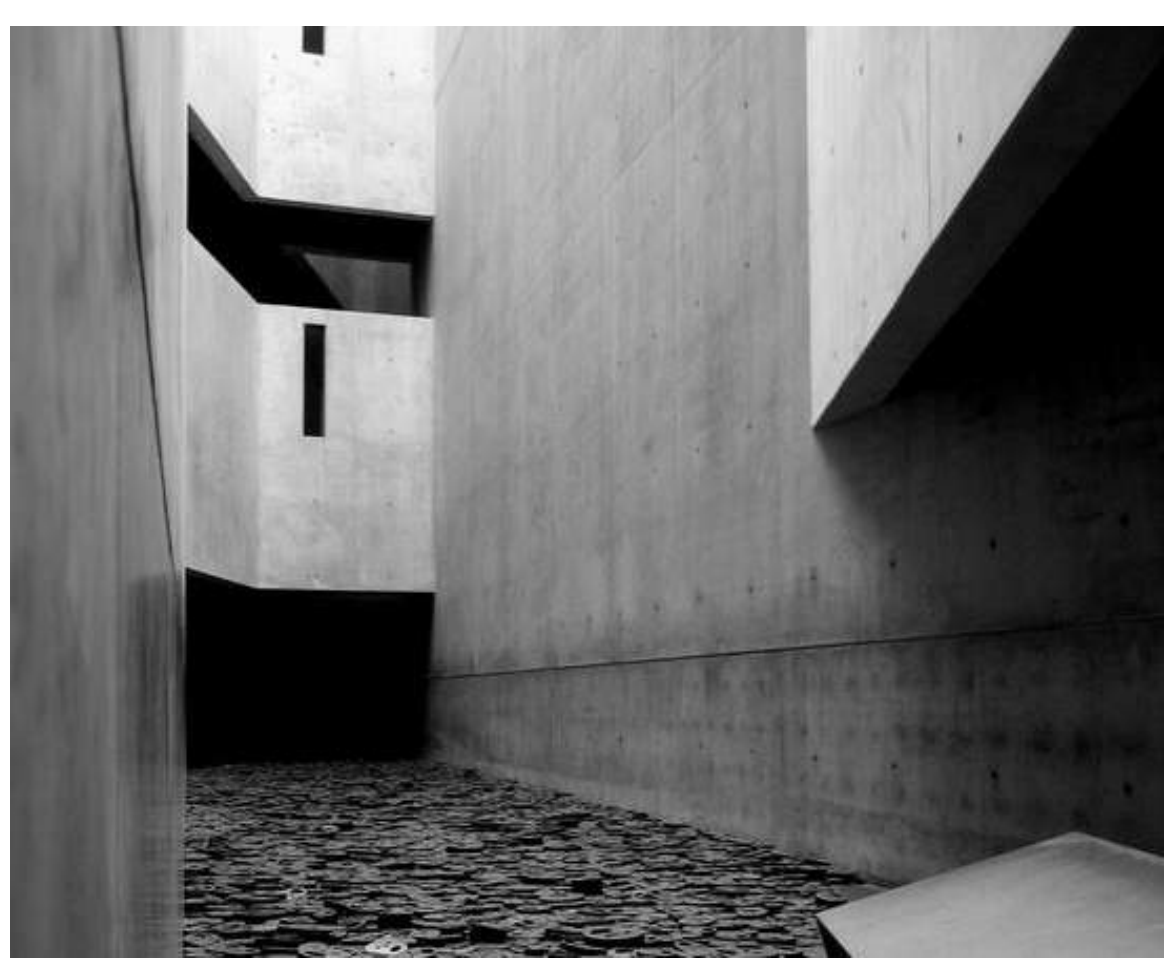




\section{I R C U L AT I O N}

Libeskind has successfully interpreted the Jewish history and translated that within the circulation of the design. There is no formal entry point on the new museum, nor is there any visual connection between the old and the new buildings. To access the Jewish Museum, the visitor must descend to an underground level of three axis providing three different routes. "The Axis of Continuity" provides connection between both museums, "The Axis of Emigration" leads to the outside Garden of Exile, lastly, "The Axis of Holocaust" leading to the Holocaust Tower and simultaneously, a dead end (Holtschneider 90).

Once at the other end of the Axis of Continuity, the visitor has the option to start their journey at ground level and ascend to the upper levels, or start at the upper and descend down, much like the Frank Lloyd Wright's Guggenheim in New York. As this design is of a narrow zig zag, a linear circulation method 
is utilised guiding the visitor from one end of the building to the other. There is no confusion from multiple decision points or obstructions, the visitor only needs to orient themselves to each floor level.

VIS UAL CONNECTIONS

Circulation of the Jewish Museum is both physical and imaginative. The view shafts created between spaces both horizontally and vertically, allow the mind to conceive an idea of where the body is about to travel by only being exposed to fragments of the surrounding spaces.

Dramatic voids connect the upper and lower levels but do not act like an atrium space. In particular, the memory void is a dim, naturally lit vast space with openings to the levels above. It is an architectural form which represent the absence of the Jewish lives lost in the Holocaust. The space requires the active participation of the visitors to complete the narrative and performance of the space (fig. 28). In these instances, the lower level of the building does not act like a museum, but more of an experience portraying what majority of humanity cannot comprehend.

\section{REVOLUTIONISING MUSEUM A R C H ITECT URE}

The exterior and overall form of the Jewish Museum is very much defined by its interior. Circulating between two parallel lines along a single path allows the visitor to orientate themselves subconsciously down the length of the building. Even though it is of a linear circulation, the zig-zag nature of the structure is intended to 'disorient and destabilise' the visitor to provoke the emotions of 'displacement, emptiness and loss' (Chametzky 220).

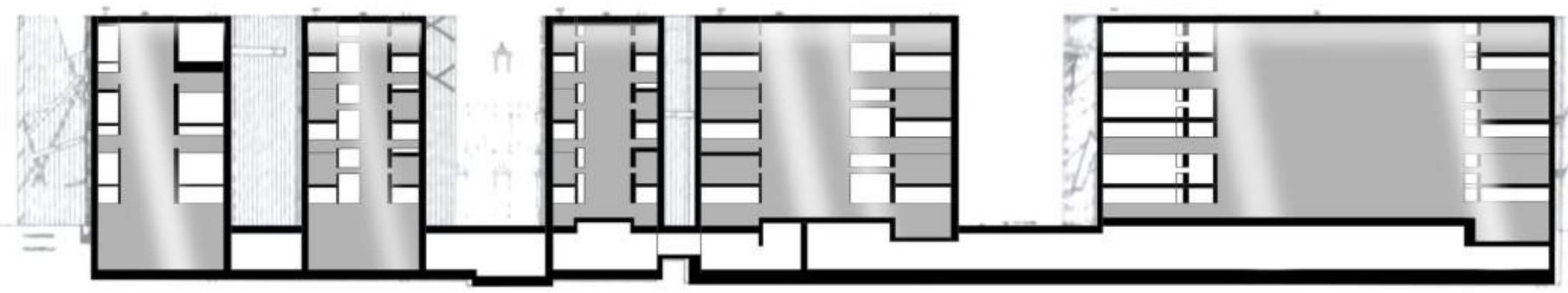

RIGHT

Fig. 30: Plan of Jewish Museum, Berlin. Level 02

FAR RIGHT

Fig. 31: Section through Jewish Museum voids. 


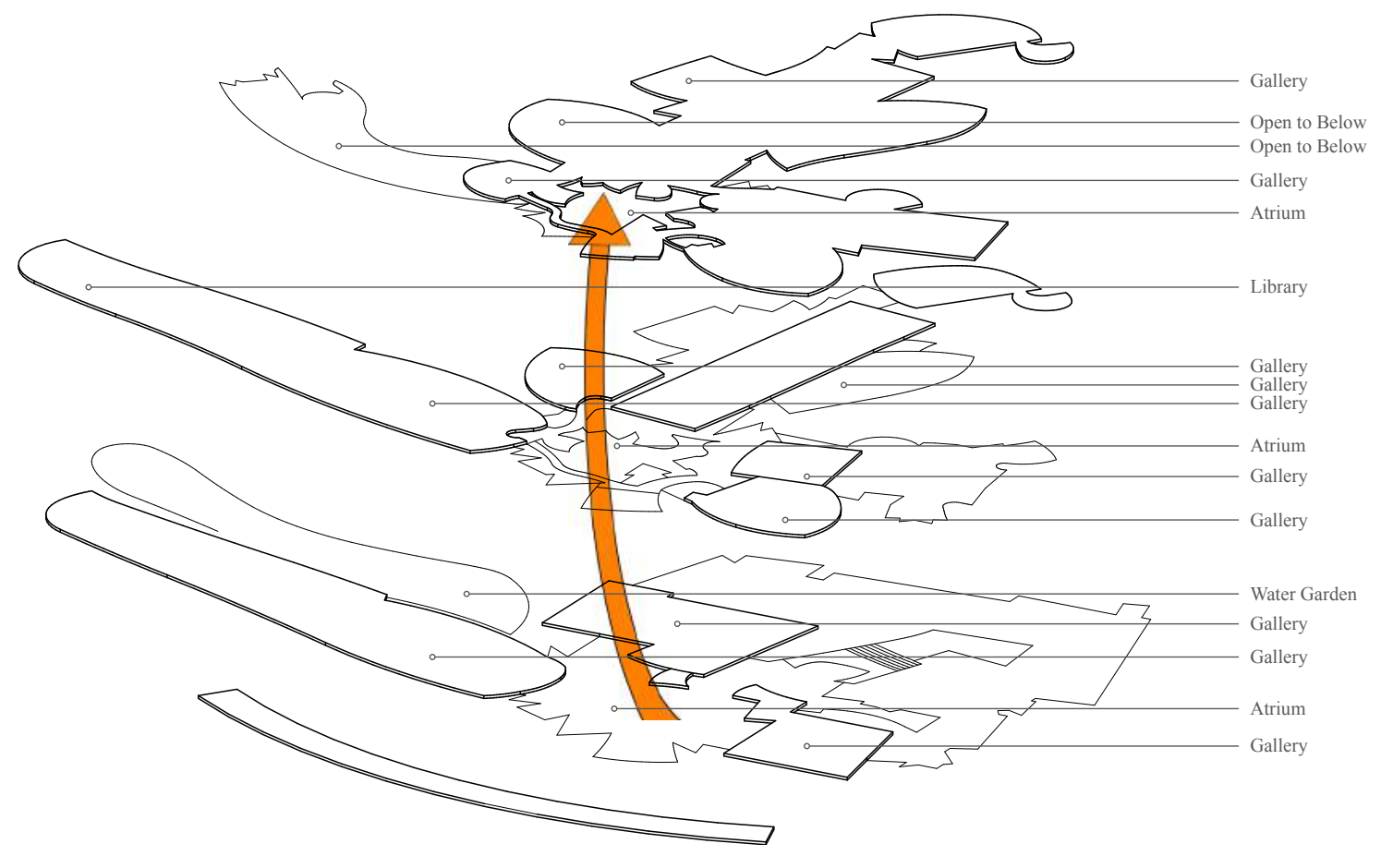

ABOVE

Fig. 32: Exploded view of floor plates Vertical Circulation. Guggenheim Museum, Bilbao.

RIGHT

Fig. 33: Guggenheim, Bilbao. Atrium 


\subsubsection{GUGGENHEIM - BILBAO}

FRANK O. GEHRY - 1997

\section{B A C K G R O UN D}

The foreign form of Bilbao's Guggenheim Museum is referred to as one of the greatest works of architecture of our time ("Guggenheim Foundation"). An inhabitable sculpture which has revolutionized the way the world view, experience, and interpret museum architecture. Not only has it evolved contemporary architecture, but it has revived what was a declining city and placed Bilbao on the world map.

\section{I R C U L AT I O N}

Consisting of 20 gallery spaces, plus the inevitable café, store and auditorium, are all arranged over the three levels of the museum. With such an erratic form, the circulation of spaces is relatively straight forward. The methodological approach is that of a "figure of 8" style. There are three wings each consisting of three levels of galleries that disperse outward from the central atrium. Depending on what floor level the visitor stands, they chose the wing they desire and make their way. The circulation requires the visitor to retrace ones steps back to the atrium in order to progress to the next exhibit (fig. 33).

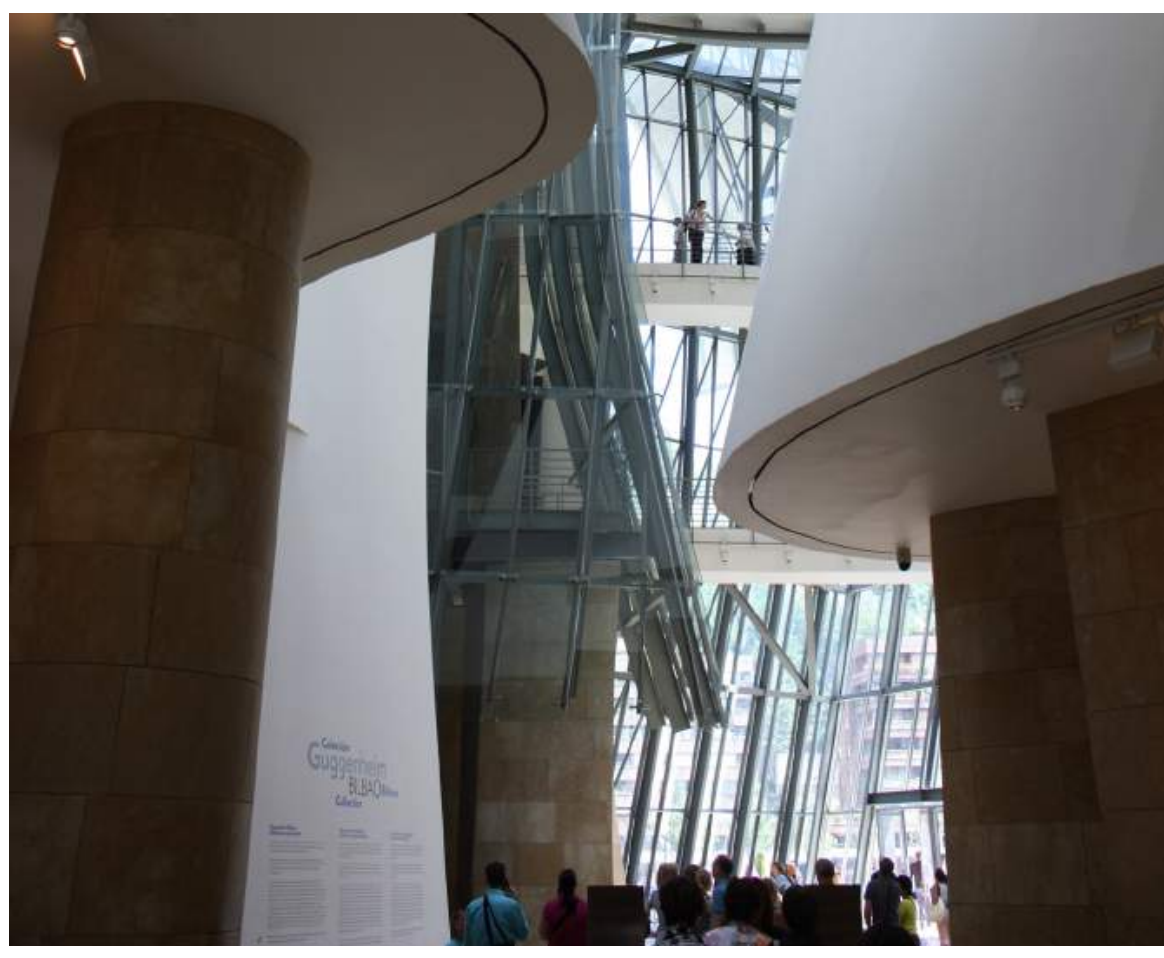




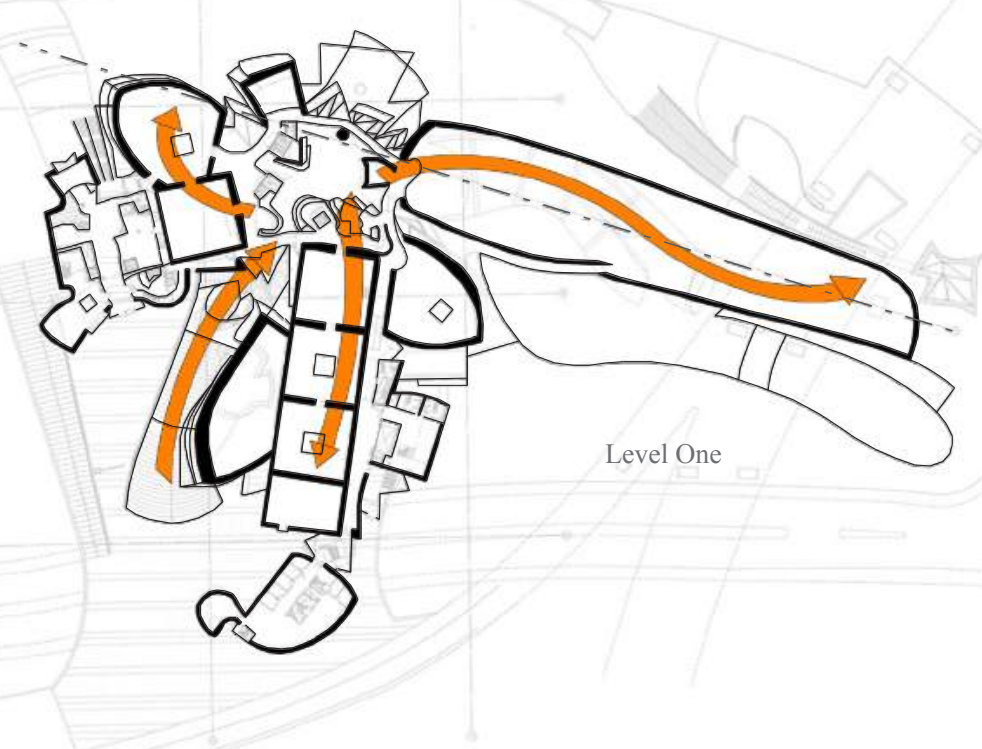

ABOVE

Fig. 34: Drawing Series. Horizontal circulation system of the Guggenheim, Bilbao. 

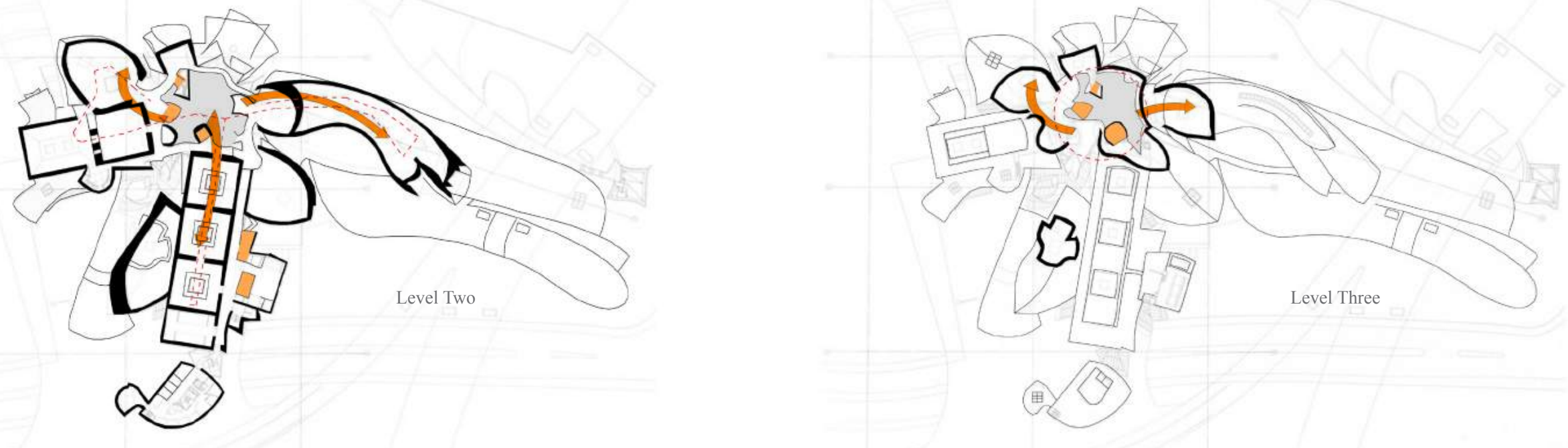


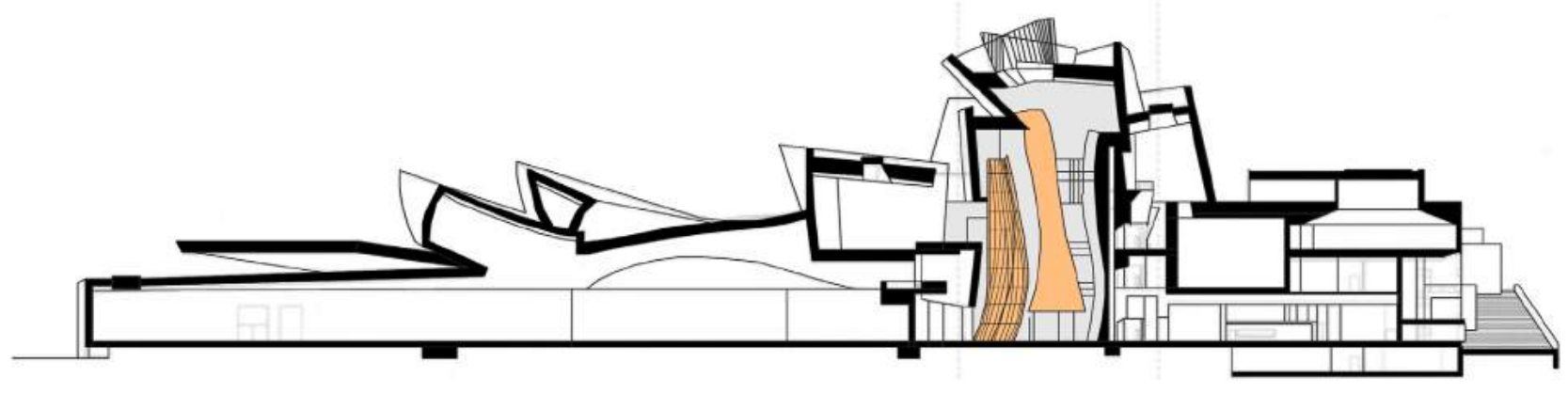

ABOVE
Fig. 35: Section through Guggenheim, Bilbao

showing vertical atrium and circulation

RIGHT

Fig. 36: Edge of atrium and modern art gallery

spaces. 
VIS UAL CONNECTIONS

Gehry has designed the entrance to the museum with some-what a traditional approach. Instead of ascending a grand ceremonial stair case, the visitor descends down a gentle array of steps to the interior of a soaring, asymmetrical atrium. The language of the atrium is continued from that of the exterior. Meandering forms of titanium, glass and stone disperse upward to accentuate the grandeur of the atrium.

\section{REV OLUTIONISING MUSEUM A R C H I T E C T URE}

There are two styles of gallery spaces. The more traditional, rectilinear spaces are intended for the late artists. For these artists mastered these works with the intention of being displayed perpendicular to the floor. Whereas for the contemporary artists of today, Gehry has arranged gallery spaces of irregular forms that challenge and create new opportunities for artists (Lewis 53). Gehry has been gentler with this approach, unlike Libeskind's extension of the Denver Museum which has resulted in many negative critiques about the functionality of the excessively sloping walls (Shiner 39). Personally, as I mentioned earlier, I view these intentions as an opportunity to develop contemporary art and inspire new ideas.

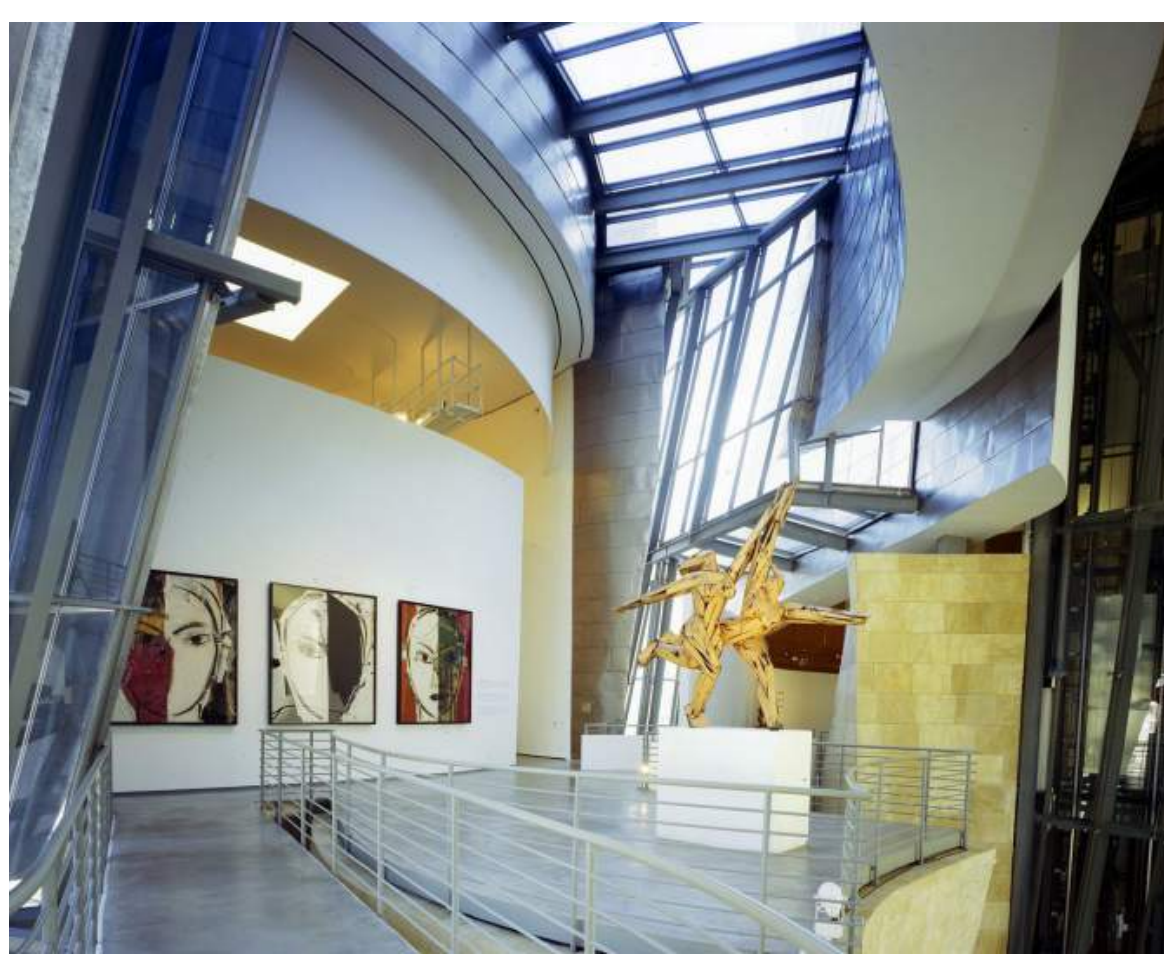




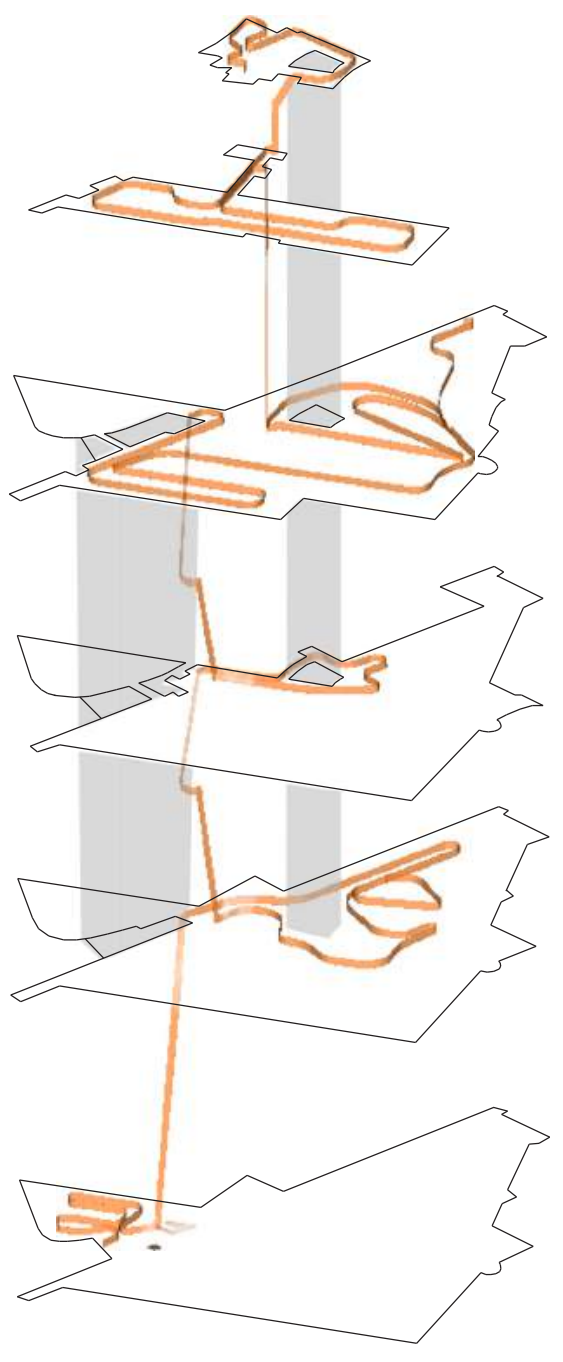

48
LEFT

Fig. 37: Exploded floor levels of Te Papa

Tongarewa. Image shows atrium voids, horizontal and vertical circulation

RIGHT

Fig. 38: 'Fault-line'wall and main circulation of Te Papa Tongarewa. 


\subsubsection{TE PAPA TONGAREWA - NEW ZEALAND} JASMAX GROUP - 1998

\section{B A C K G R O UN D}

Te Papa Tongarewa received a lot of both positive and negative critique in the media since it became public knowledge - and still is. This has resulted in a positive outcome as it has changed the way the people of New Zealand experience museums and architecture (Lake-Hammond 93).

Te Papa has a significant difference when compared to the previous case studies. It was designed by a group rather than an individual. This may have been one of the reasons as why New Zealand was not gifted an 'icon' building (in reference to its aesthetic) but on the other hand, the extensive and ambiguous brief needed a collection of minds to decipher it. The focus of this thesis, however is on the interior rather than the aesthetic influence of the exterior.

\section{I R C UL AT I O N}

To orient visitors through the interior of Te Papa, the exhibitions rely on the entry, central core, the wedge and the four meter thick basalt wall (Parkinson 62). These four elements are derived from the fault-line metaphor - both bicultural and geographical- and what aided the final design of the National Museum. After investigating the various critiques on the

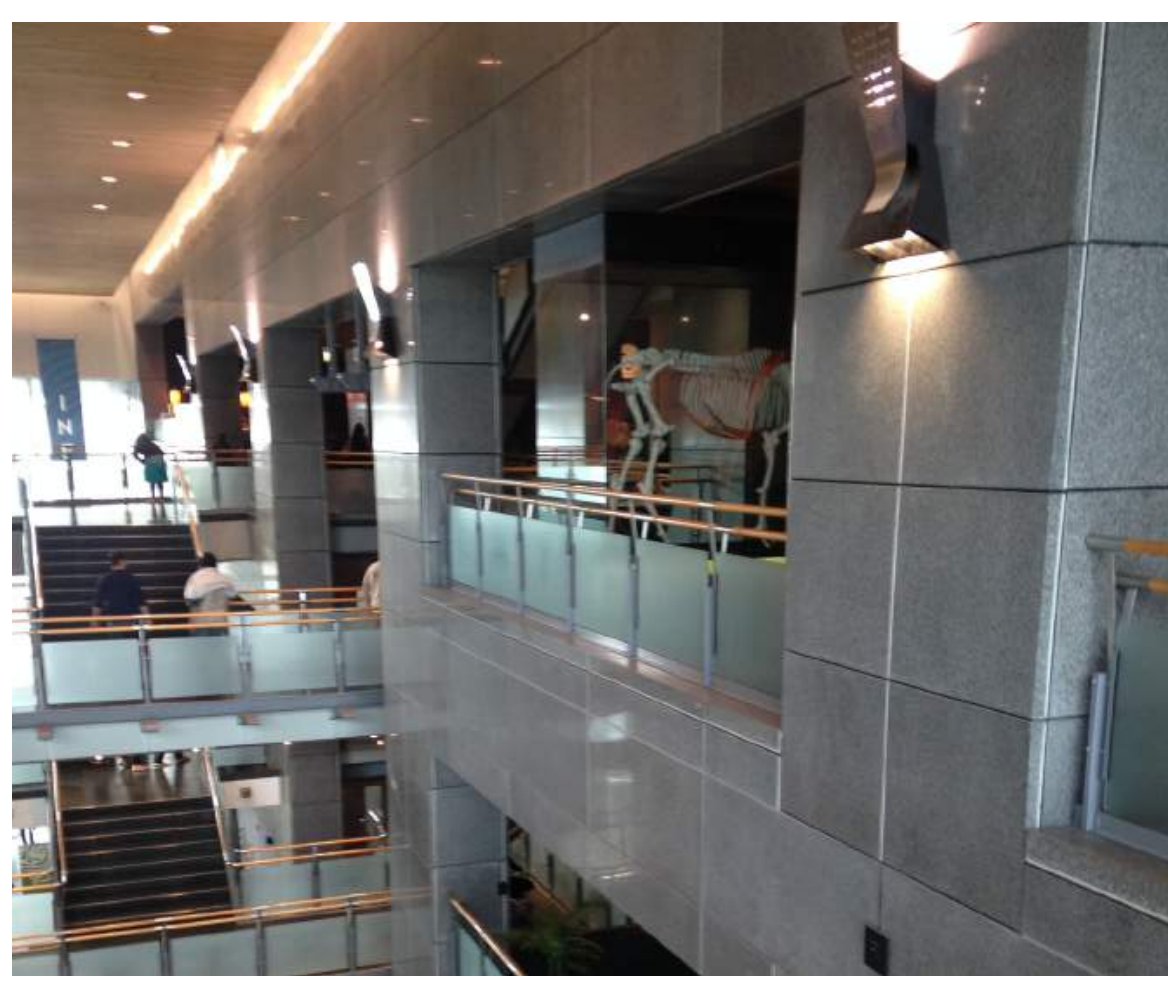




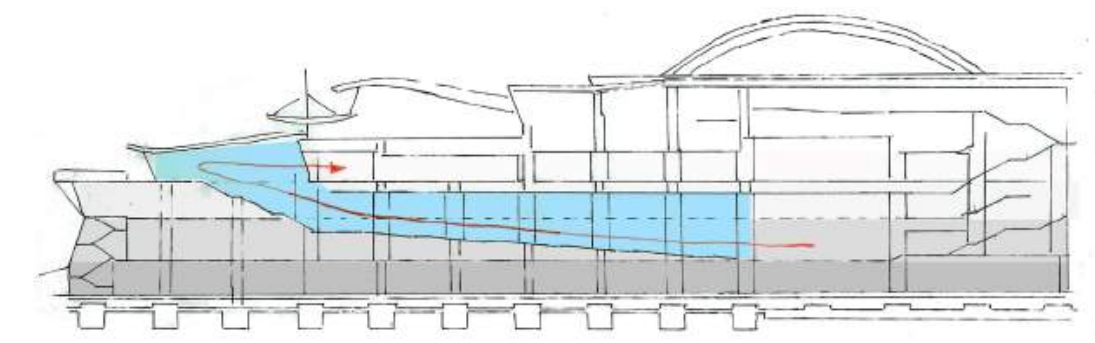

50 INTERPRETING THE MUSE

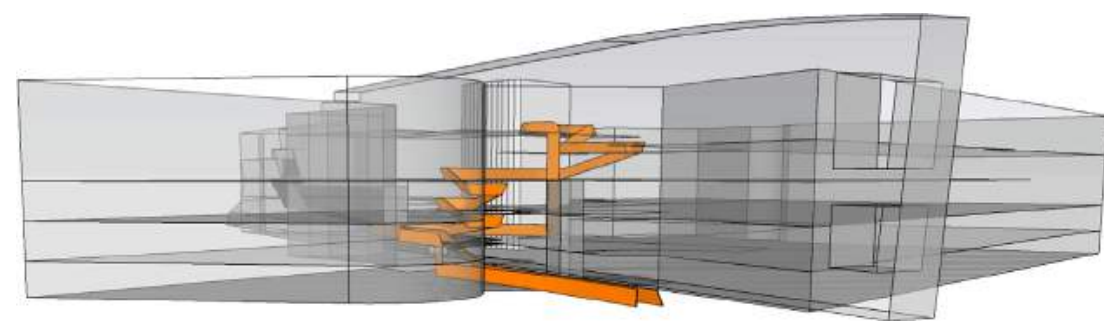

LEFT

Fig. 39: Sectional drawing showing circulation

from main atrium (level 02) to the Marae (level 04) missing any connection with level 03.

ABOVE

Fig. 40: Three-dimensional image showing shortest route to the upper most level. 
museum, it is assumed that there are three too many elements to orient the visitor. With such a heavy focus on this metaphor, the visitor has somehow become the secondary - in some cases tertiary- influence to the circulation.

If simplified, the circulation system resembles a multidirectional or 'figure of eight' style. This can be seen in plan but once inside the physical form, there is no obvious system and the site map is heavily relied on.

\section{VISUAL CONNECTIONS}

It has been said that an atrium is the heart of the building. Guy Marriage notes that Te Papa "has three atria, and one heart" ("Significant Social Space" 161). Positioned in close proximity and separated only by the "fault-line" wall and bridging walkways, the borders of each atria have become indistinct and cause confusion for the visitor (fig. 36). Te papa works in respect to having a diversity of spaces of different exhibits environments for visitors to experience. As an interior architect, that is what one aims to achieve. For the experience that the architecture gives us is more fundamental than the motifs and narratives that the forms are attempting to convey. It is the senses that are initially addressed before the logic of the mind can process (Bloomer 36). This doesn't seem to be the approach taken for Te Papa's design. It is less than clear to majority of the population to read the metaphorical influences (Marriage 162).

\section{REVOLUTIONISING THE MUSEUM}

As said in the original briefing documents to the Hon Maggie Barry (Minister of Arts, Culture and Heritage), Te Papa "is New Zealand's most successful cultural experience" (Museum of New Zealand) which revolutionised architecture as a whole within New Zealand. Te Papa is a destination architecture within New Zealand which could be said because of what it holds, not because of what it is. I intend to untangle the interiors faults to enrich the re-imagination of the National Museum. 


\subsubsection{TO CONCLUDE}

Questions that have emerged during this investigation, are those that question the ability of Athfield and Gehry's proposal. I suspect the assumption that their design would simply not compare to what museums are today. In saying this, there is very little to compare. Missing the opportunity of having this design as New Zealand's National Museum is not as great a loss as rejecting two of the world's greatest architects. So in respect to Athfield and Gehry, I aim to revive their design and develop it to be a design able to compare and provoke the modern muse.

Museums which address complex issues such as the National Museum of Australia, translate the complexity of the issue into a complex structure, resulting in confusion, misinterpretation and disregarded design (Fleming 58). Perhaps this is the case with the design of Te Papa. For upon starting this investigation, I had not read the bicultural and geological motifs from the architecture itself. It wasn't until reading literature of Te Papa's critics that I became informed of these influences.
A great number of literature focuses on the 'art museum' rather than the museums of natural history and social sciences because of the close relationship between art and architecture (Fleming 58). The spaces of natural history and social sciences allows the architecture of the interior to represent a narrative design whereas the spaces of the arts is assumed to leave the narrative to the works displayed. Yes, I believe that is the case with the artworks of the late masters, but for contemporary artists of the modern world, the architecture should bring new opportunities to the definition of modern art.

The blank canvas of Ian Athfield and Frank Gehry's proposal offers opportunities for horizontal circulation but this is limited within the vertical. Upon analysis, their structure would have been three or four storeys and requires a reorder of the architectural object to fully exploit opportunities, space, light, drama and narrative. Great vertical volume will be a significant contributor to the overall experience and rhythm of the museum.

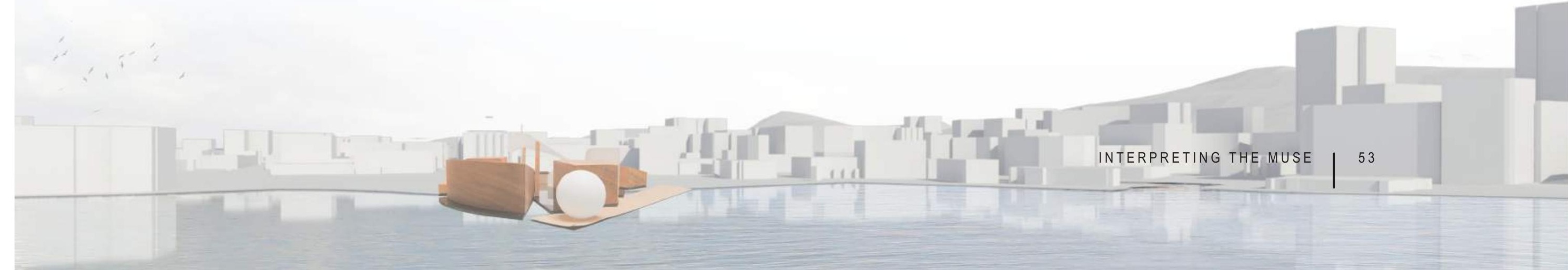





\section{2}

REALITY OF THE INTERIOR 
2.1

SYNCHRONISED SPACE

$\overline{ }$




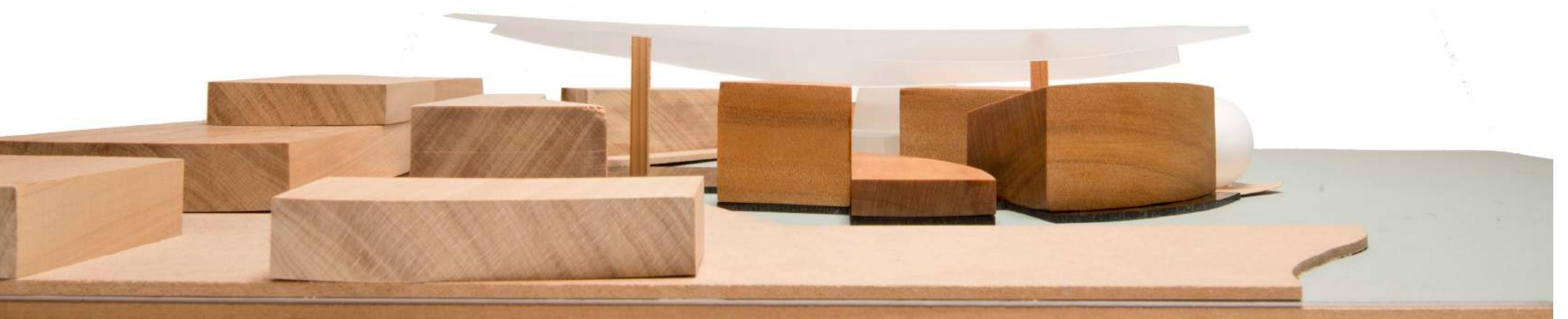




\subsubsection{REFORMATION}

Upon investigating the original form, it became apparent that the form had dated from its conceptual design when compared to architecture of today. Establishing a circulation system within the original, it was recognised that the voids became disconnected and unbalanced once drafting the potential interiors. Thus the realisation to reform the overall design was the first step to initiate its development.

Approaching this museum from the inside out established the realisation to reform the proposals configuration. Gaining monumental heights and panoramic views is where a successful circulation concludes and where the memory is imposed. These elements cannot be obtained within the original form and which can be seen in its elevation (fig 41).

Gaining height to increase panoramic views of Wellington City was one of the main aims to succeed in the new form. Along with height gain, a greater exploration into vertical circulation as well as the horizontal can be executed. Orientation of the structure is significantly important for the design narrative as an object and is explored through physical model iterations. 

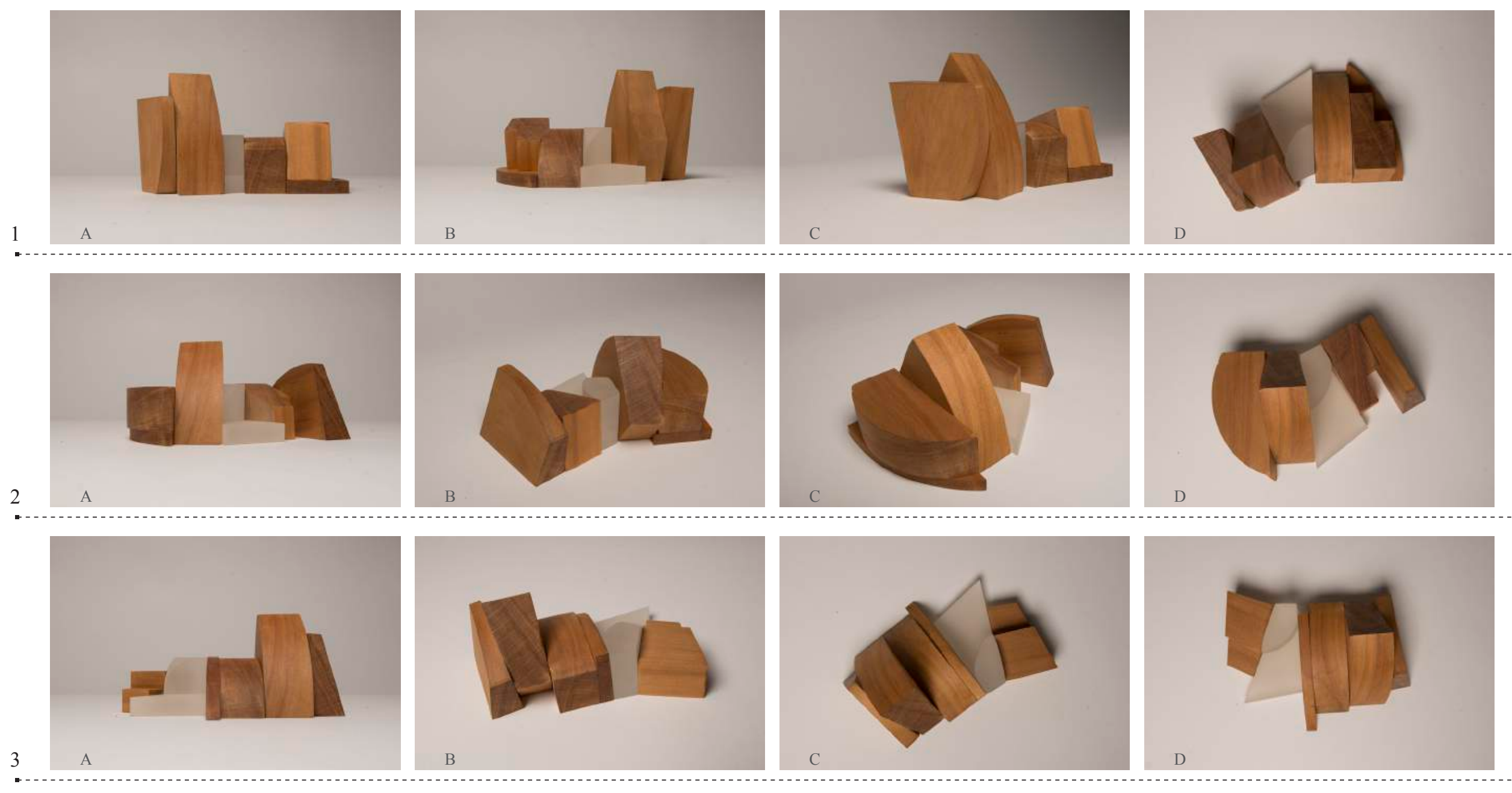


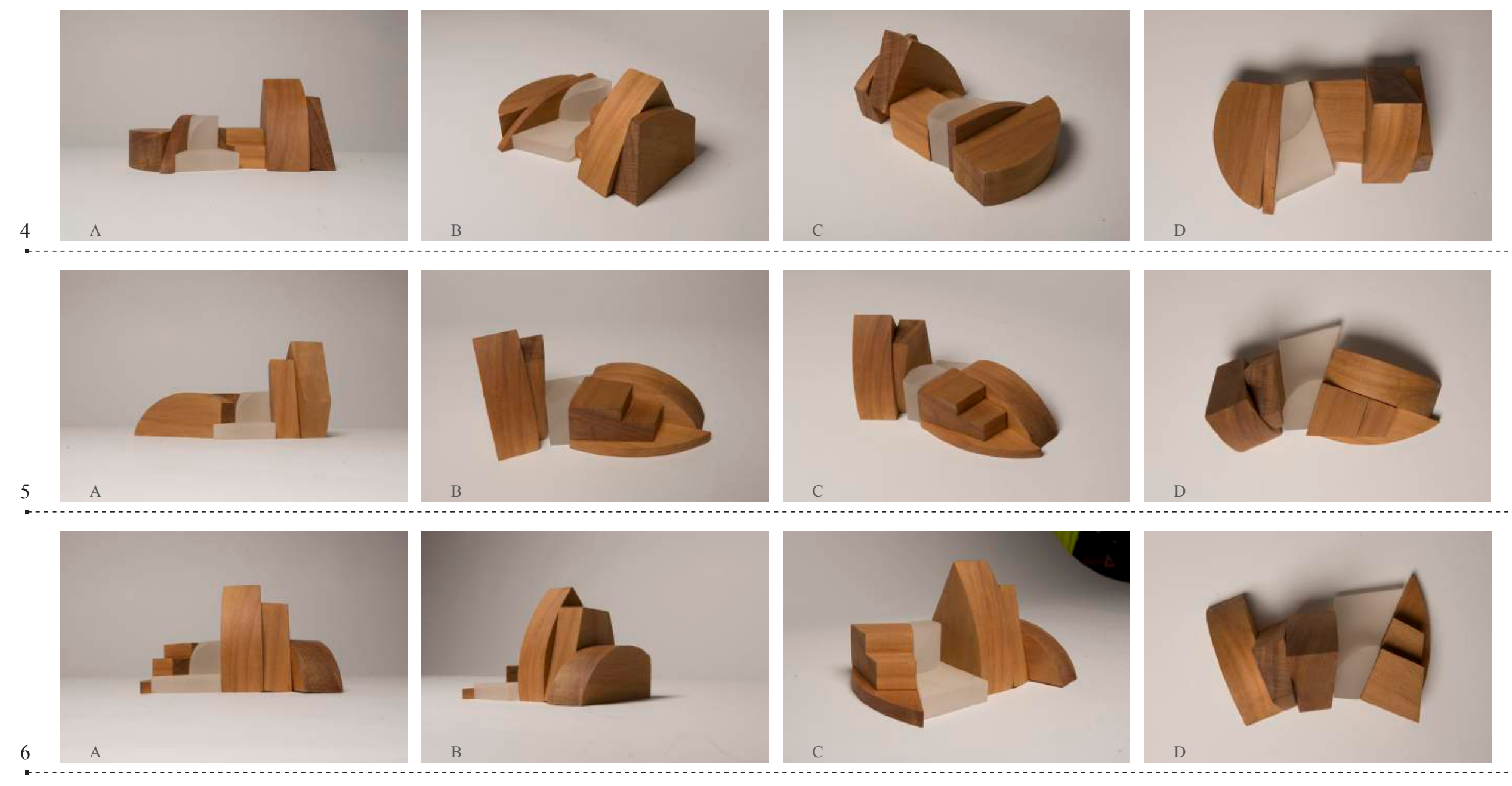

\begin{tabular}{l|l} 
SYNCHRONISED SPACE & 61
\end{tabular} 

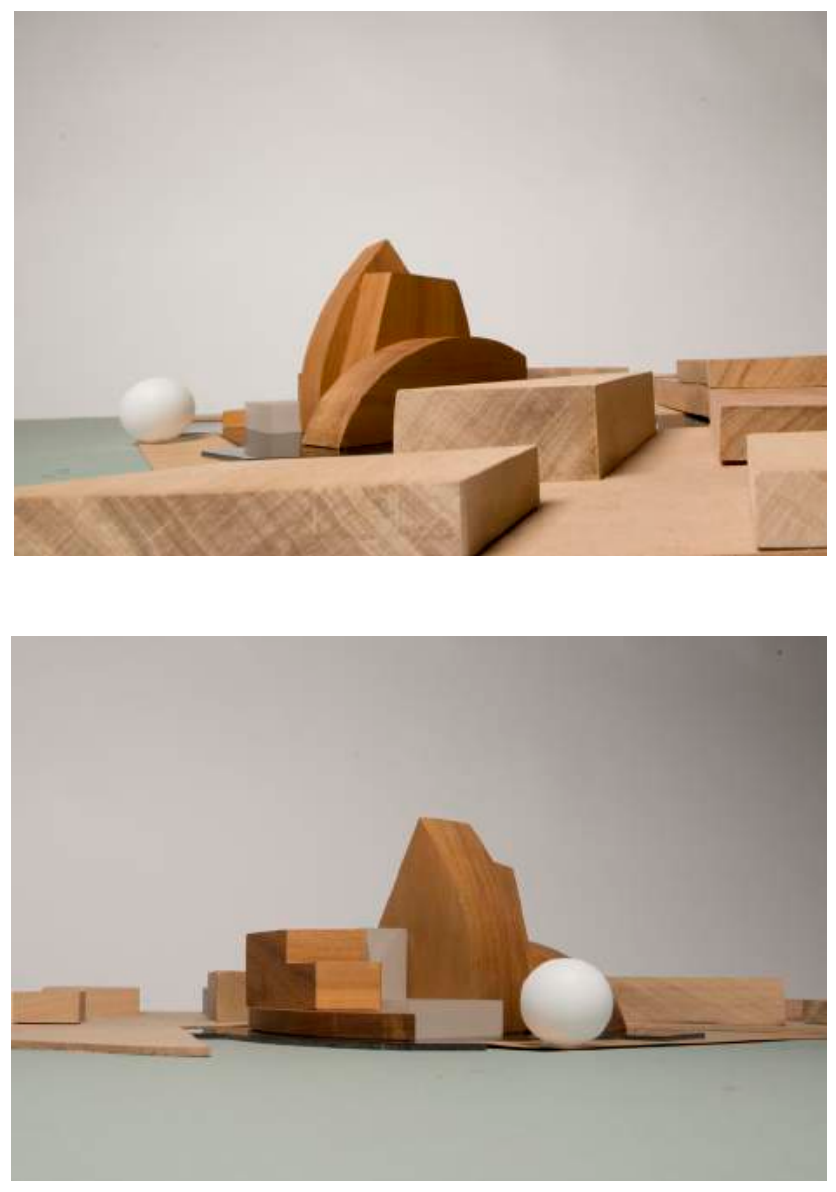

ABOVE

Fig. 43: Final model formation. Extreme height qualities offer opportunities toward atrium design. 

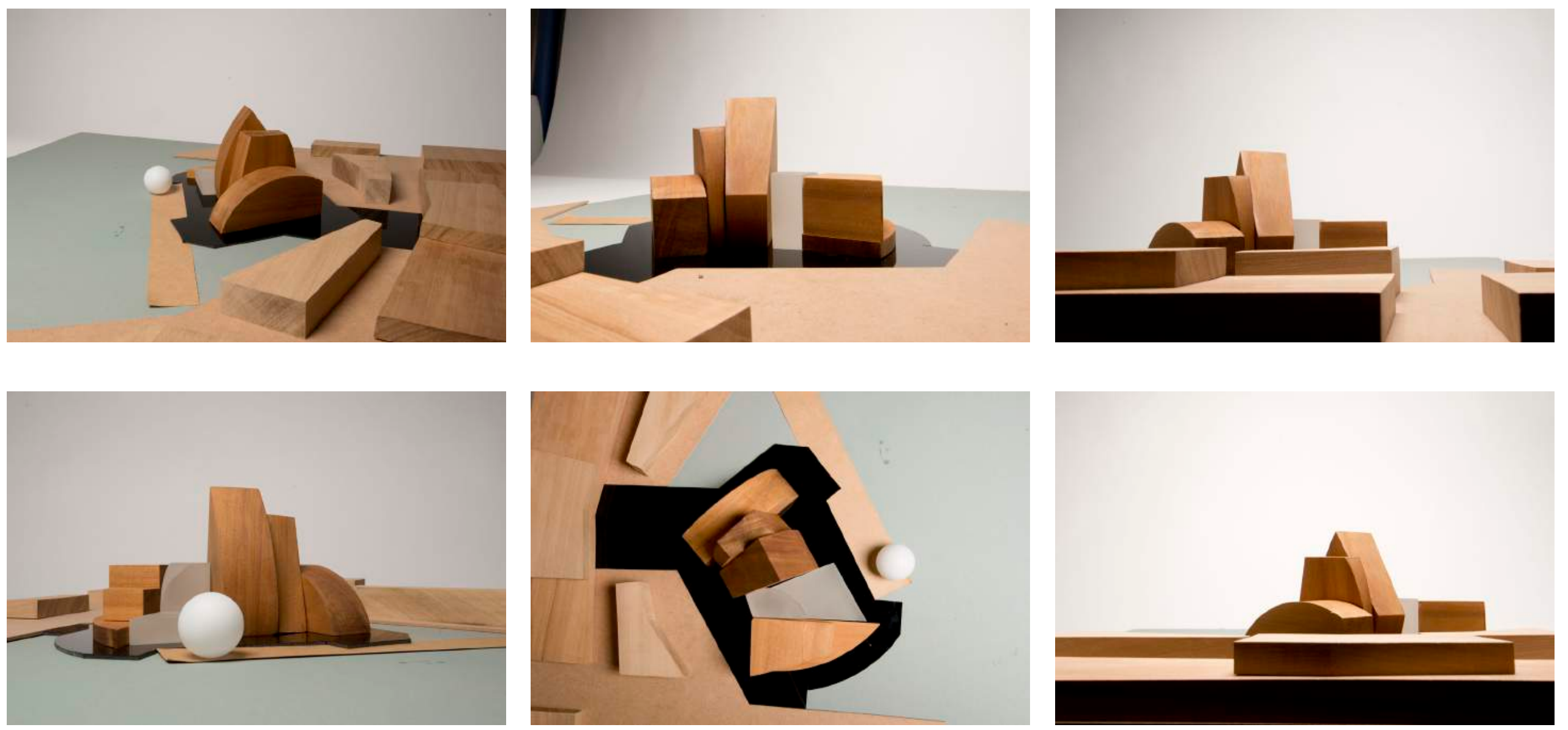

\begin{tabular}{l|l} 
SYNCHRONISED SPACE & 63
\end{tabular} 

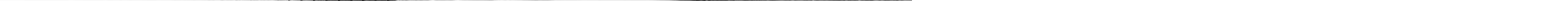

FAR LEFT

Fig. 44: Guggenheim Museum, New Your City.

Frank Lloyd Wright. Atrium void.

LEFT 


\subsubsection{ATRIUM}

"... [The] element which became the only sign or signature of the external architectonic condition, this central element which is devoted to the public offers the only linkage between the solitude of the internal, of the sacred world, and the outside world, the profane." - (Abraham 121)

Atriums originated as a form of courtyard in the ancient Greek and Roman House (fig. 44) which was utilized as a social area (Bednar 05). Today, the function of atria is still that of a social centre, but with the evolution of the tall building, it now provides visual connections between floor levels and influences vertical circulation (Sully 50)

The first atrium was introduced for the sole purpose of ventilation. Circulation and a private outdoor area were benefits to the concept. A rectangular space with an open roof provides access to the surrounding rooms of the house as well as ventilation and a source of natural light (Bednar 06). This building form was mainly utilized by the wealthy as it portrayed a sense of social status and luxury. These same principles are maintained within the modern day atrium. The grandeur and luxury of the atrium create a memorable experience for the visitor as well as benefiting the economic value by minimizing energy use and enhancing circulation systems (Saxon 06)

It is important the atrium accepts its dominance and physically interacts with the host structure. For if the atrium has no relevance to the aesthetic, scale or function of the building, the atrium will either be minute and insignificant, or obese and intimidating (Shum 29). The aim of this thesis in reference to the atrium is to challenge how the atrium stands within the building envelope and the form it can take on.

Thanks to the technological breakthrough of the elevator 100 years ago, the skyscraper was born and the atrium was revived. Sporadically evolving until 30 years ago, no other building form has advanced with such speed and success which has now become the most generic configuration of multi-storey buildings (Saxon 01)

Frank Lloyd Wright and his Guggenheim Museum in New York is said to be the "living link between the first modern atrium and the second" (Saxon 13). Wright's Guggenheim is the most iconic building in reference to circulation. A spiral ramp that gradually circulates the visitor up the atrium and offers systematically placed sub routes to galleries. This circulation system is an example of Anthony Sully's well-defined route method. 


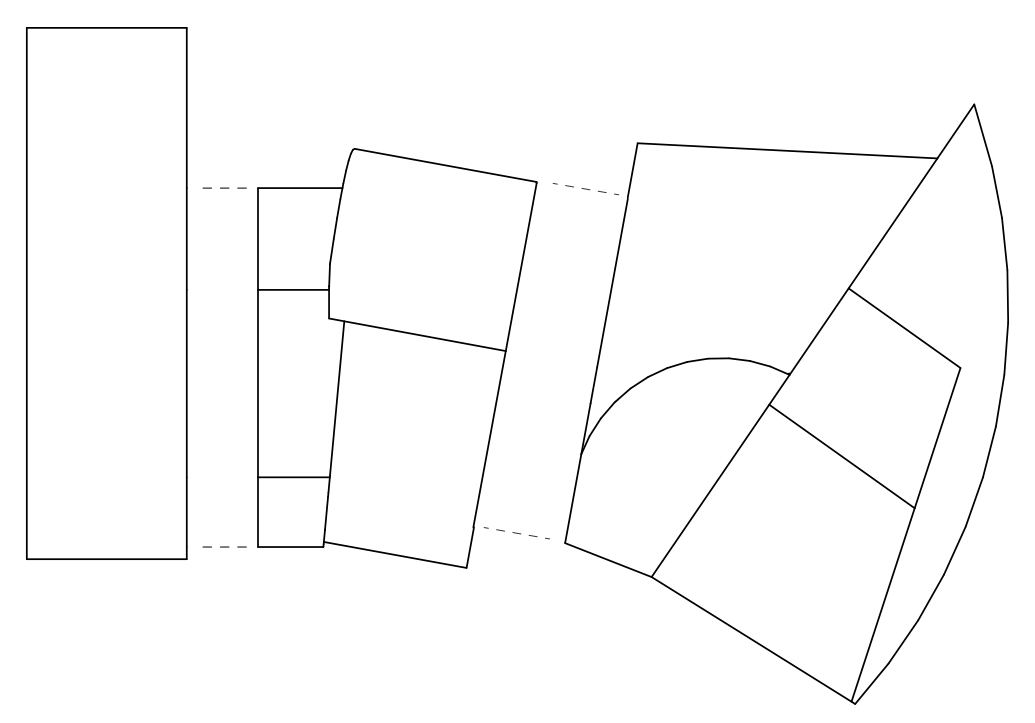




\subsubsection{VESSEL}

"Architecture becomes the idealised language of historical associations whereby ideal ought to be defined as a form of radical clarity" - (Abraham 113)

Inspired by Raimund Abraham, a simplified approach at investigating objects that contain or enclose will prompt the formation of the atria. These objects will be found within the collection of New Zealand's national treasures. Selection of each object will be made in reference to the form it will be enclosed within. Through section drawings, the relation between object and structure.

The methodological approach is to conceptualise a certain type of space of simplicity and significance that will then inspire a structure to be moulded in reference to the particular space. A way of designing architecture from the inside out.

The change in perspective at the height of an atrium lengthens your line of site and widens your peripheral vision causing time to halt and self-reflection to occur. Like a lookout at the top of a hill or the crow's nest at the top of a mast, the experience is not one that is obtained day-to-day. Instead of being amongst nature and mankind, disconnecting yourself and standing aback looking upon man and his land as a mass, you see what you are a part of and what you contribute to. An opportunity to read the world as opposed to perceiving it (Leach 168). 

2.2
UNBUILT AS A REALITY 


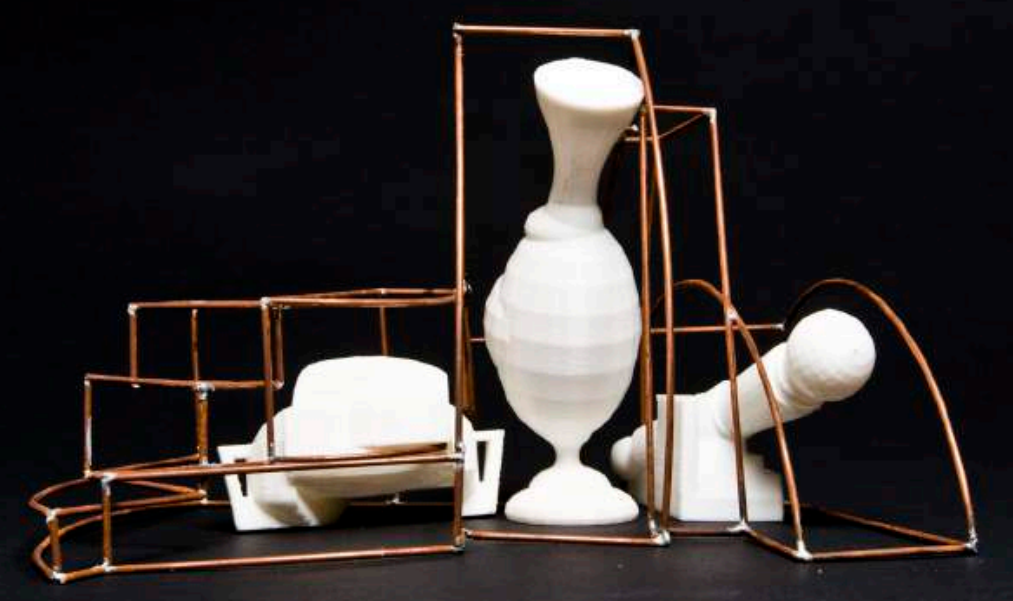

LEFT
Fig. 47: Proposed structure inverted to show atrium 


\subsubsection{SHAPING SPACE}

A vessel is to contain or hold within limits. An atrium is a vessel in which contains natural light, ventilation, and the main circulation system. The structure of the building produces a perimeter of constraints for a possible atrium space, or does it provide an opportunity to liberate the atrium, which could in turn develop a new hyperspace, a mutation. From an interior perspective, the structural form of the exterior envelope offers three separate components, each requiring an atrium and potentially circulation system (figure). This challenges the aspect of the atrium being a space upon entry. Instead of being the transition point from outside to inside, it will transition between forms and program of the interior.

An exploration into objects that enclose or contain will inspire the design of the atria. Being a national museum, what better way than to explore national artefacts for want of a better cliché. The aim of the selection process and abstraction of the forms was to develop the atrium in section. In plan, the atrium displays a different language and interpretation to its surrounding structure, whereas in section, the dialogue remains in the same language. In want to break away from the 'stacking' effect of floor levels, the final adaptation of the atria will not be symmetrical on any axis. The objects chosen include a vase of Greek and Roman influence, a treasure box from the indigenous, and a cannon from James Cook's HMS Endeavour.

History as we know it cannot be changed. Our interpretation however, is constantly being adapted, abstracted, distorted, and reinterpreted. This is the approach applied to the alteration of these three forms to emphasise the narrative. 

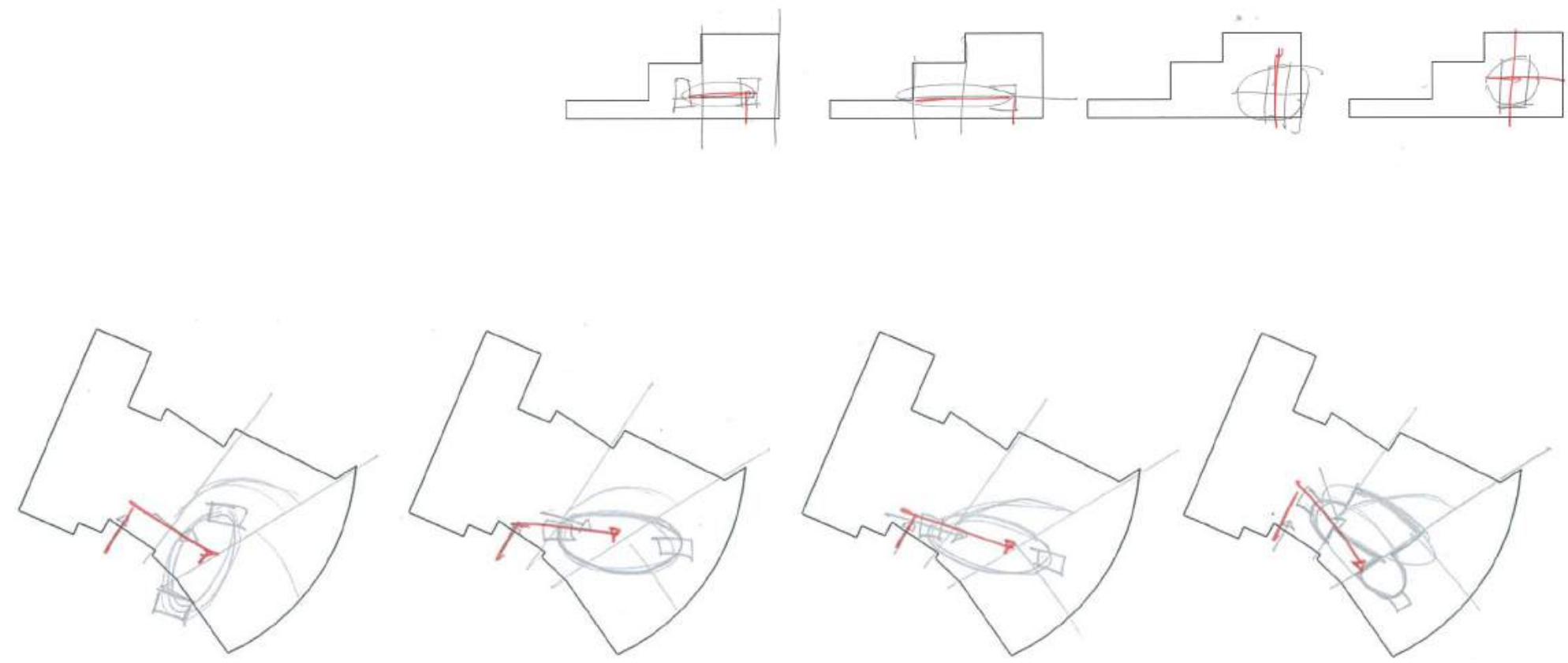

ABOVE

Fig. 48: Drawing series. Exploration of placement for treasure-box atrium.

RIGHT

Fig. 49: Treasure-box artifact from Te Papa Tongarewa collections 


\subsubsection{TREASURE-BOX}

THE OBJECT

The treasure box or Wakahuia holds the personal items most treasured to a single person or family. One can only experience its contents if invited. An unknown carver crafted this particular treasure box between 1800 and 1900("Wakahuia (Treasure Box)"). The fact that the year, the carver, and the original owner are unknown is like turning the treasure box inside out. By not exposing the elements which exist on the outside of the artefact and being able to physically look inside to its empty interior, will be the main inspiration for this space.

\section{INTERPRETATION FOR PROGRAM}

$$
\text { ALLOCATION }
$$

Overlapped onto the museum concept, the treasure box (museum) holds the artefacts of our Maori ancestors. A national building would not be an icon or treasured monument if it did not appreciate our indigenous past and cultural heritage. The original proposal by Sir Ian Athfield and Frank Gehry housed the Maori

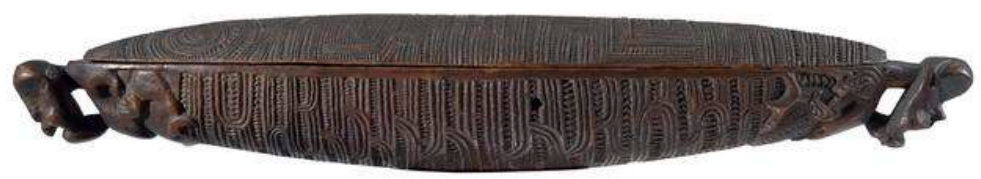



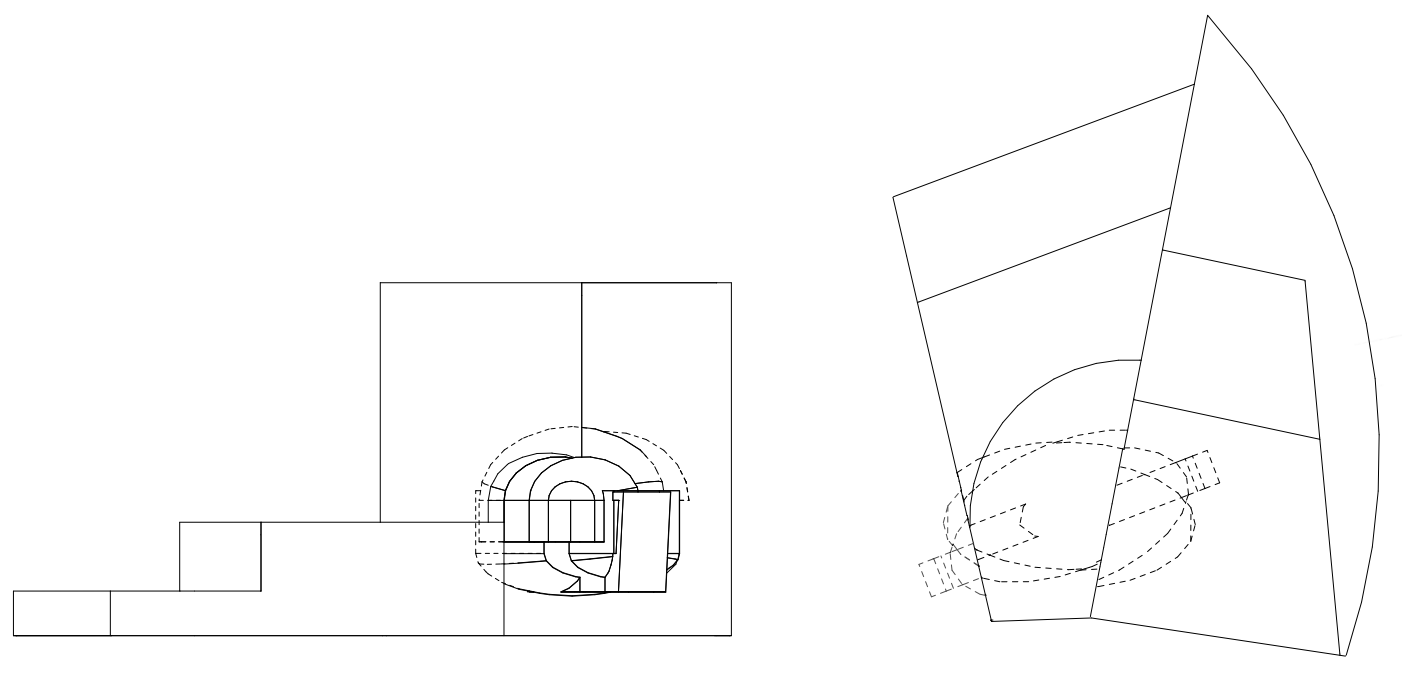

\begin{tabular}{l|l}
74 & UNBUILT AS A REALITY
\end{tabular}
LEFT

Fig. 50: Elevation and plan drawings showing refined placement of treasure-box atrium.

ABOVE

Fig. 51: Three-dimensional image showing placement of treasure-box atrium on overall floor plan.

RIGHT

Fig. 52: 3D-printed treasure-box void 
influences within the curved glass form; it will remain within this form within the new arrangement. It is necessary to maintain the connections to the original proposal, as that too has become part of the buildings history as well as New Zealand's.

\section{ATRIUM DEVEL OPMENT}

As the treasure box conceals what is within, the atrium of the Marae Atea will conceal what is on the outer. It will be the dividing factor between public and private sectors. Restricting the private areas to the two eastern forms will allow the larger western forms to fully concentrate on the arts, history and natural history. The atrium will still function like the others and will remain its public access, it will act as a reverse of the standard atrium and the traditions of the wakahuia.
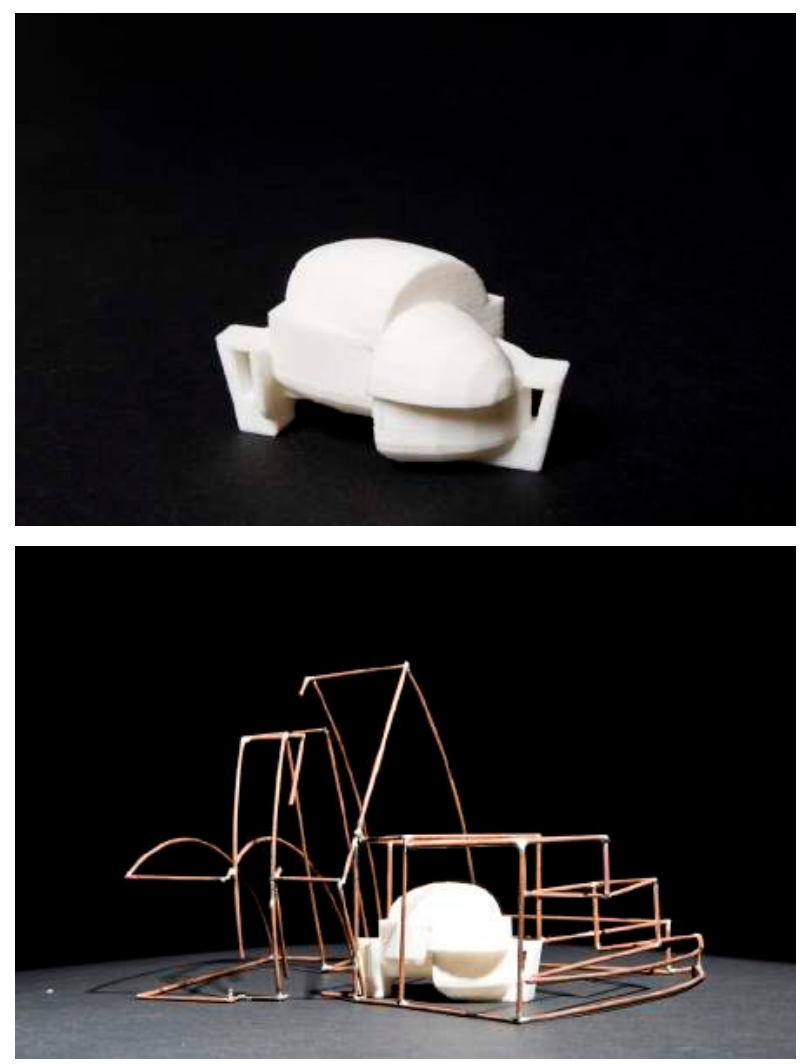

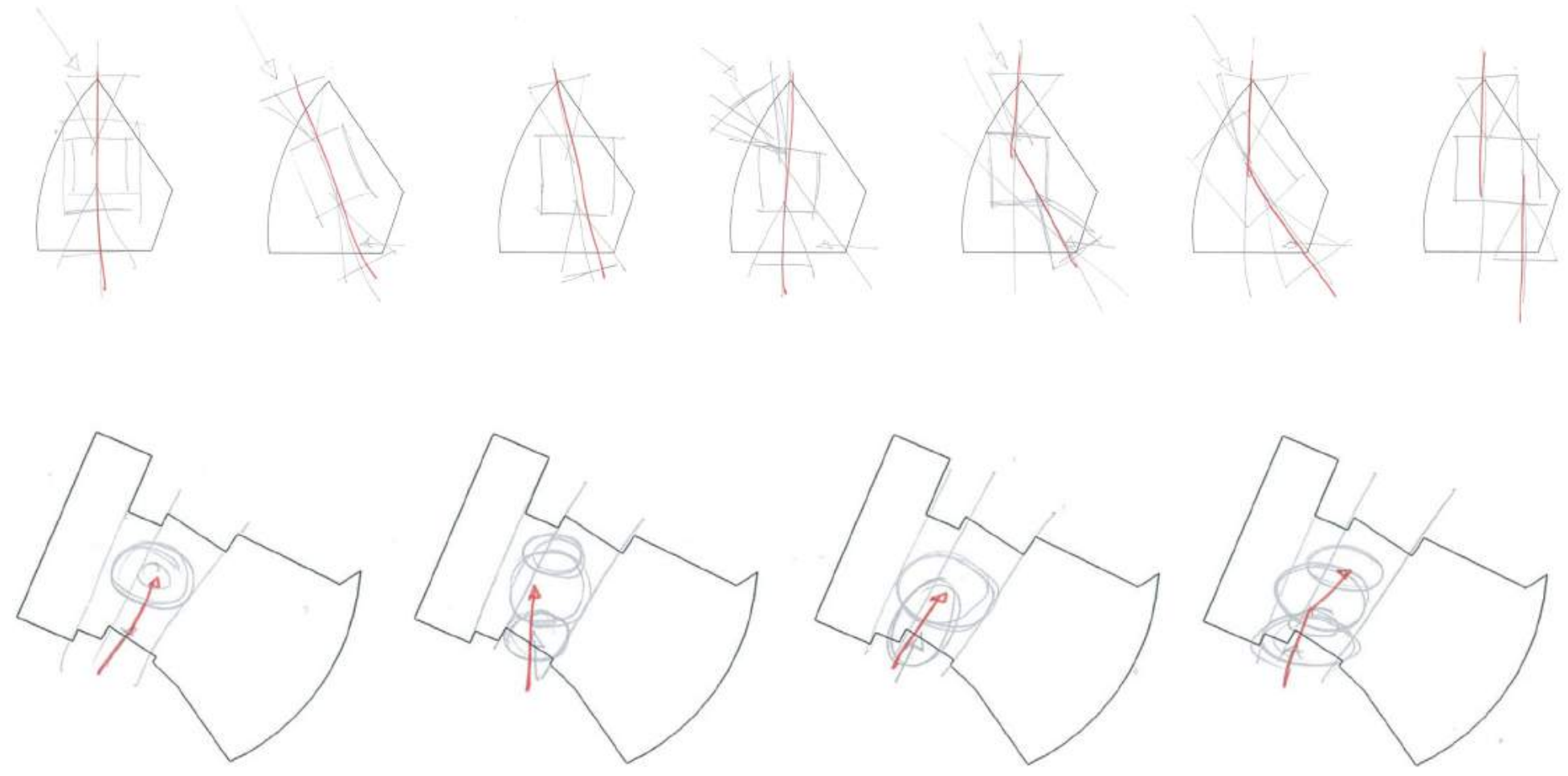

ABOVE

Fig. 53: Drawing series. Exploration of placement for vase atrium.

RIGHT

Fig. 54: Vase artifact from Te Papa Tongarewa collections 


\section{2 .3 VASE}

THE OBJECT

A sterling silver vase based on Greek and Roman styles is the vessel chosen for The Arts. This ornament was crafted in the 1870 's by a local Christchurch company that is still in business today ("Vase"). The engraving on the vase's torso is illustrating a waka in a harbour framed by a fern frond. The physical form of the vase offers opportunities that benefit the asymmetric form of this particular section of the museum.

\section{INTERPRETATION FOR PROGRAM} A L L O C ATION

The vase - as I have interpreted - is a representation of domesticity within New Zealand. The devotion in which we have to our country is something to be recognised and appreciated.

Every household has some form of vase that is treasured either as a stand-alone item or a vessel in which transfers the outside to the inside. A symmetrical void with an opening at its apex that reflects at the base to collect water is a description of both the vase and the Roman house (domus). This museum is the home of our country's treasures and I am placing the vase centrally on its mantelpiece.

The atrium offers the experiences of a lookout at the top of a hill, the crow's nest at the top of a mast, the awe-inspiring experience that is not day-to-day. The change in perspective that lengthens your line of site and widens your peripheral vision

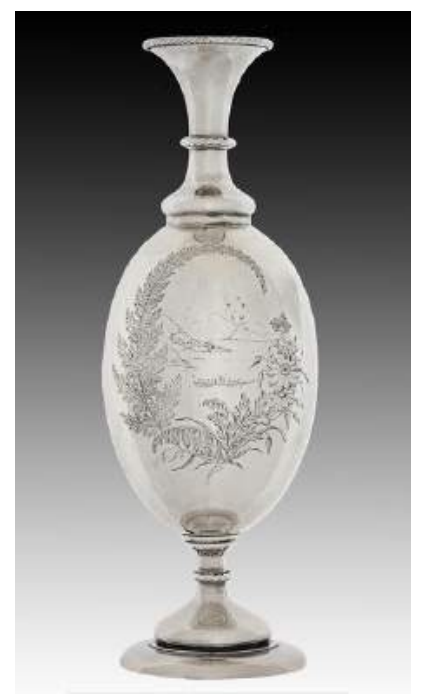



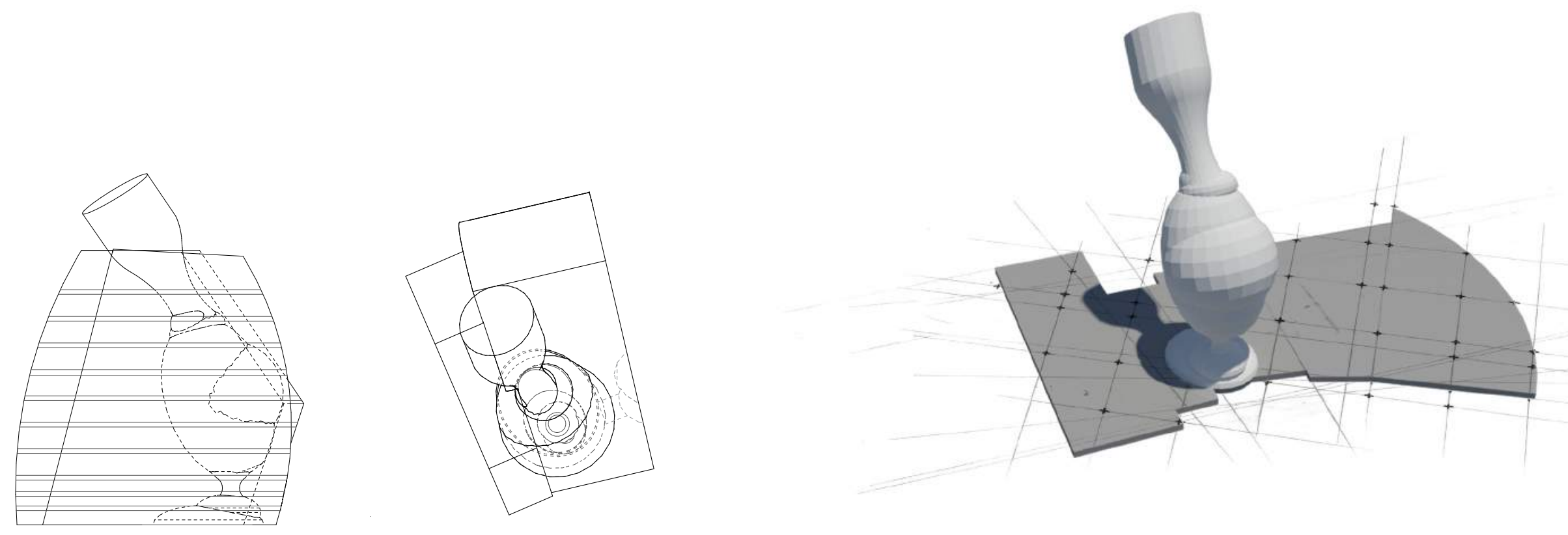

LEFT

Fig. 55: Elevation and plan drawings showing refined placement of vase atrium.

ABOVE

Fig. 56: Three-dimensional image showing placement of vase atrium on overall floor plan. 
causes time to halt and self-reflection to occur (Bednar). Instead of being amongst nature/mankind, standing aback and looking upon man/land as a mass. Disconnecting yourself to see what you are a part of and what you contribute to. Extruding the vase to the full height of the museum will allow these panoramic views and experiential qualities.

\section{ATRIUM DEVELOPMEN T}

As this vase has connections to the Roman and Greek styles, the atrium will adopt the traditions of the ancient Roman atrium. Placed centrally and upon entry (slightly overlapping) the now void leans with the contour of the building form. Extruding the full height, the void pierces the external skin creating an opening at the apex exposing the inside to the natural elements. A mutation of the roman atrium brings this design forward into contemporary/postmodern architecture. Fredric Jameson describes the differentiation between modern and postmodern in his book "Postmodernism, or, the Cultural Logic of Late Capitalism". Modernism holds on to the "nature' or 'being' of the old, the older, and the archaic" (ix) whereas postmodernism takes the modern and eliminates nature from its grasp. The aim of this atrium is to develop it in postmodern style and double back to the modern to maintain the nature of its heritage.
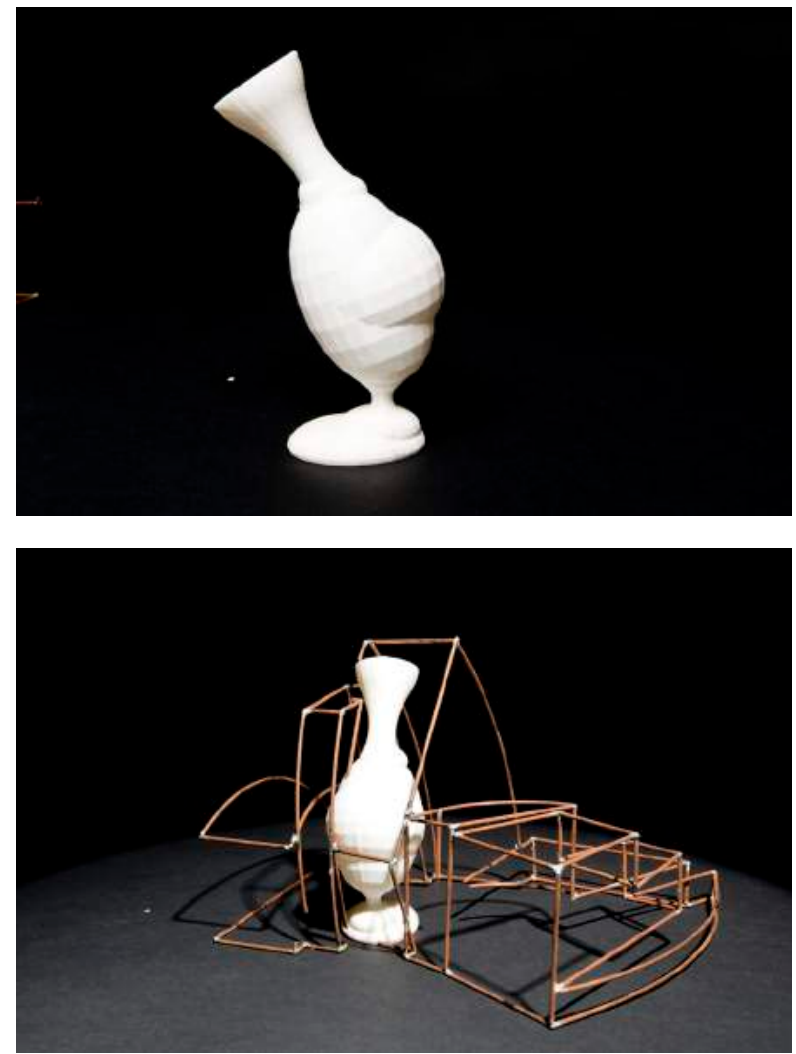

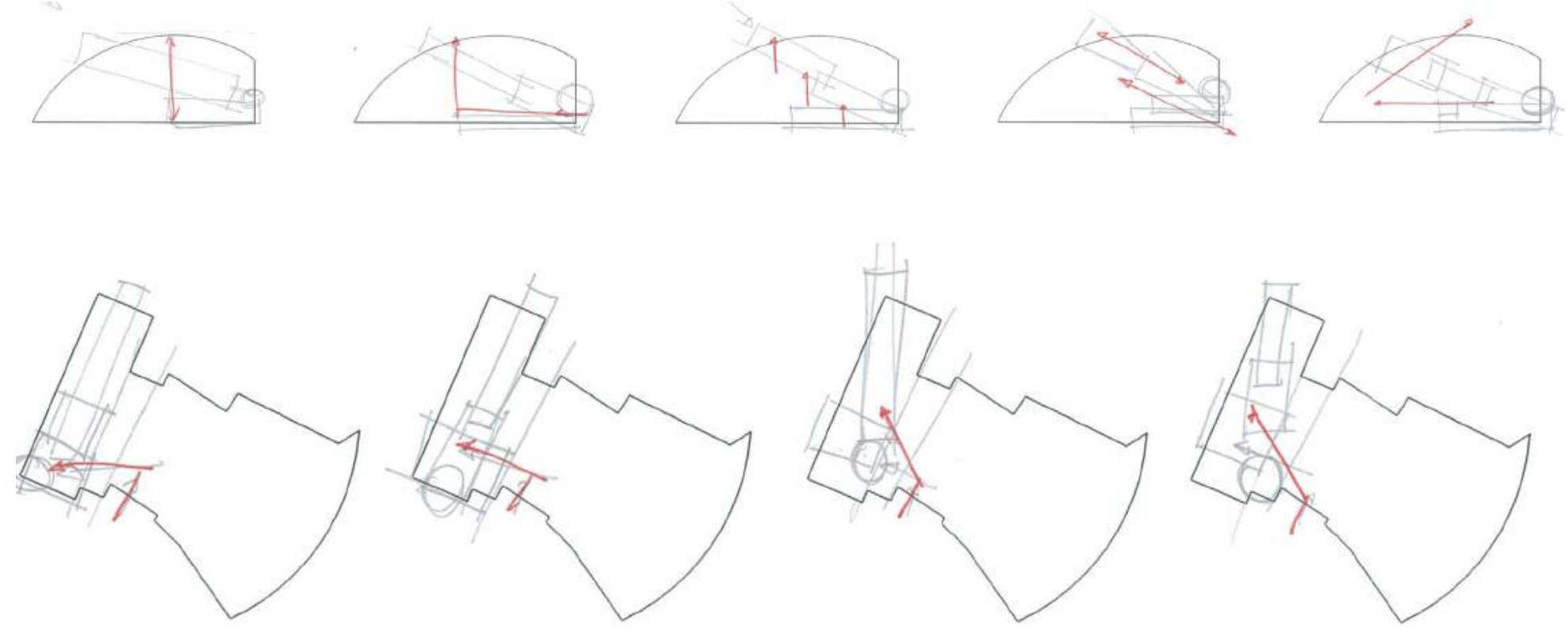

ABOVE

Fig. 58: Drawing series. Exploration of placement for cannon atrium.

RIGHT

Fig. 59: Cannon artifact from Te Papa Tongarewa collections 


\subsubsection{CANNON}

THE OBJECT

This particular cannon was one of six aboard James Cook's Endeavour. Meandering up the east coast of Australia during Cook's first voyage of discovery, they ran aground not knowing they were between a complex network of islands and the Great Barrier Reef. Running aground was inevitable for the ship. In attempt to lighten the ship, six cannons were thrown overboard along with numerous other items ("The Endeavor Cannon"). After approximately 200 years, the cannons were prised off the reef, restored, and distributed to six museums within Pennsylvania, England, Australia and New Zealand.

After the First World War came the modernists who rose out of "conflicts and ironies dramatized in the late nineteenth and early twentieth-century museum narratives" (Hoberman 166).

We have the museums we have today because of our experienced hardships (world wars, biculturalism, depreciations). We depict the controversy, hardship and conflict of our past and conceive it into a monumental form of memory.

\section{INTERPRETATION FOR PROGRAM} ALLOCATION

Interpreting the cannon as a motif of conflict will represent the clashing entities of different cultures and our

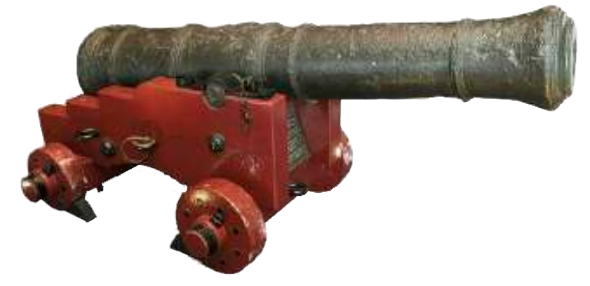



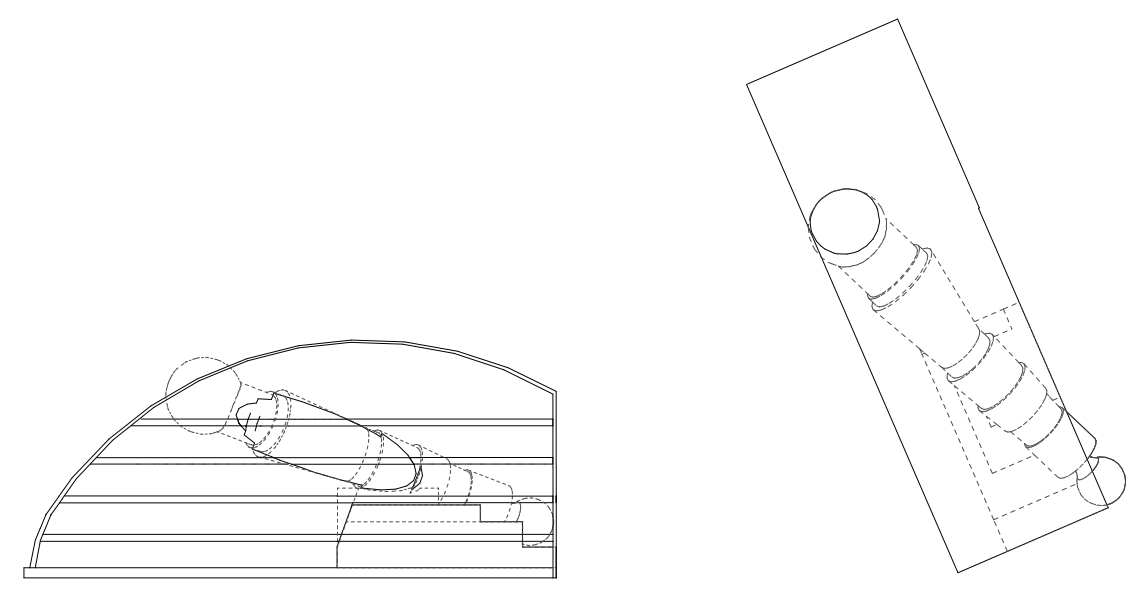

LEFT

Fig. 60: Elevation and plan drawings showing refined placement of cannon atrium.

ABOVE

Fig. 61: Three-dimensional image showing placement of cannon atrium on overall floor plan. 
forever moving landscapes. Our differences will be recognised as an upward journey of constant change and ongoing challenges that continuously have a light at the end of the tunnel, no matter how bright.

Prior to the twentieth-century, museums were held in historical buildings that were connected to particular families (the riches), after the First World War and the rise of the modernists, buildings were designed from history dedicated to the hardship and differences of our people (Jameson 303).

The idea behind the cannon as an atrium for the Natural Environment and Library departments is to emphasise the conflicts of our historical proceedings. From the beginning of time, land and man have developed excrementally resulting in both positive and fatal outcomes. The fragmentations are what define our world today and what inspires the abstraction of the cannon motif.

ATRIUM DEVELOPMENT

This will challenge the standard formation of atrium design. Rather than the regular vertical space of what we know to be an atrium void, the obscure form at a 45-degree angle will be filled with a variance of light depending on the time of day and time of year. Standing at the pinnacle, one will be able to view into each level and see what they house. This is a contrast to viewing only the edge of each floor level in vertical atria.
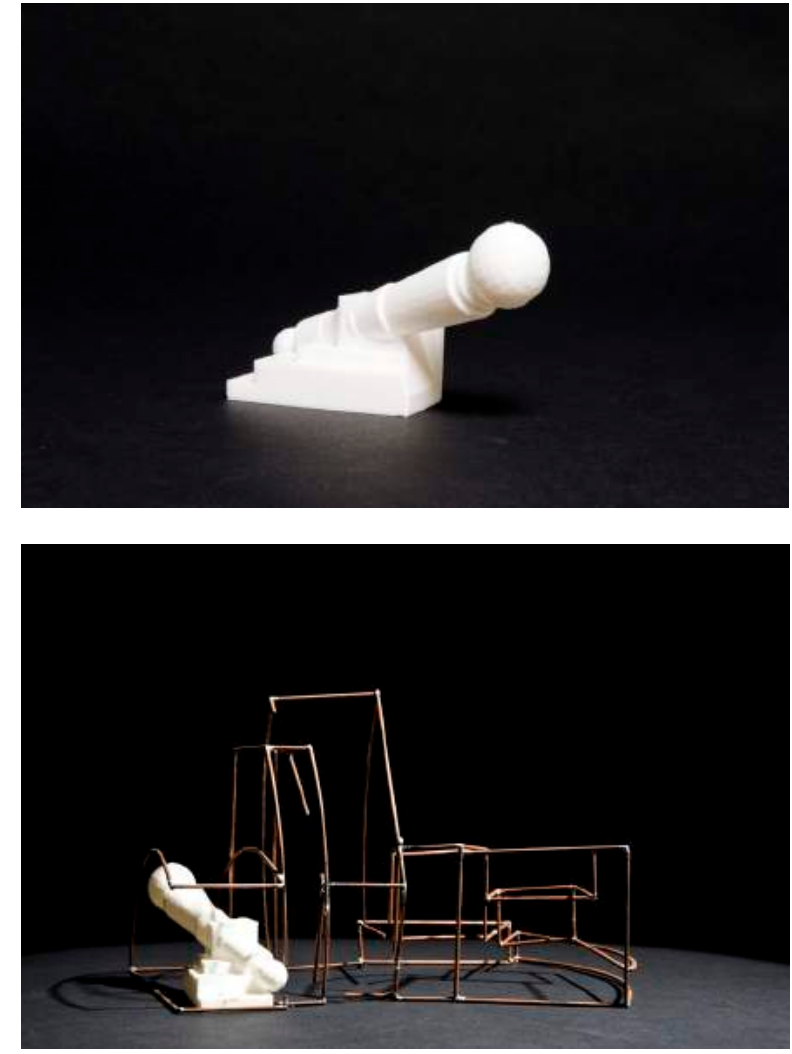


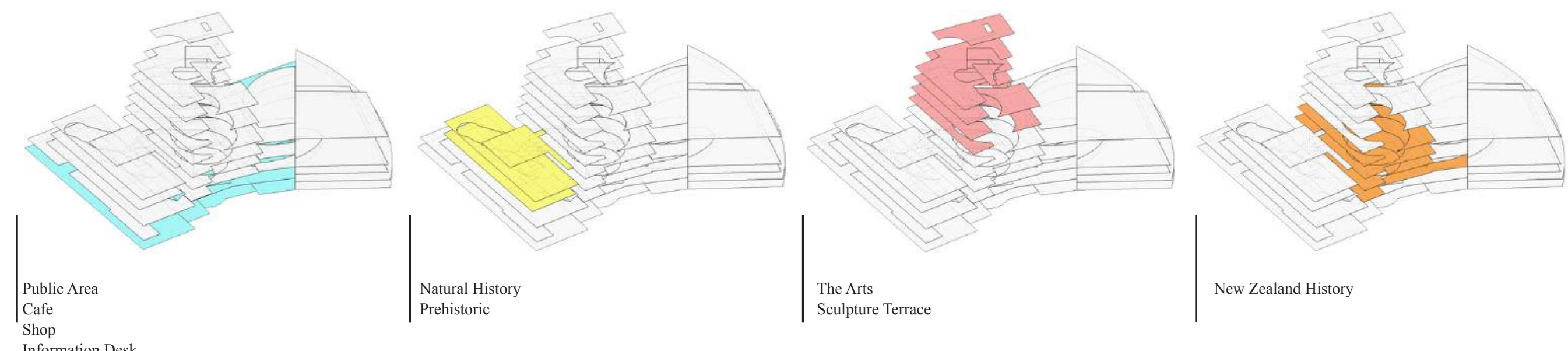


2.2.5 PROGRAM ALLOCATION

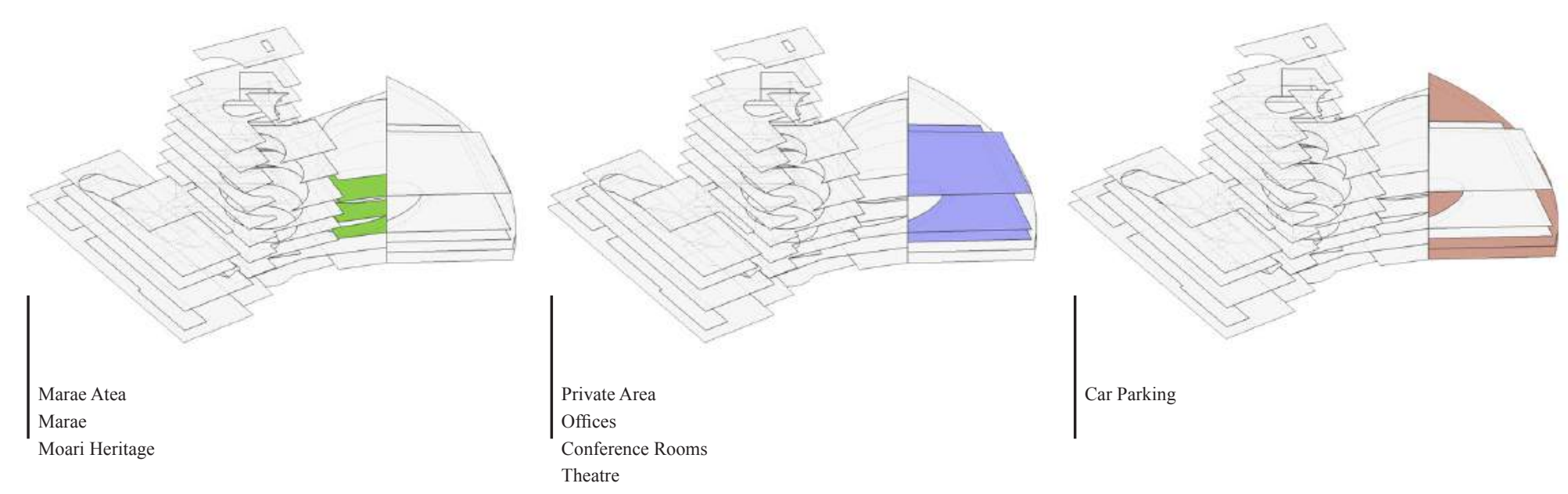




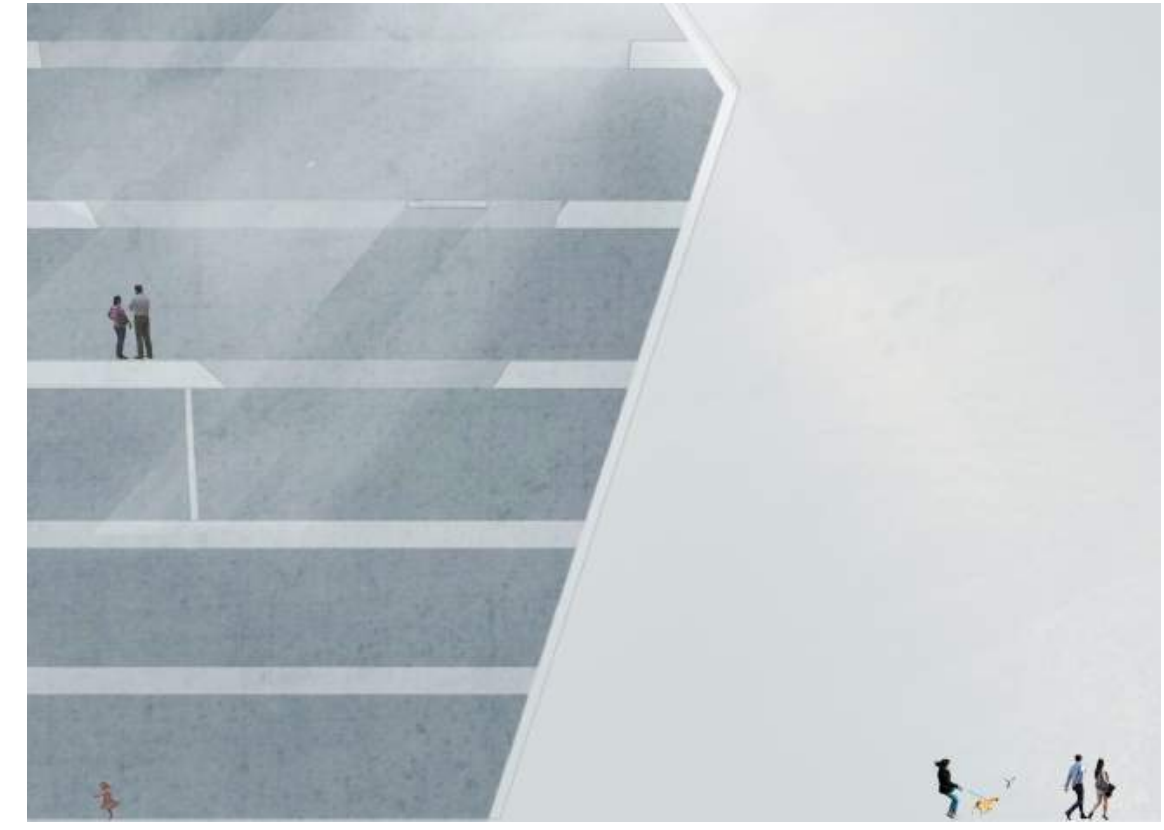

\section{The plan is a generator - (Corbusier 45)}

The journey and activity of a space have to be treated on equal terms. The plan of an interior is a two-dimensional representation of a three-dimensional reality (Goldberger 129). A diagram which suggests where to access spaces and differentiates the major and minor spaces. Looking at a floor plan and seeing a significant area of blank space within the confines of the external walls, you know that that is indication of a grand space of an architectural experience unable to be communicated in 2D form.

Investigating architectural history and theory, it has become evident that literature focused on circulation design is somewhat thin. A topic that is so important to teach and to practice, has little significance within professional writings. Looking at architectural drawings however, the floor plan is a primary tool which communicates the evolution of interior configuration. From the mid eighteenth-century, the Renaissance and Baroque period practiced mathematical precision which was easily communicated through a floor plan drawing. Doorways and thresholds perfectly line up with one another creating a progression of spaces in a linear circulation. Today, the floor plan is 


\subsubsection{DEFINING CIRCULATION}

used as a tool to simplify the not-so-symmetrical configuration of spaces. Visitors need the floor plan to decipher how to get in and out of each space rather than to understand the methods of construction.

Philip Johnson sates in his essay titled "Whence and Whither: The Professional Element in Architecture", that architecture is not the design of space, nor the organisation of forms, these are both secondary to the primary element of organising procession.

“Architecture exists only in time” - (Goldberger 125)

Circulation defines the interaction of people through horizontal and vertical movement. Consideration of people that work in the interior on a daily basis and the visitors that occupy the space for a short period of time will determine differing circulations through particular spaces (Sully 38 ).

Circulation originally referred to the path that leads to each individual room particularly within housing of the early 1900s (Lederer 15). Housing design in the 1920s reduced circulation to occupy the minimum amount of the floorplan. This was to maximise living areas and to present the quickest route possible between spaces.

In the world of architecture, circulation does not initiate at the entrance. The entrance is merely a threshold of transition between outside and inside (Lederer 202). Circulation is continuous from home, to the city, to the park, to the museum and back again. Some areas more controlled tham others. This applies to circulation methods within Ian Athfield and Frank Gehry's design. The inner courtyard provides a specific route to access each individual void, which leads in to individual circulation systems unique to their own interior. This presents the issue of causing confusion of varying circulations.

The design uses iterative circulation approaches as to convince the visitor of know specific route, or provide significant variance between circulations to offer unique, singular experiences. Visitors will treat each interior volume as a new experience. Circulation methods will need to be established to each individual void that is both unique to housed exhibitions and similar enough as to not cause confusion to wondering visitors. 


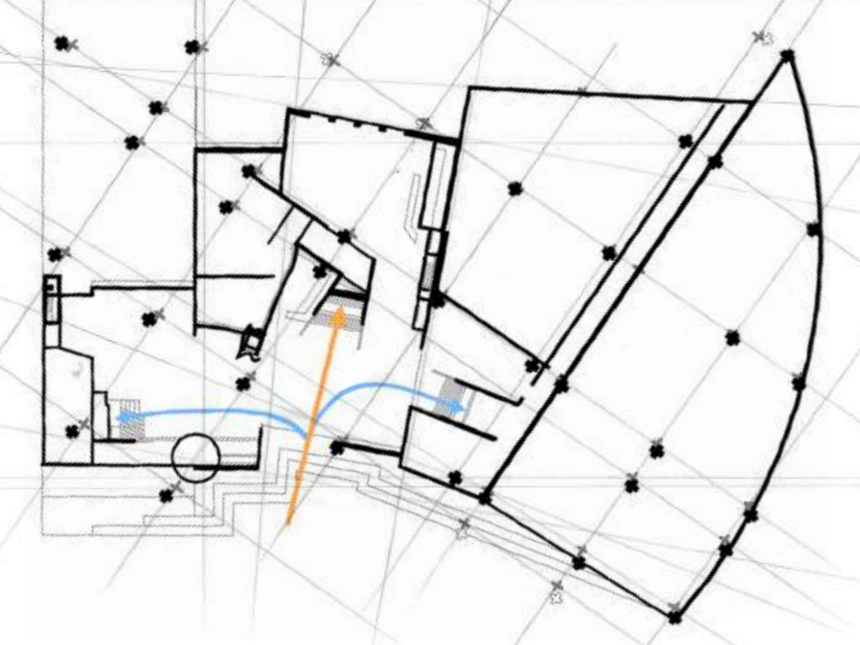


H O R I Z ON T A L

Partitions and columns allow visitors to choose certain routes or allow the interior to influence the visitor's route. Acknowledgment of the visitor's emotions and the activity they are involved in are considered within the early design stages. The architecture does not control the emotions nor the activity, but are a consideration that affect the design. Likely horizontal experiences are defined within Anthony Sully's book Interior Design: Conceptual Basis. For a partition that is parallel, perpendicular, diagonal, concave or convex to the visitor, can influence the route taken or not (Sully 42). Once circulation influences are in place, design of the themes, finishes and lighting may be visualized.

Three options of circulatory routes are most commonly used within interior spaces (Sully 43). A well-defined route provides the visitor with a single route from A to B with multiple divergent paths that lead the visitor back on to the main route
Multi-directional routes offer a similar strategy. A single origin and destination point, but the interior offer a multitude of options to get from point A to point $\mathrm{B}$. A directional corridor on the other hand, has a single route from point $A$ to point $B$ with no diverging routes of any kind.

Within museum design, all three methods of directional circulation are used. Most commonly, the well-defined and multidirectional routes are used for the more public spaces of a higher foot traffic whereas a directional corridor is more comfortable in gallery/exhibition setting. For a display of art tends to have an ordering or categorized system, a single corridor offers a systematic organisation.

In 2-dimensional form, the shapes and paths created on the plan seem simple and straight forward, but once inhabiting the space in a three-dimensional structural maze, it is difficult for the mind to decipher due to the lack of visual differentiation. 

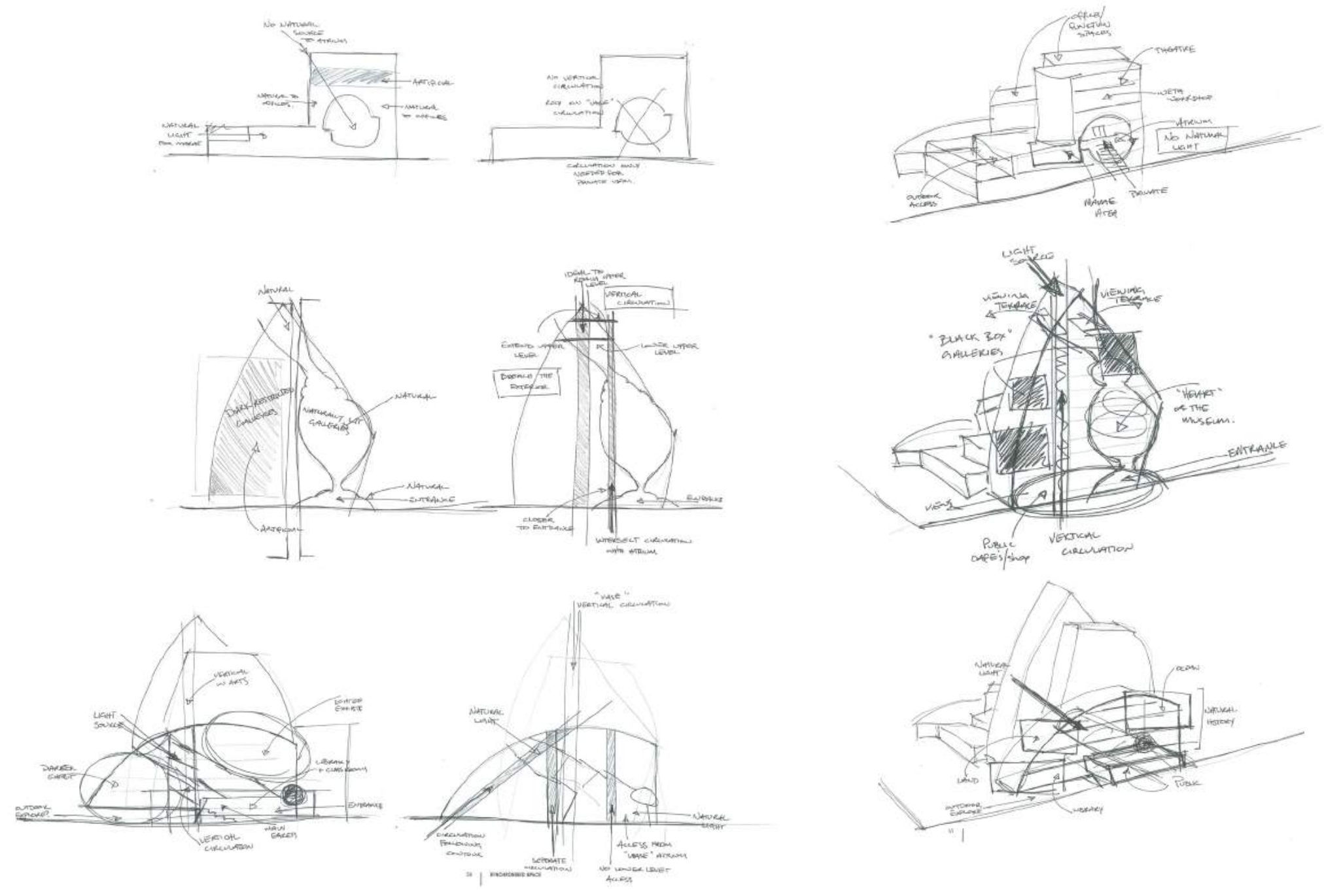

90 UNBUILT AS A REALITY 
VER T I C A L
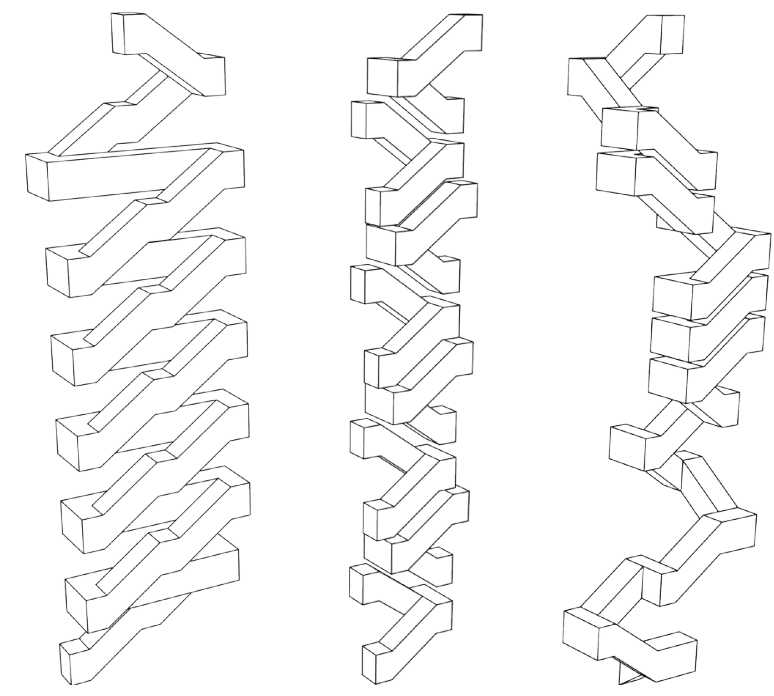

Stairways and elevators are the two most commonly used tools for accessing floor levels above and below. These two elements should not merely perform as functional spatial connectors, but also a permanent design feature to the interior. The stairway and elevator should be easily accessed and should ease the transition of experiences between levels (Kumar 08). The stairway has been a particular sculptural feature since the early ages of architecture in which to showcase artistic masonry and craftsmanship (Lederer 09).

With this particular structure, the staircase will need to be of certain design as to not tire the visitor of neither its aesthetic nor its function (Lederer 19). The thought of travelling vertically through eleven storeys is daunting and unpleasant, thus needing a strong visual and physical connection between stair, atrium, and elevator.

The connection between stair and atrium are of an important one. With the particular form of the structure and of the atrium, it is inevitable that the two will become segregated at certain points. Designing each as their own identity to ignite a relationship which allows the visitor to meander willingly between them.

RIGHT

Fig. 66: Sketch series of atrium void potential.

FAR RIGHT

Fig. 67: Vertical stair exploration 

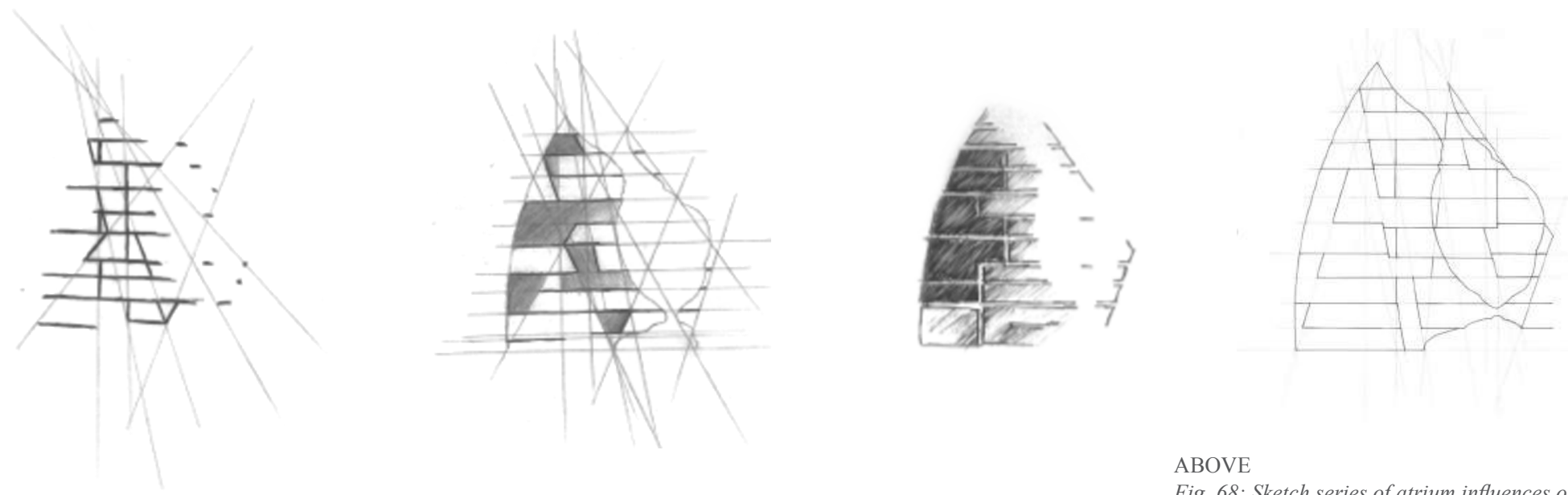

ABOVE

Fig. 68: Sketch series of atrium influences on gallery spaces and natural light.

RIGHT

Fig. 69: Three-dimensional section of atrium void. 


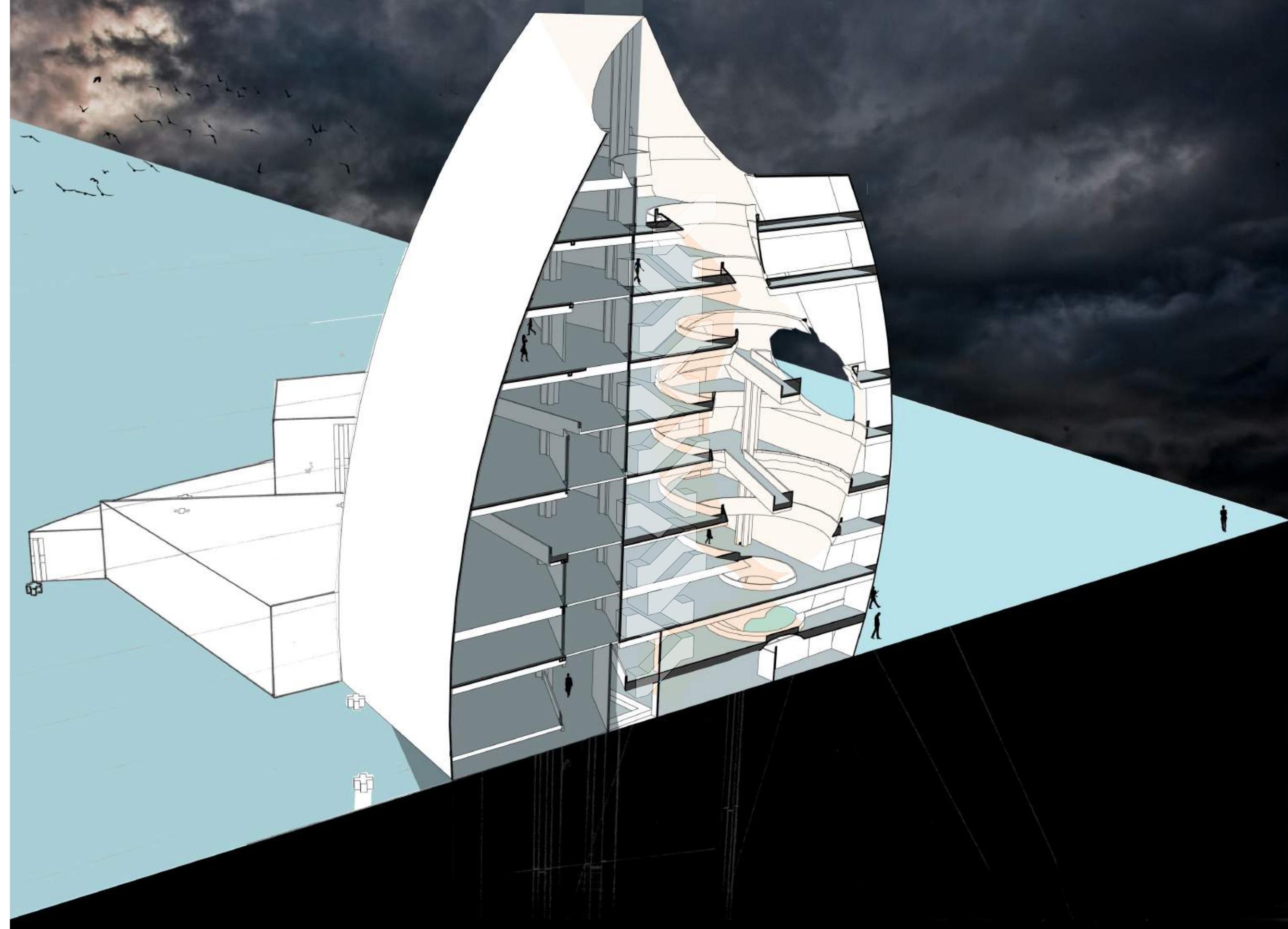



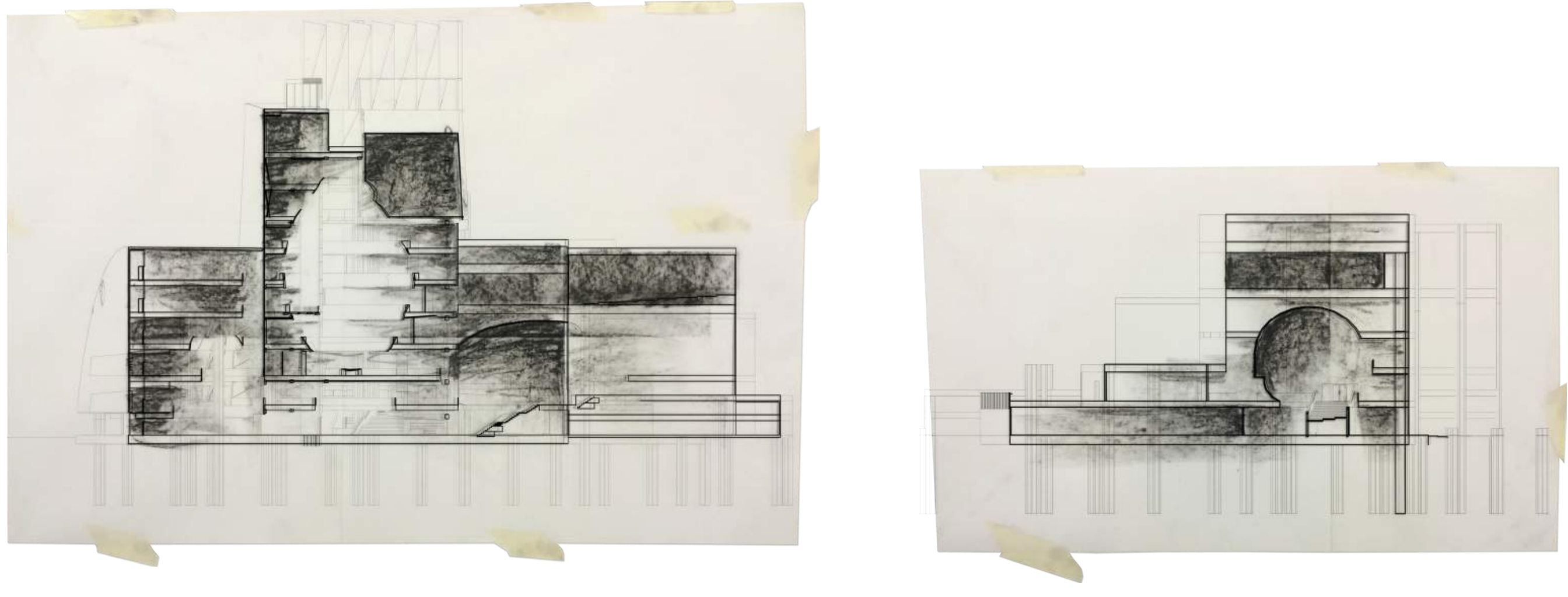

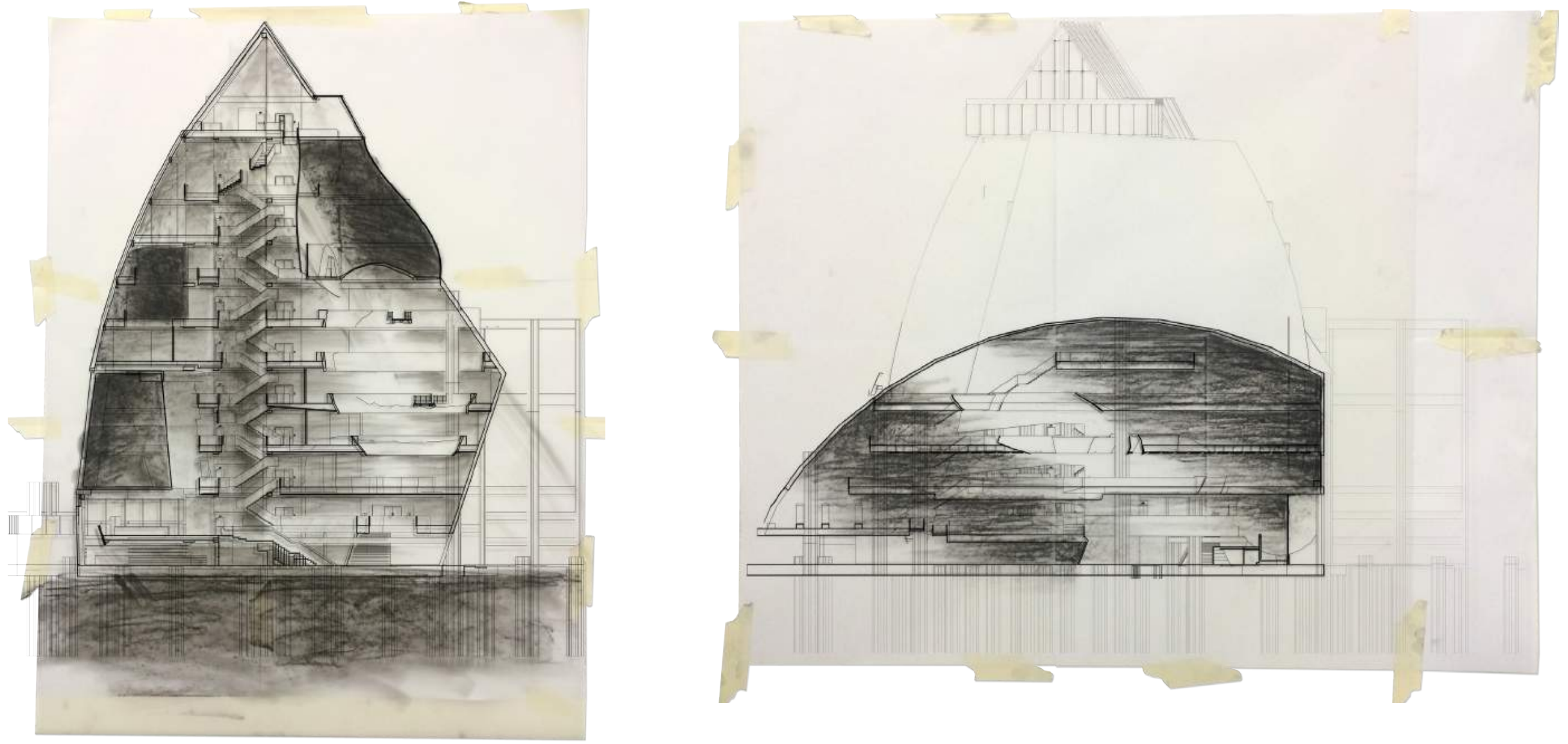

\begin{tabular}{l|l} 
UNBUILT AS A REALITY & 95
\end{tabular} 

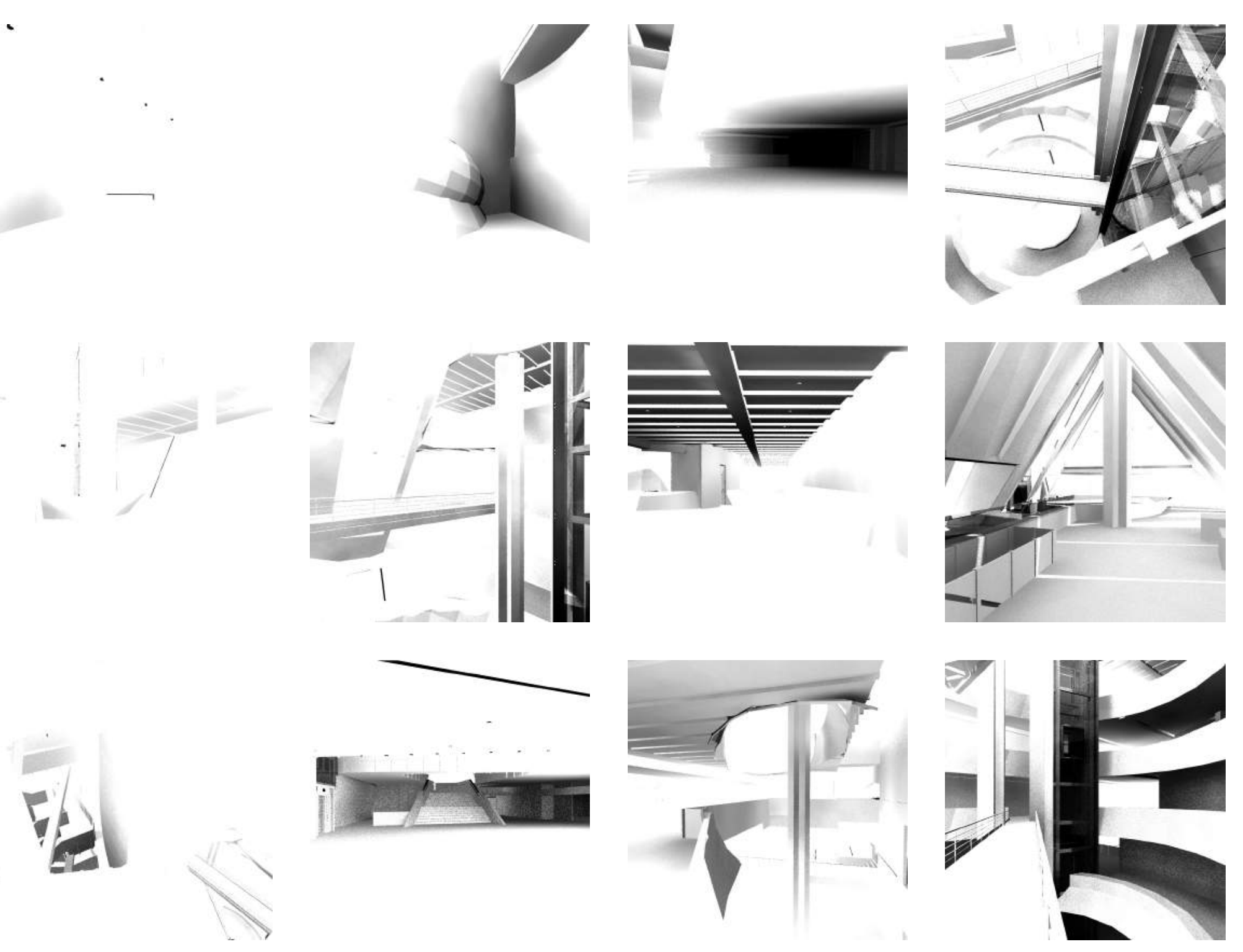

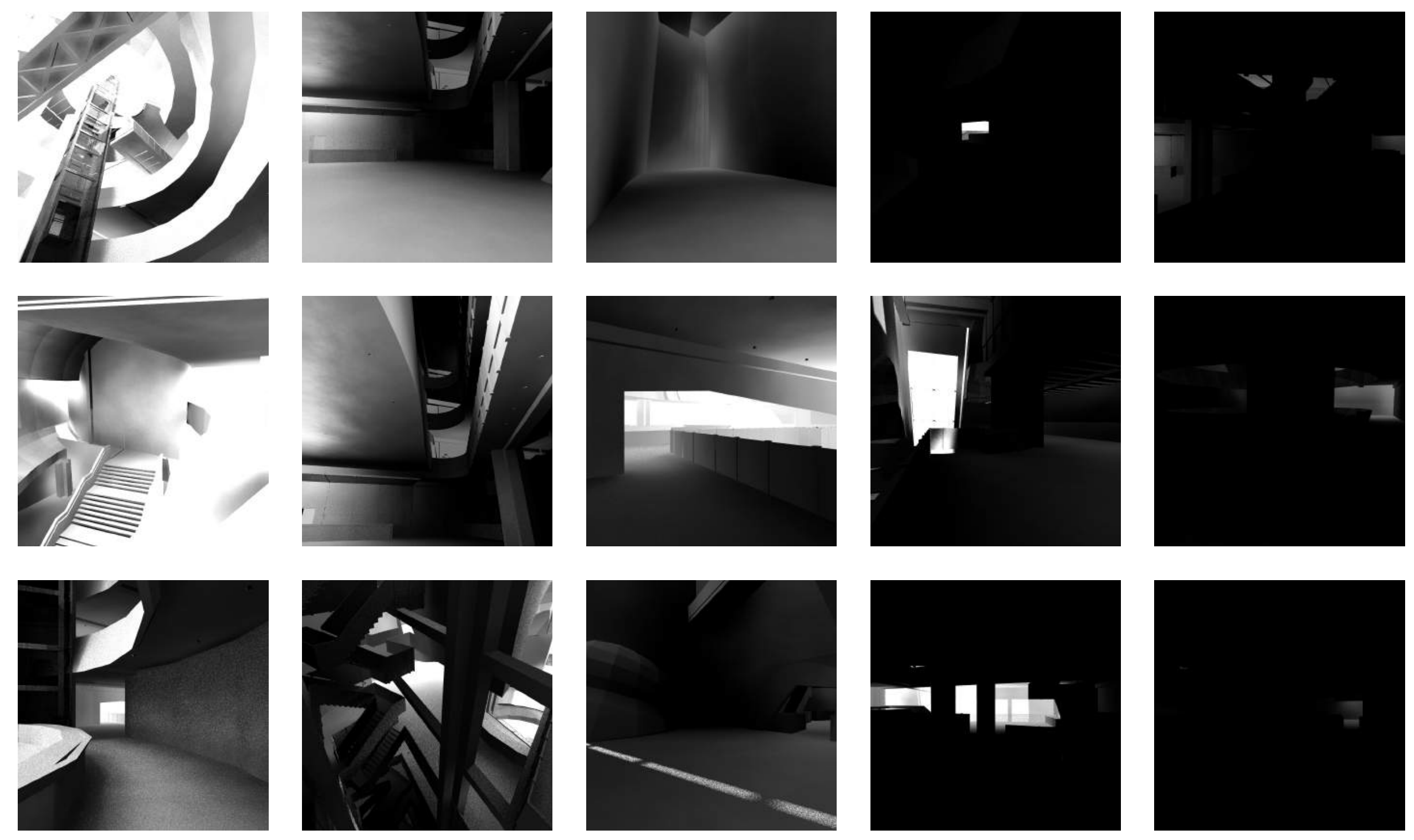

\begin{tabular}{l|l} 
& \\
UNBUILT AS A REALITY & 97
\end{tabular} 

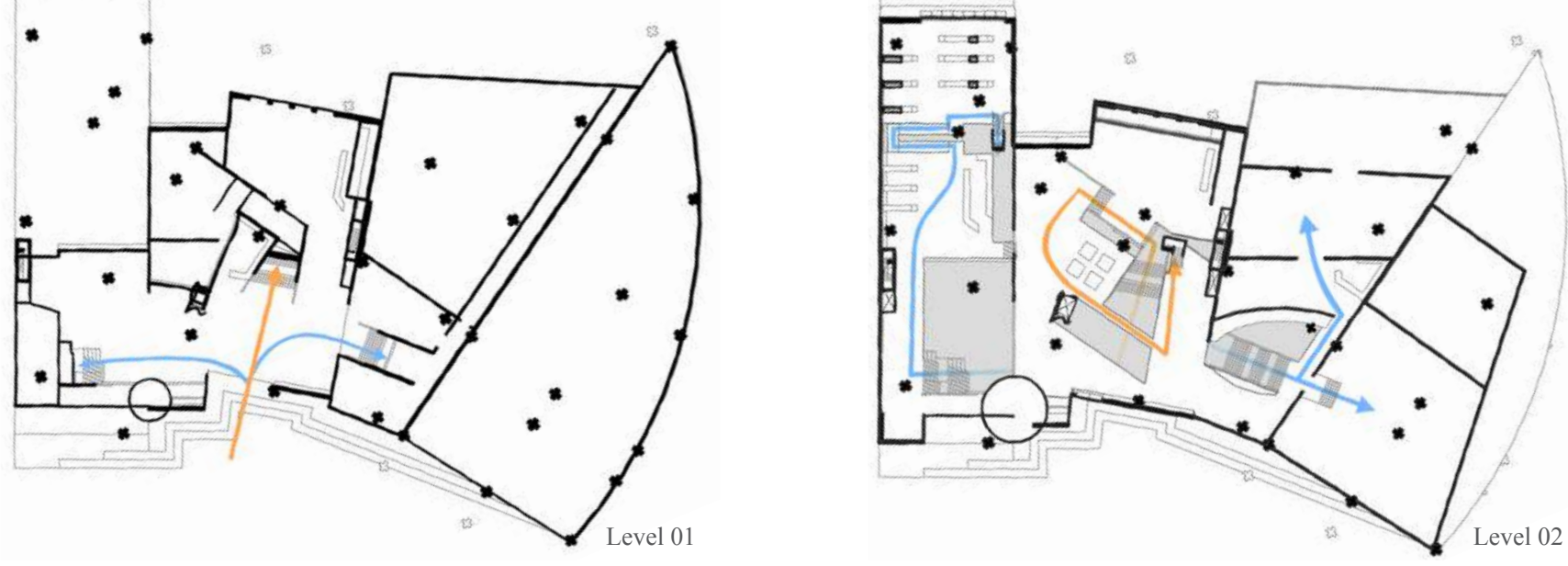

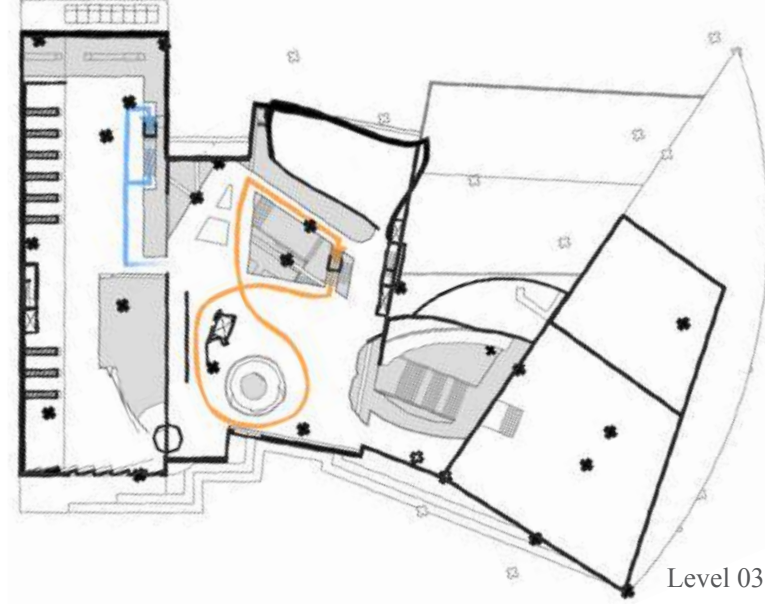

ABOVE

Fig. 72: Line drawing series of horizontal circulation. 

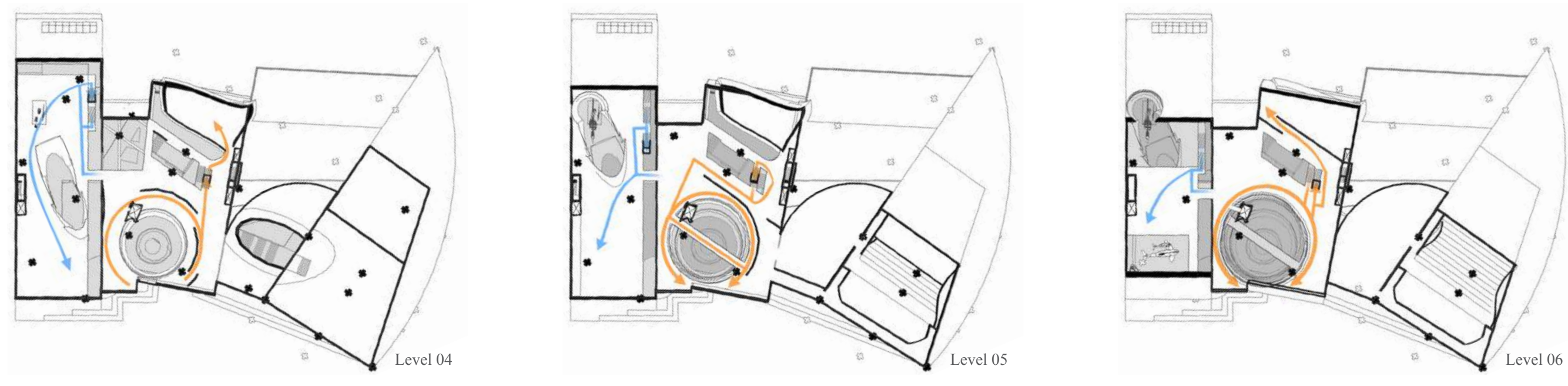

\begin{tabular}{l|l} 
UNBUILT AS A REALITY & 99
\end{tabular} 

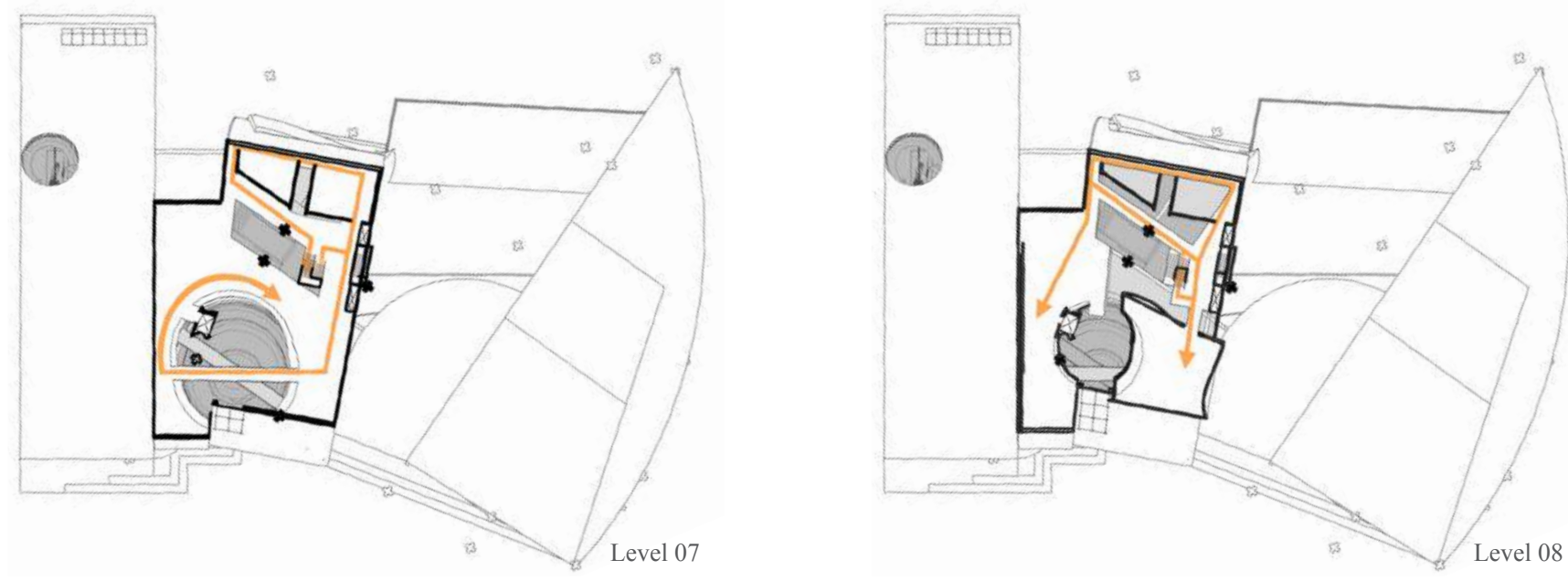

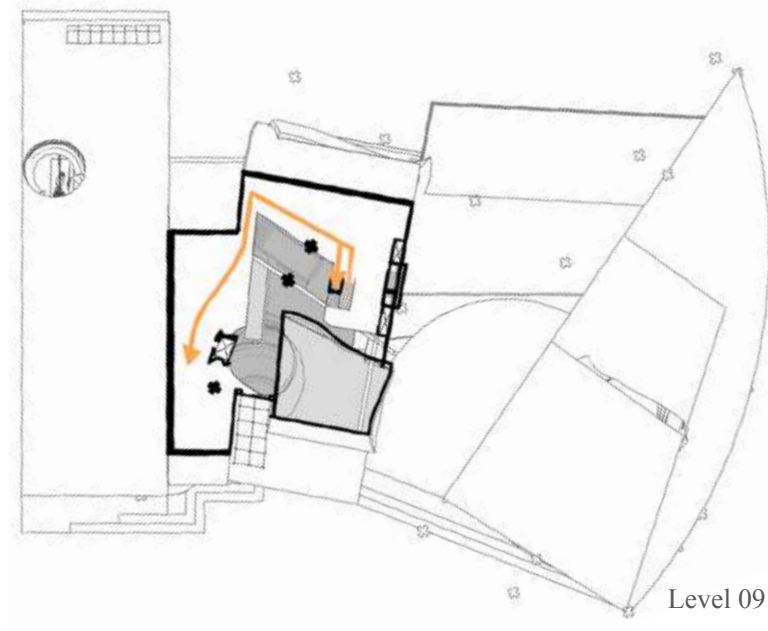

ABOVE

Fig. 72: Line drawing series of horizontal circulation continued, 

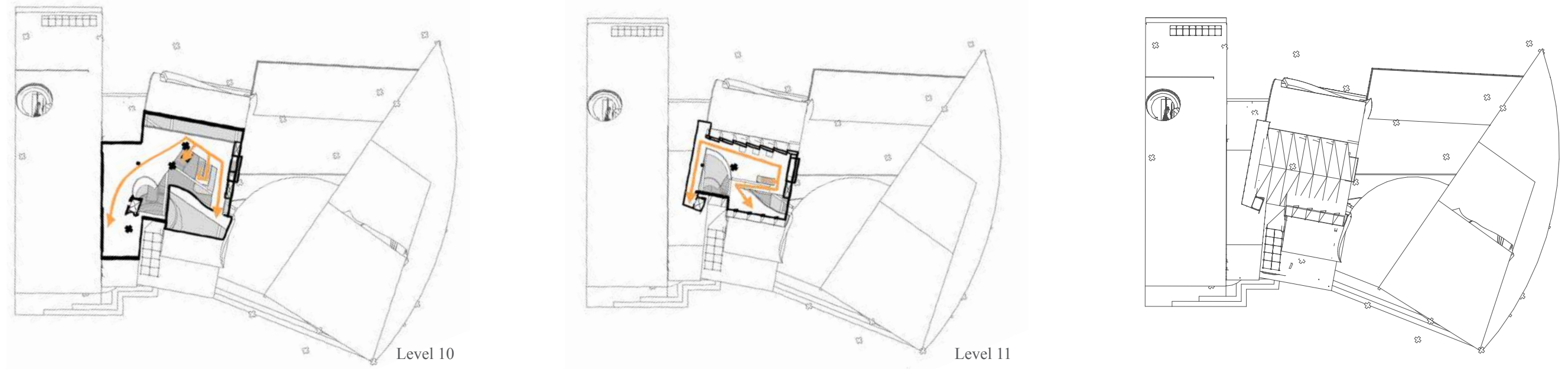

\begin{tabular}{l|l} 
UNBUILT AS A REALITY & 101
\end{tabular} 


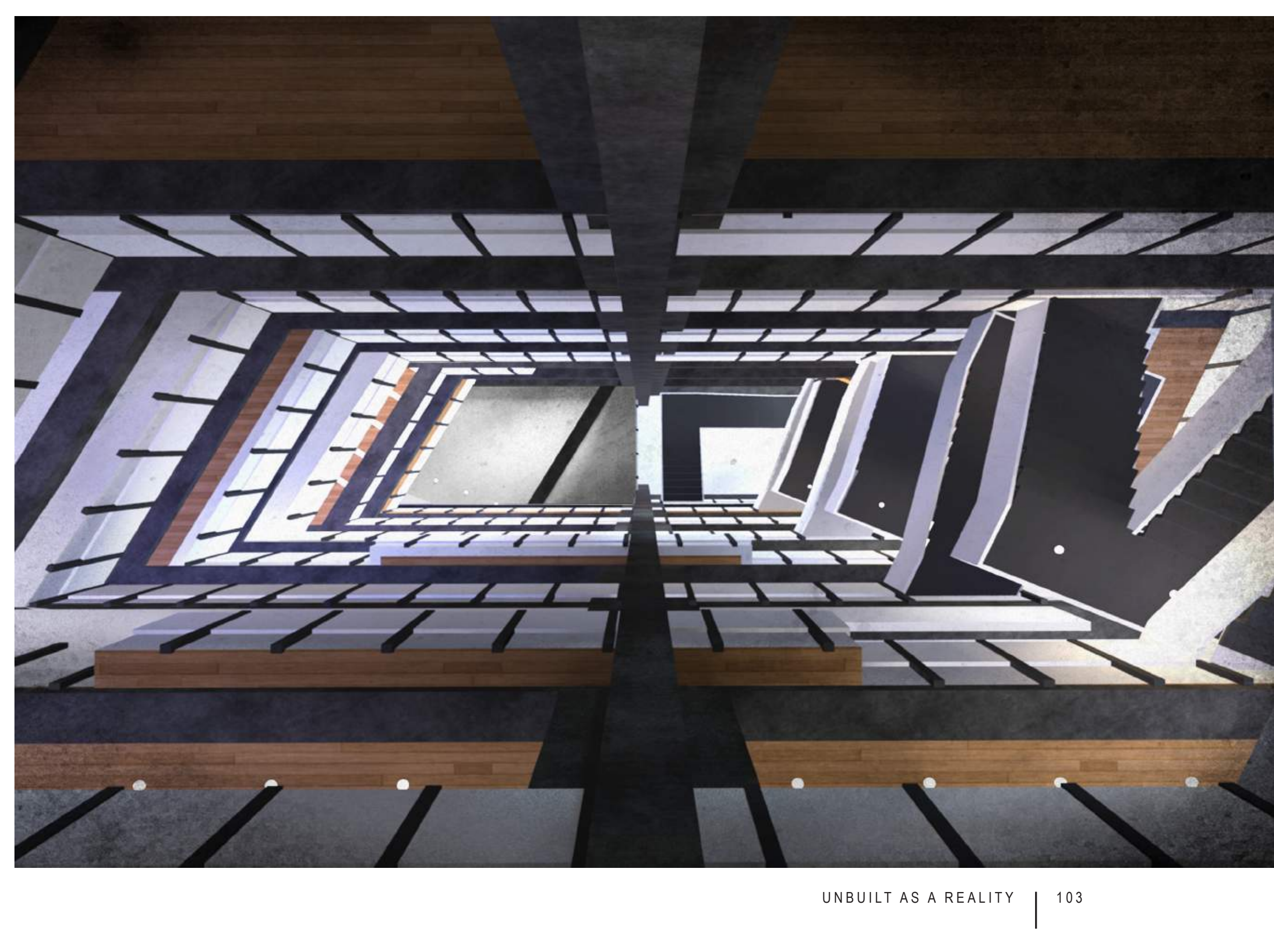



2.3

THE EXPERIENCE 


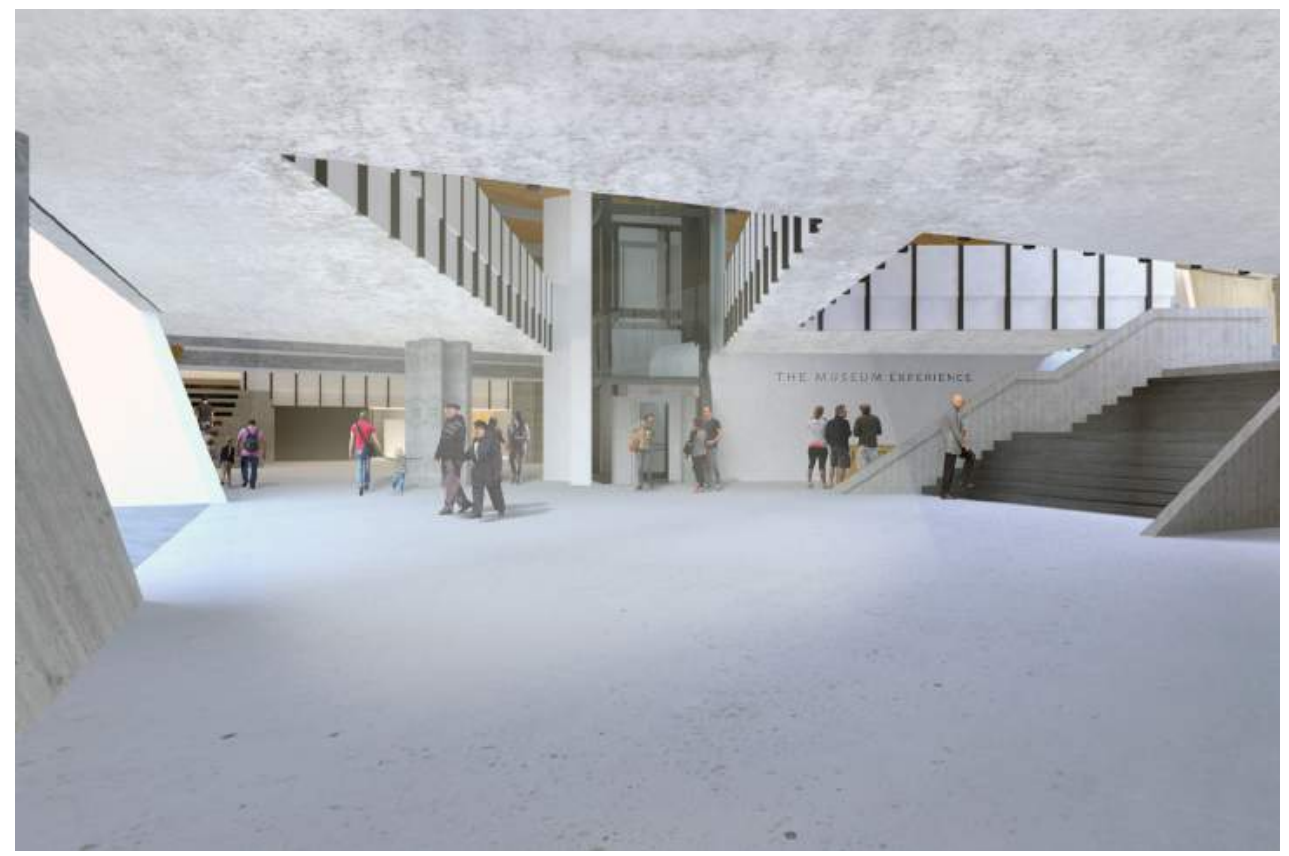

LEFT
Fig. 74: Section of atrium void. Showing the

Fig. 74: Section of atrium void. Showing the
influence to the vertical and horizontal circulation and the spaces to be experienced.

RIGHT

Fig. 75: Main entrance to the museums public

spaces. 


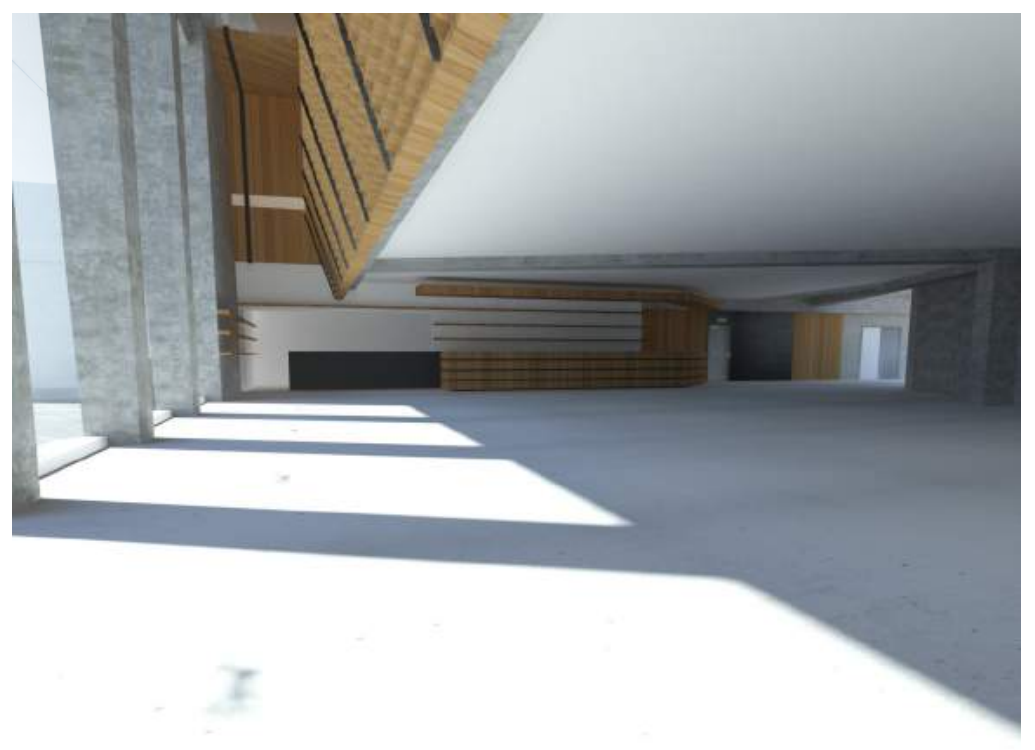

110 THE EXPERIENCE

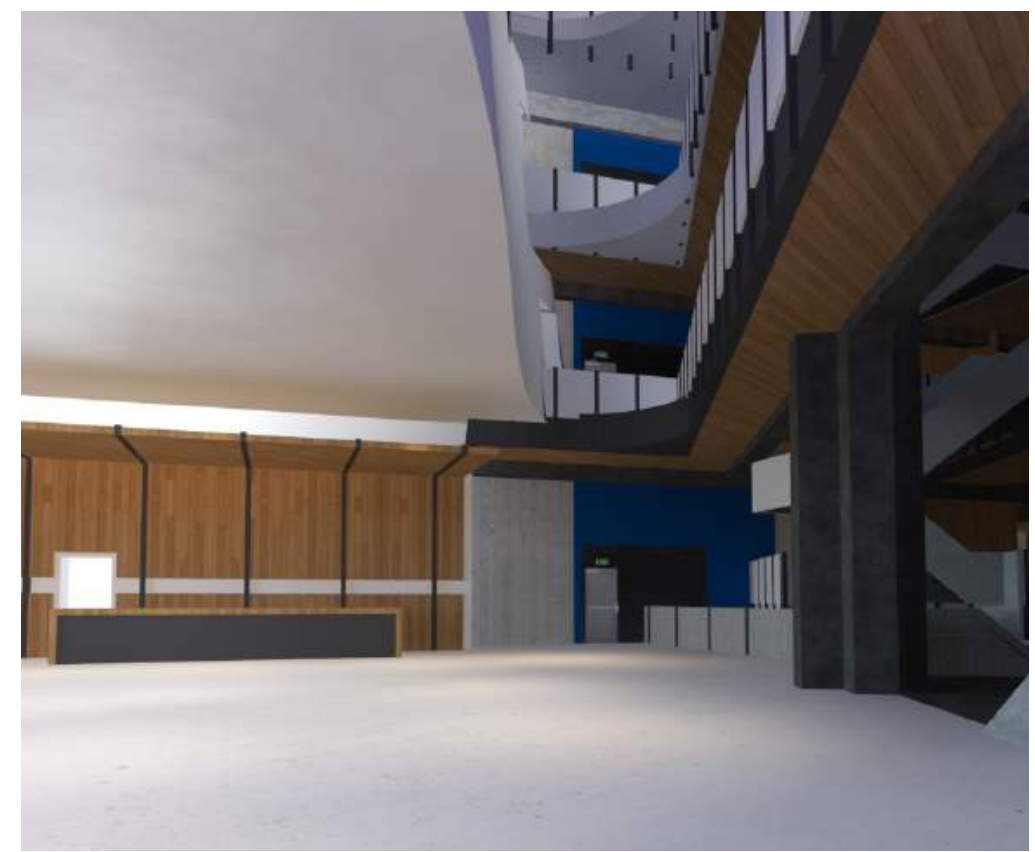

LEFT

Fig. 78: Cafe space with views out to Wellington Harbour:

ABOVE

Fig. 79: Shop above cafe. Views to Wellington

Harbour. visual connection to stairway void and the beginning of the New Zealand History department.

RIGHT

Fig. 80: Section of treasure-bo atrium and void of our indigenous heritage. 
c i

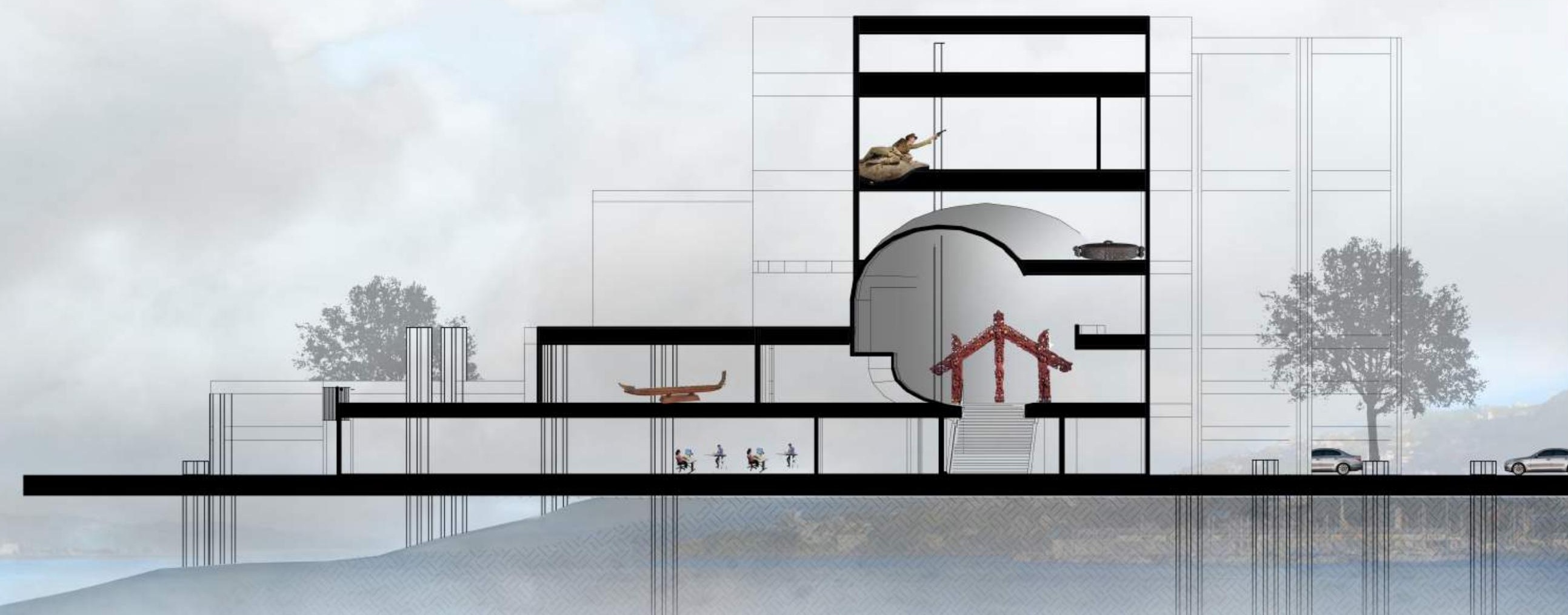




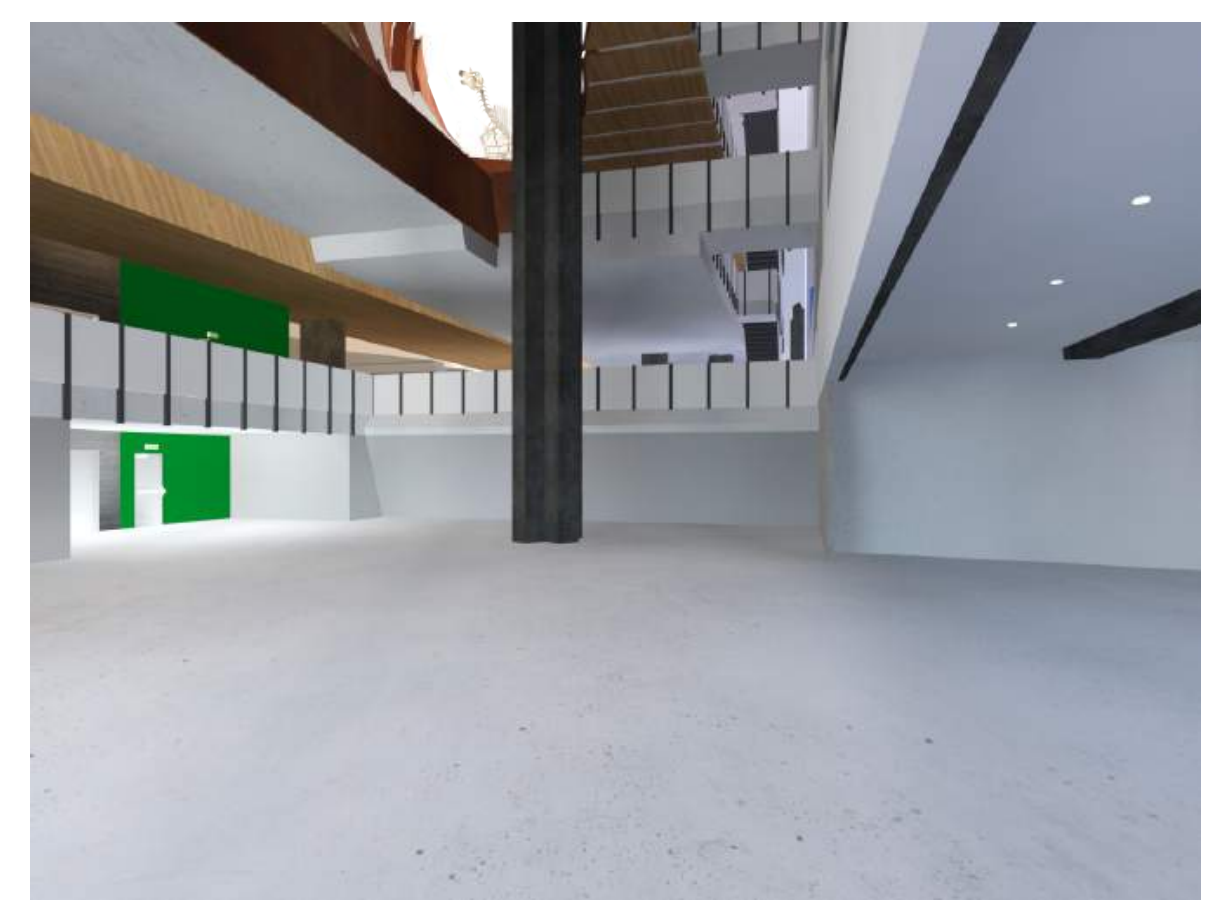

LEFT

Fig. 81: Level one of the cannon atrium. Main entry to the Library and .National Environmen epartments. indigenous heritage.

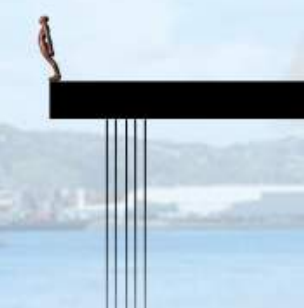




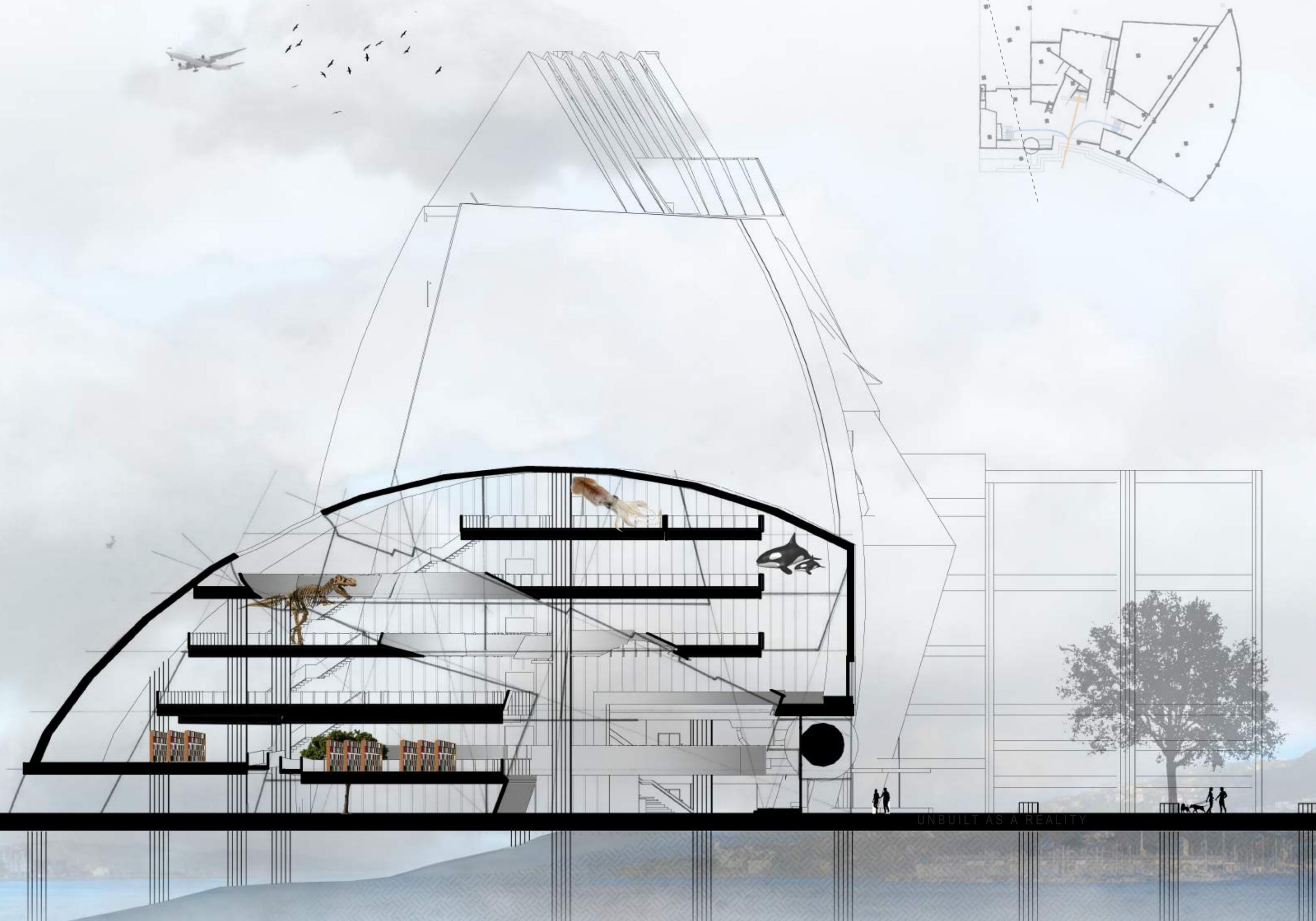




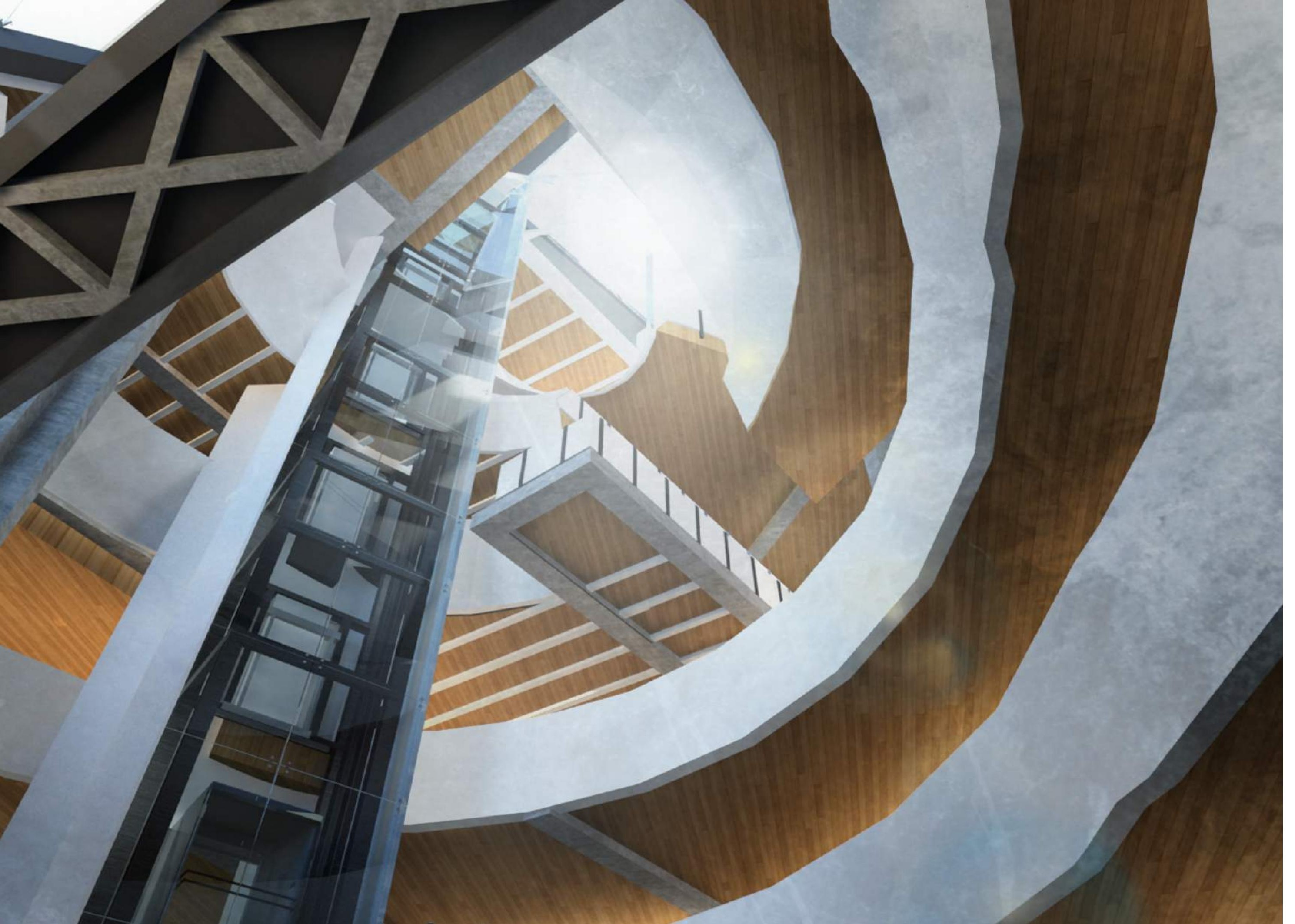




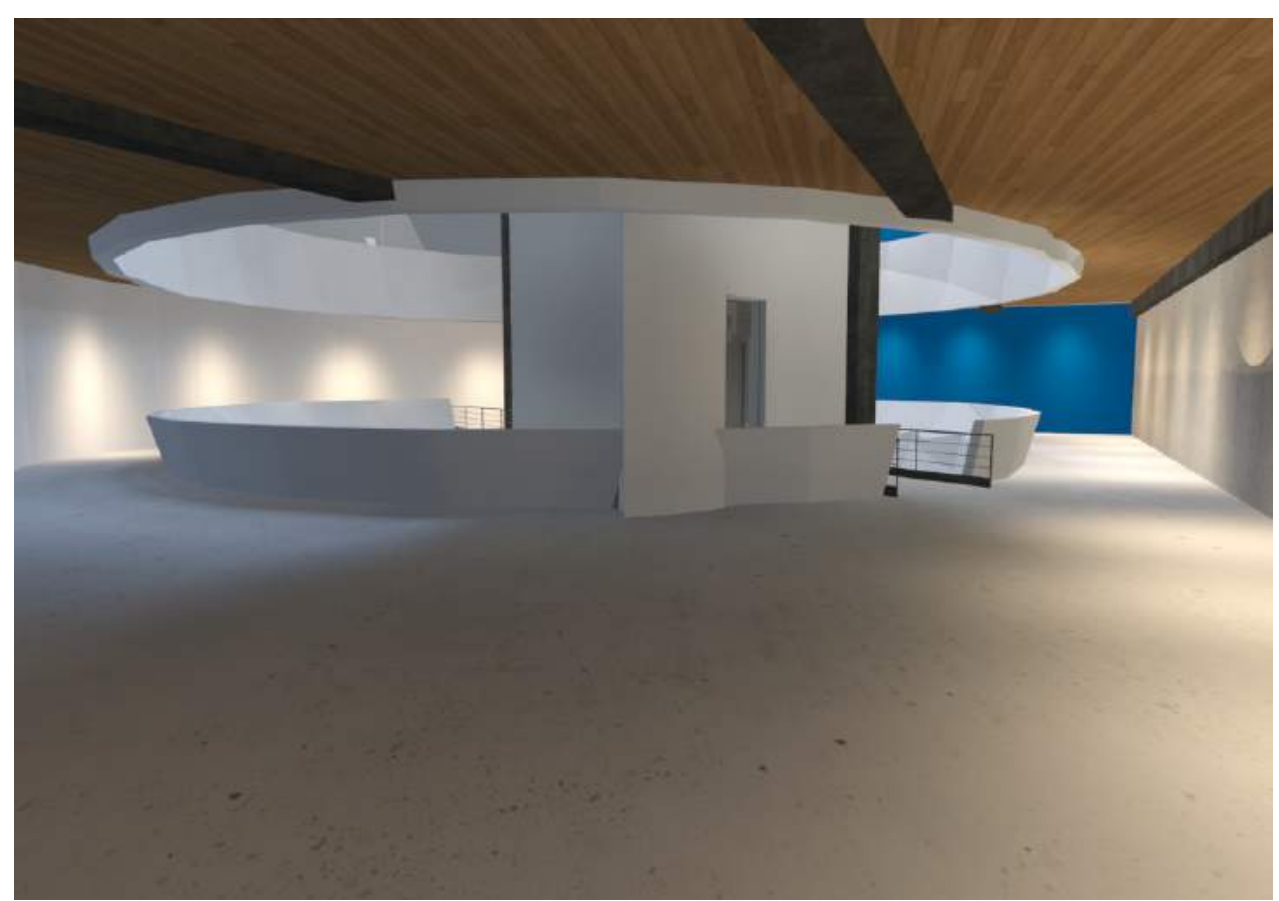

LEFT
Fig. 83: Looking to the upper level of the vase

atrium. Form intersected by vertical and horizontal circulation

LEFT

Fig. 84: Open space for art installations. Circular

form initiating movement and rhythm. 


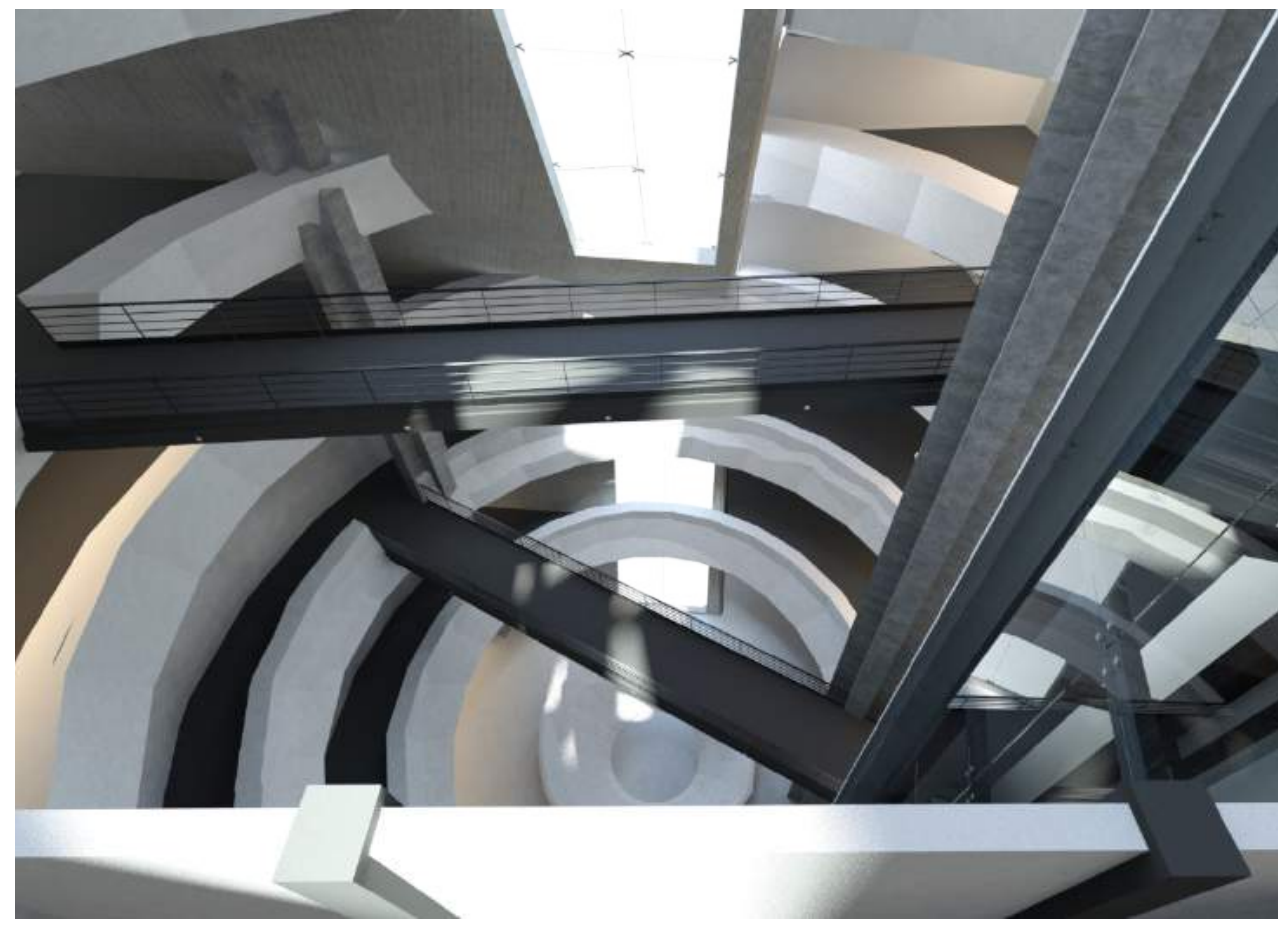

LEFT

Fig. 85: Looking down from level 10. A moment to remember the museums experience and carry on to

RIGHT

116 THE EXPERIENCE

Fig. 86: Level 10 of the Arts department. Optimum internal look out point of the vase atrium. 


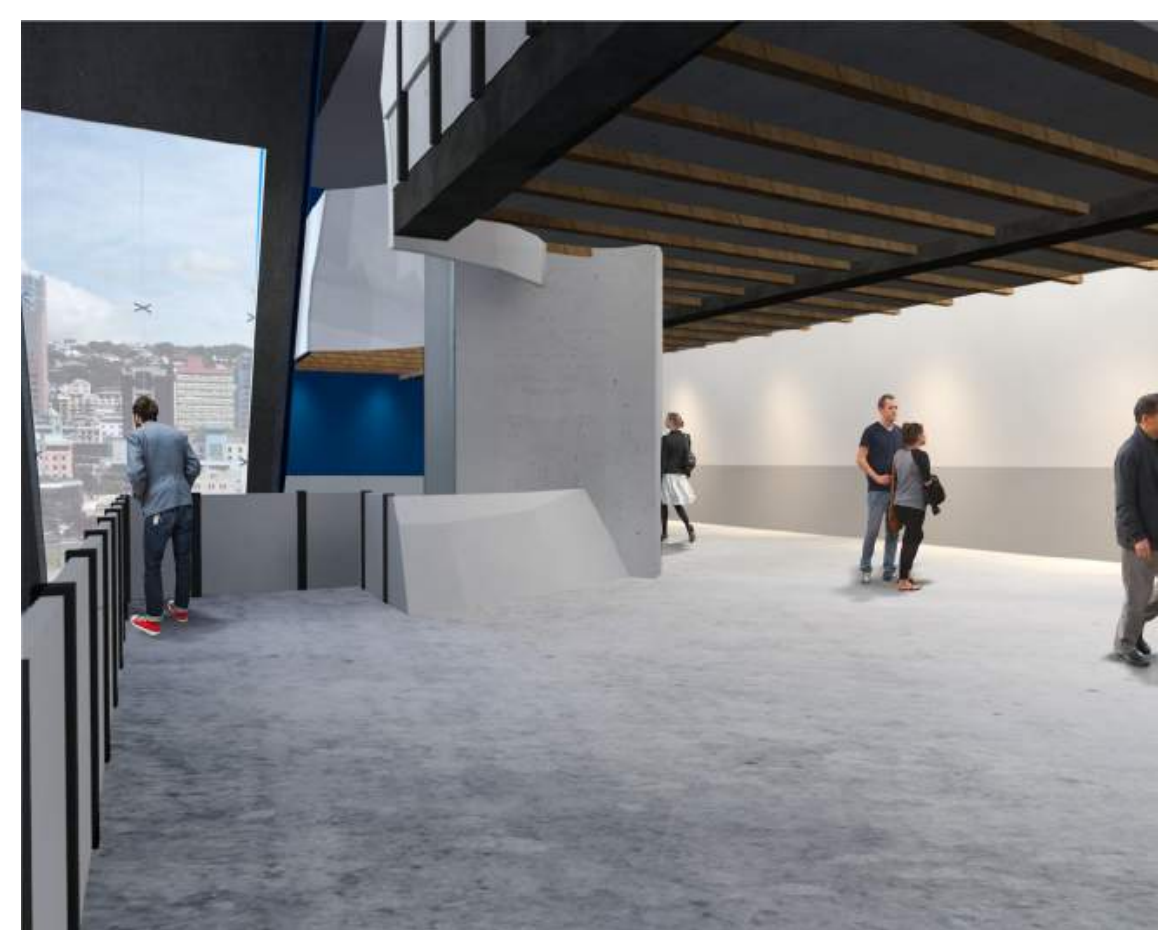

\begin{tabular}{l|l} 
THE EXPERIENCE & 117
\end{tabular} 


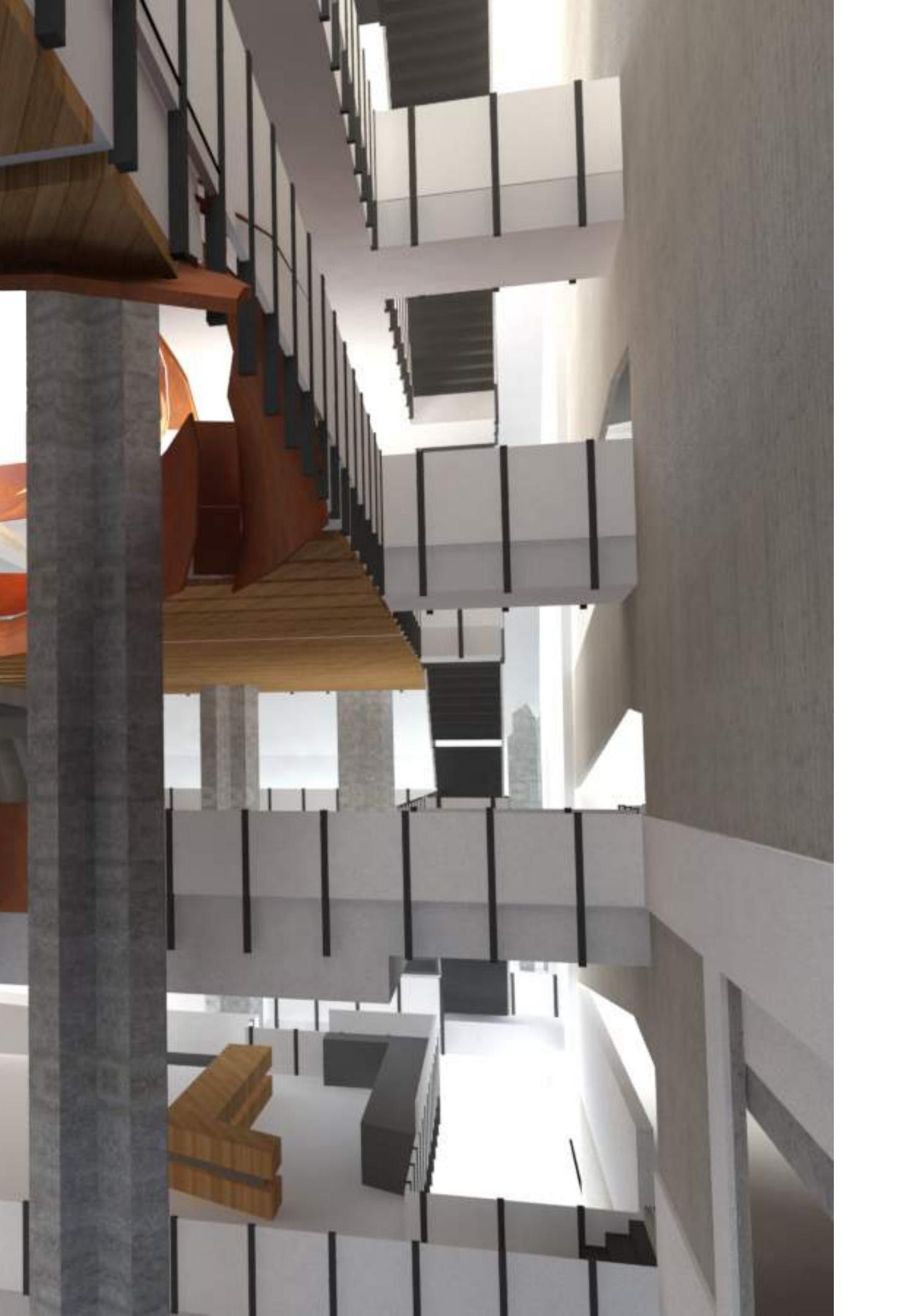




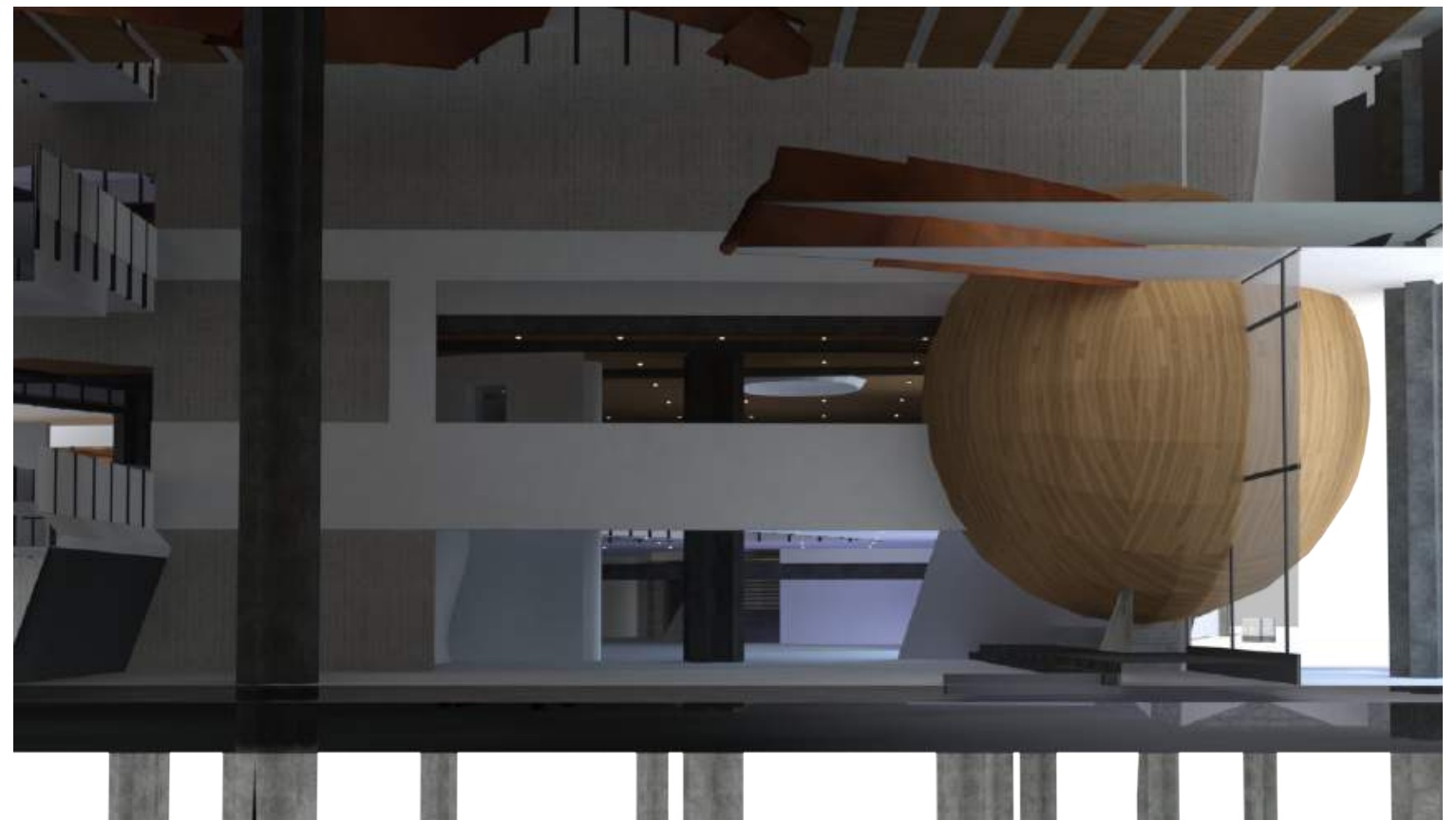

LEFT
Fig. 87: Cannon atrium emphasising on the

adaptation of our history.

RIGHT

Fig. 88: Lower section of the cannon showing the

connection through to the adjacent void. Sphere of

the cannon left behind to symbolise some things in

history will not alter. 


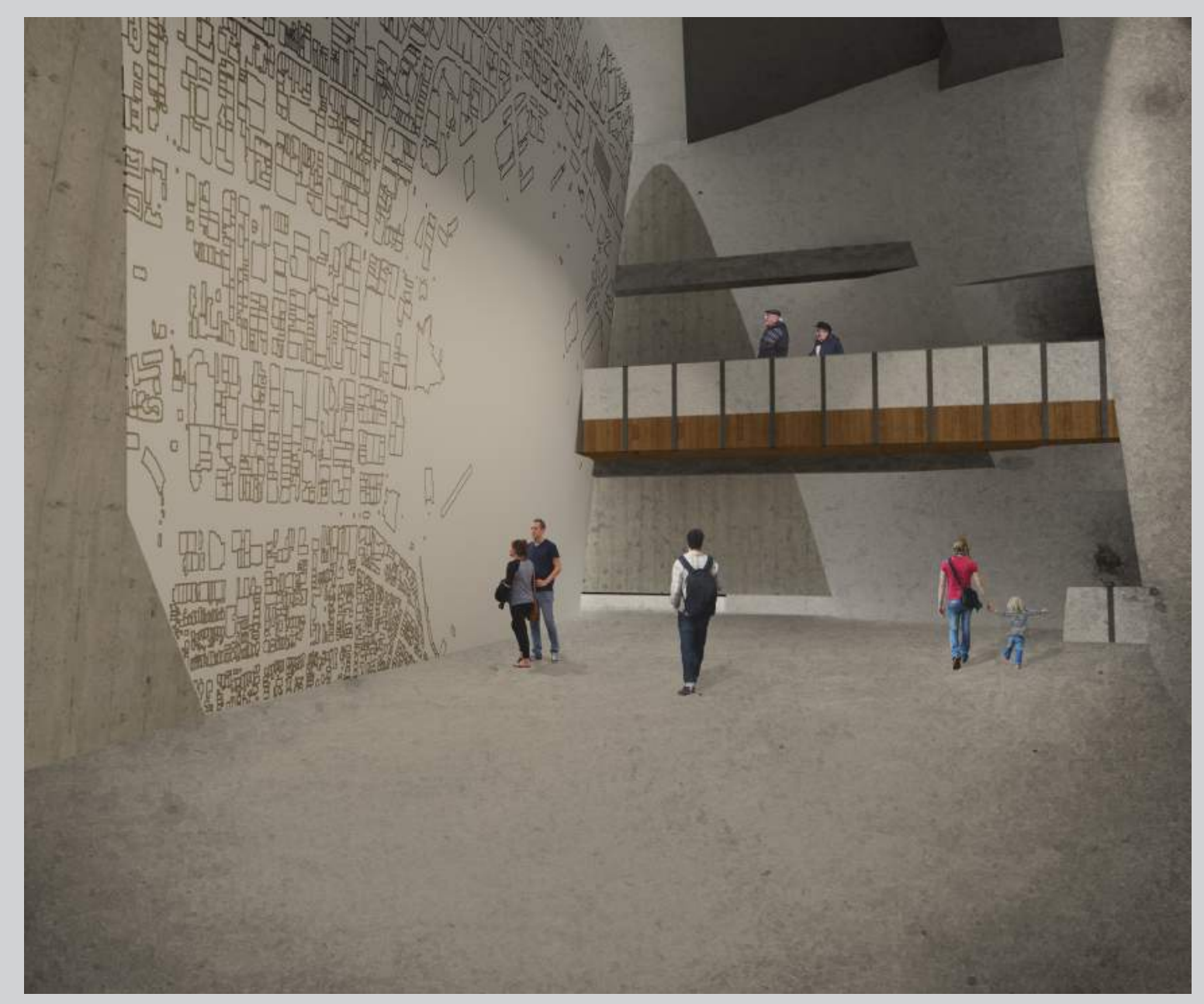

120 THE EXPERIENCE 


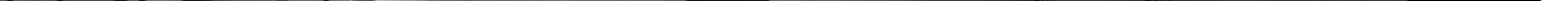


Fig. 90: Section portraying the connection between upper gallery void and the vertical/horizontal

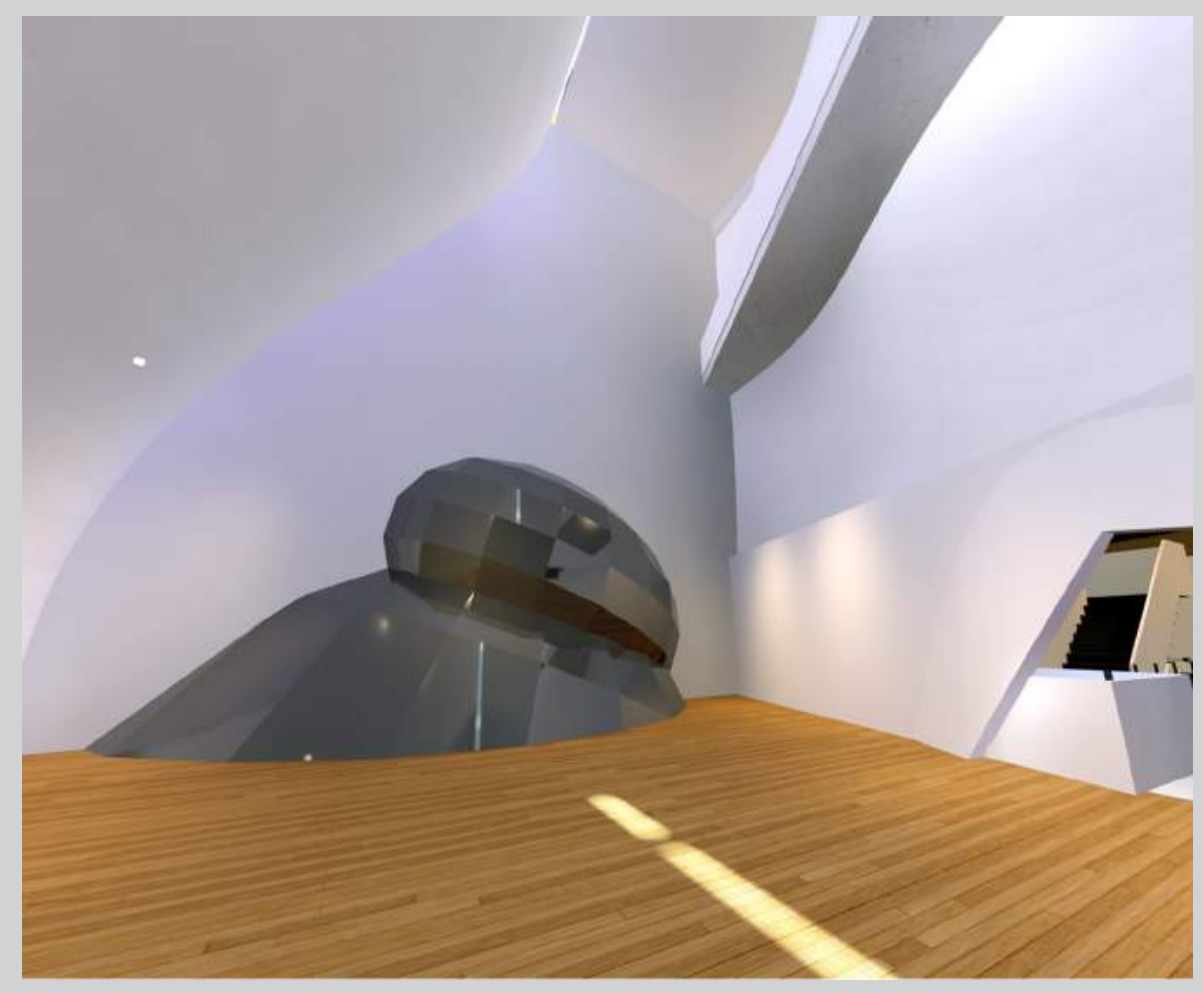

RIGHT

Fig. 91: Upper gallery void 


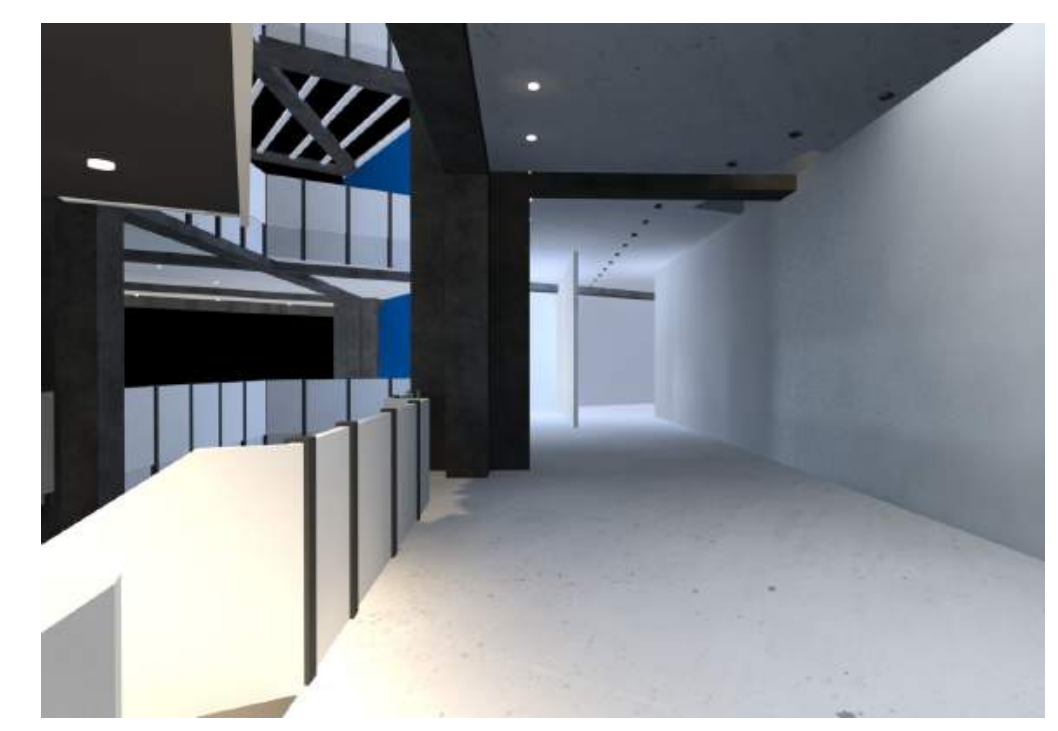

124 THE EXPERIENCE 

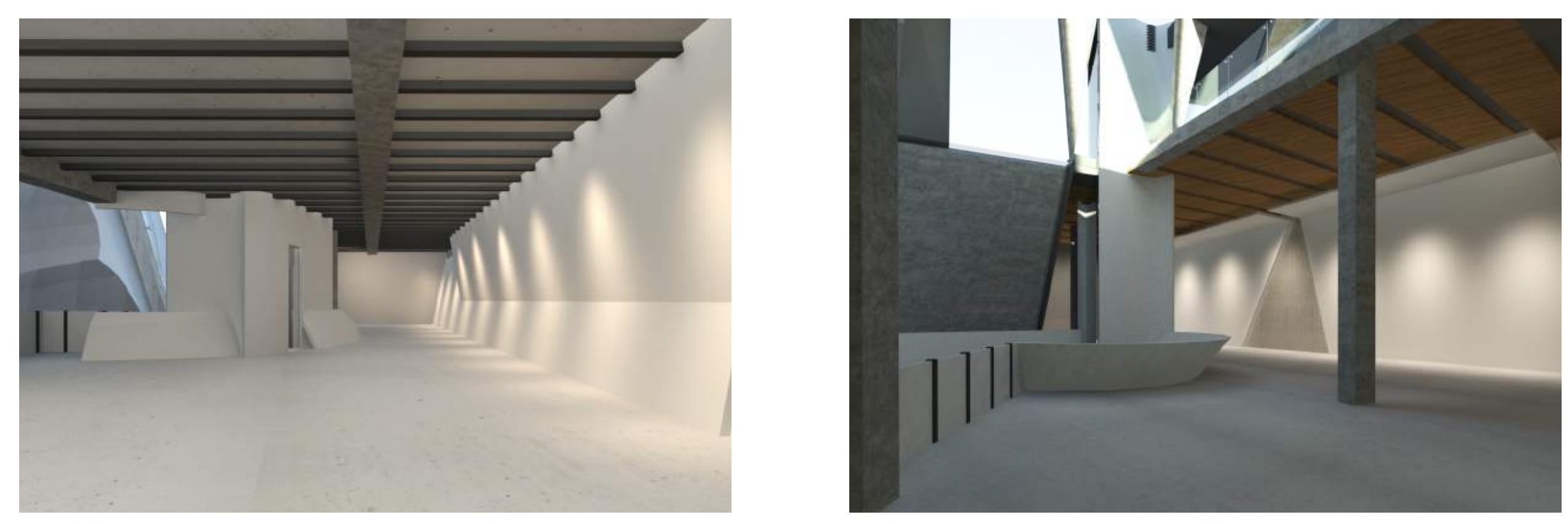



\subsubsection{MEMORY OF THE EXPERIENCE}

Te Papa, the National Museum of New Zealand, began as a self-conscious attempt to architecturalise New Zealand nationalism through an artifice of representative objects. Criticism of Te Papa has subsequently identified failings concerning the experiential component; its interior architecture.

This research explores an alternative museum of what could have been an icon for New Zealand's architecture and National Museum. An experience of monumental interiors is uncommon within New Zealand architecture and is what should be achieved within our national museum.

Museums tell stories through architecture as well as the objects within. We don't know what the internal experience of Athfield and Gehry's design could have been, and unfortunately we never will. We can only hope that it would have exceeded the internal experience of Te Papa Tongarewa. The focus of Te Papa is on the telling the story of our nation as a whole whereas the aim of re-imagining the Athfield/Gehry museum is to exploit the individual. The physicality of the cannon, vase and treasure-box atriums aim to tell the metaphorical story of our nation, but it is the experience of the interior that prompts the story unique to the individual.

Designing the museum from the inside out has resolved a symbolic and monumental interior of historical narrative. Nations require symbols as a form of representation, but a concept of nationhood that loses sight of individual experiences forgets that it is the people that complete the performance of an interior space. History is not static, and the way we read and understand our history varies with time as well as with the individual. It is the adaptation of our historical influences and national identity that will change the way in which we perceive, interpret and remember the museums internal experience. 


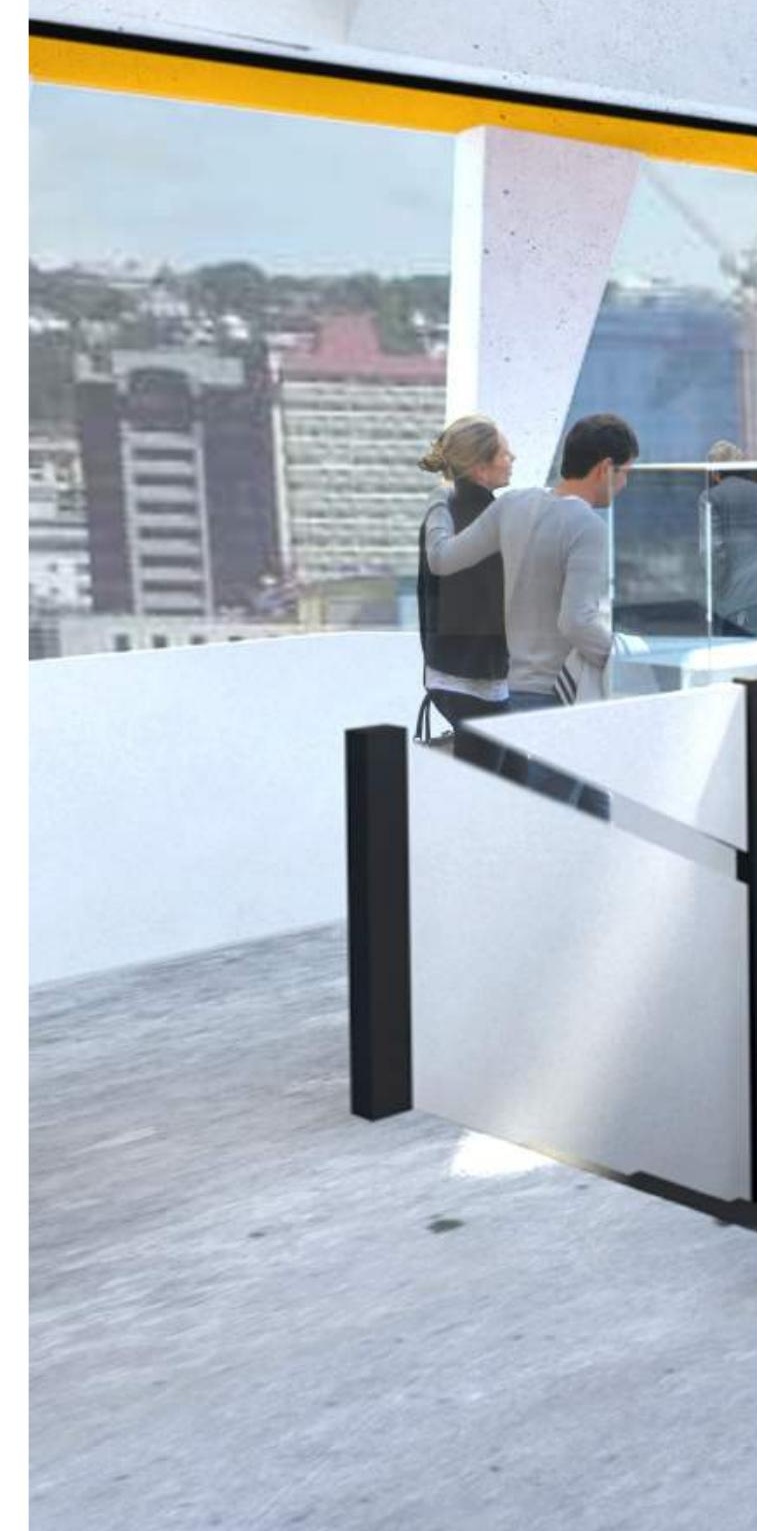




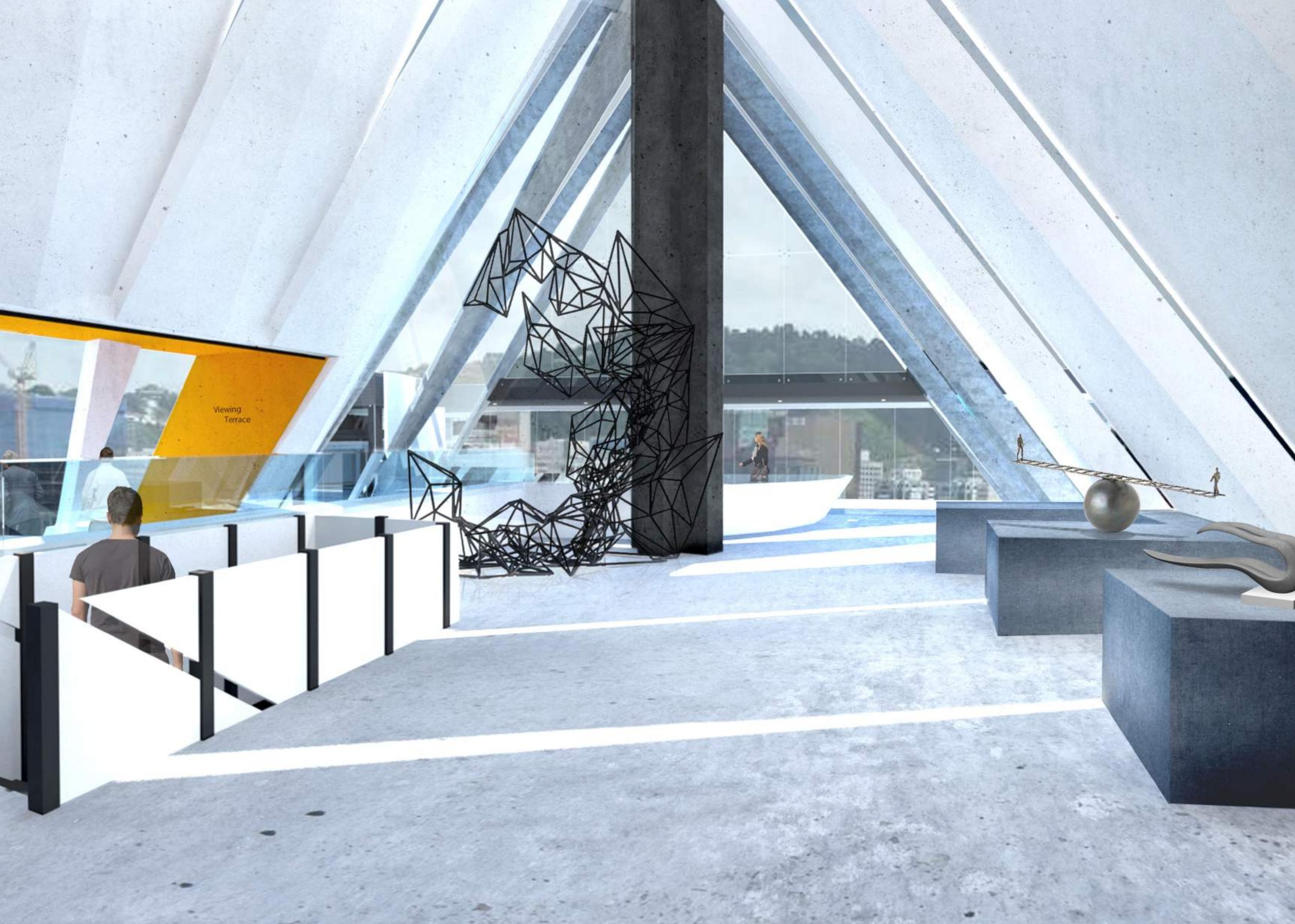




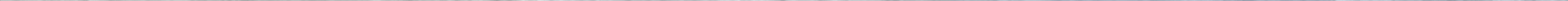




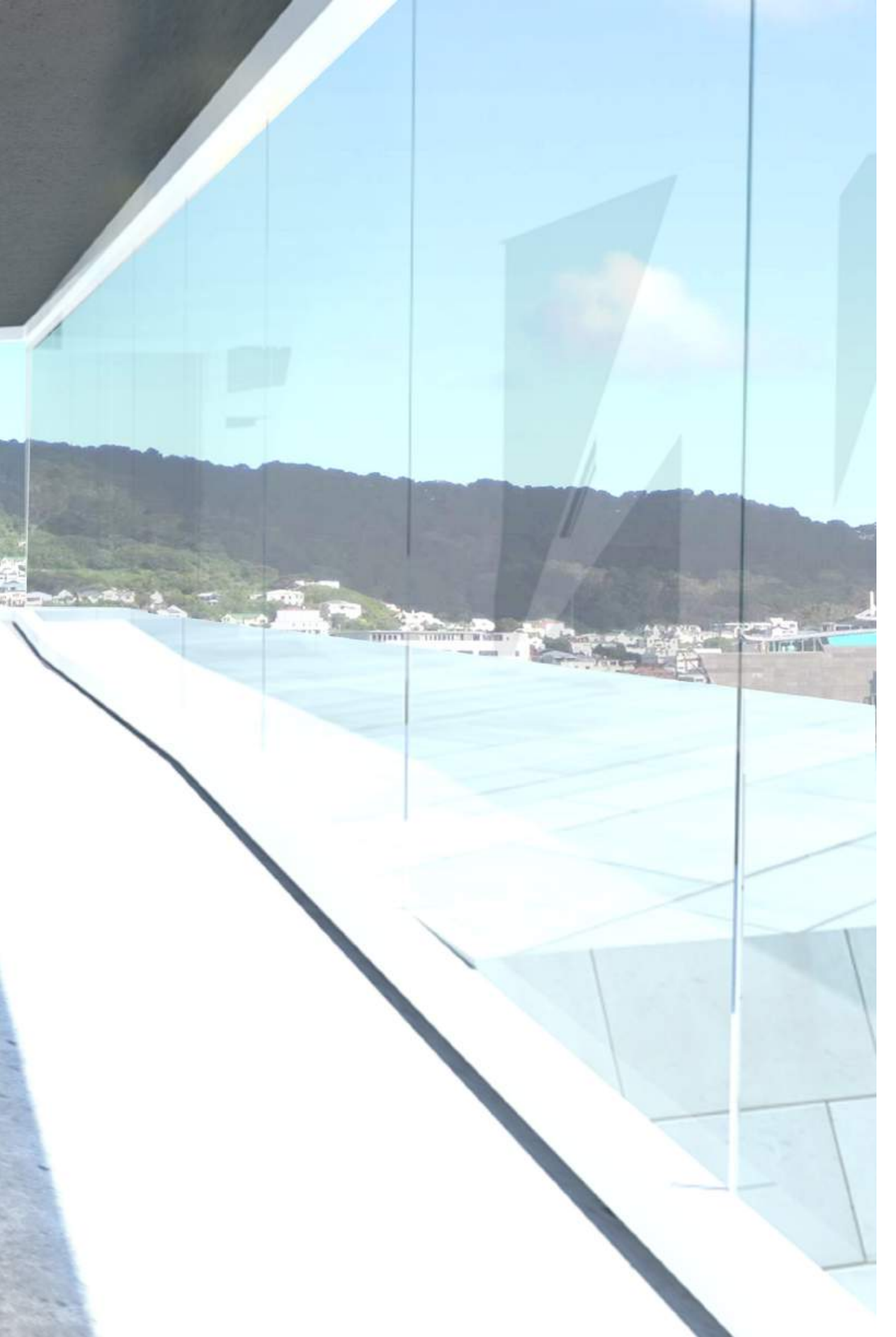

Fig. 96: Sculpture garden and viewing terrace. Viewing south 



\section{LIST OF FIGURES}

Fig 01: Created by author.

Fig. 02: Created by author

Fig. 03: Created by author

Fig. 04: North corner of Te Papa Tongarewa and the 'Solace in the Wind Sculpture'. Photographed by author. 29 March 2015.

Fig. 05: Bossley, Pete. "Concepts in Culture.” Architecture New Zealand February 1998: Print, p. 19

Fig. 06: Ian Athfield and Frank O. Gehry Museum of New Zealand Proposal. 1989.

Fig. 07: Port of Wellington. Digital image. Tours from Port of Wellington. Legend Tours and Travel. Web. 18 Nov.

2015. http://www.legendtours.co.nz/cruise-ship-travellers tours-from-port-of-wellington.

Fig. 08: Te Papa Tongarewa - Discover - STQRY https://discover stqry.com/v/te-papa-tongarewa/s/6fbd67883a060bee4d86f $3 \mathrm{c} 262019165$

Fig. 09: Image series produced by author

Fig. 10: Ian Athfield and Frank O. Gehry "Plan Drawing 01" National Museum of New Zealand Proposal.

Fig. 11: Ian Athfield and Frank O. Gehry "Longitudinal Section (a)" National Museum of New Zealand Proposal.

Fig. 12: Ian Athfield and Frank O. Gehry "Section" National Museum of New Zealand Proposal

Fig. 13: Ian Athfield and Frank O. Gehry "National Museum of New Zealand Proposal'

Fig. 14: Image produced by author

Fig. 15: Image produced by author

Fig. 16: Image produced by author

Fig. 17: Bernhardt, Michael. "Measuring MoMA" MoMA Atrium Calculations. 09 November 2015. https://mikebernhardt.wordpress. com/category/measuring-moma/

Fig. 18: Bitter, Bredt. "Denver Art Museum / Daniel Libeskind" 09 November 2015. http://www.archdaily.com/80309/

denver-art-museum-daniel-libeskind/5012a67028ba0d14 7d000191-denver-art-museum-daniel-libeskind-photo

Fig. 19: Moreno, Moris. "Dali Museum, Florida" Al Hilal.

23 March, 2011. http://www.architecturelist.com/2011/03/23/

dali-museum-florida-by-hok

Fig. 20: Image rendered by author

Fig. 21: Bean, Morey. "Libeskind's Extension to the Denver Art 
Museum". 10 September 2010. http://buildipedia.com/aec-pros/ featured-architecture/libeskinds-extension-to-the-denver-artmuseum?print $=1 \& \mathrm{tmpl}=$ component

Fig. 22: Solomon R. Guggenheim Foundation. "Installation Views". The Lighting of a Great Museum. 06 November 2014 http://blogs.guggenheim.org/findings/lighting-great-museum/

Guggenheim Museum, New York City. Frank Lloyd Wright. Curving walls of the continuous gallery space.

Fig. 23: Bloomer, Kent C. and Charles W. Moore. "Museum for a Small City (1942)". Body, Memory and Architecture. London: New Haven and London Yale University, 1935. Print, p. 73

Fig. 24: Tate Modern, “Tate Modern, Starr Auditorium” Curator's Talk: Tino Sehgal. 22 September 2012. http:// www.tate.org.uk/whats-on/tate-modern/talks-and-lectures/ curators-talk-tino-sehgal

Fig. 25: Image rendered by author

Fig. 26: Image created by author. Replicated from Pine, Joseph and James Gilmore. "Experience Realms" The Experience Economy. Boston, Massachusettes: Harvard Business Review Press, 1999. Print, p. 46

Fig. 27: John Pawson. "Moritzkirche". Augsberg, Germany, 2013. http://www.johnpawson.com/works/moritzkirche/
Fig. 28: Image created by author

Fig. 29: Chris Peters "Jewish Museum,

Berlin". 28 June 2012. https://www.quora.com/

What-are-some-of-the-most-dramatic-interior-spaces

Fig. 30: Image created by author

Fig. 31: Image created by author

Fig. 32: Image created by author

Fig. 33: Ardfern. "Museum Interior Bilbao" 15 July 2010

https://commons.wikimedia.org/wiki/File:Guggenheim Museum_interior,_Bilbao,_July_2010_\%2801\%29.JPG

Fig. 34: Image series created by author

Fig. 35: Image series created by author

Fig. 36: John Brown, "Guggenheim Bilbao Exhibitions". Guggenheim Museum Bilbao. 09 September 2015 http://www. etraveltrips.com/guggenheim-museum-bilboa/

Fig. 37: Image created by author

Fig. 38: Photographed by author. 01 June 2015

Fig. 39: Image created by author

Fig. 39: Image created by author 
Fig. 40: Image created by author

Fig. 41: Model created and photographed by author. 15 January 2015

Fig. 42: Photo series created by author.

Fig. 43: Photo series created by author.

Fig. 44: Lowinger, Gene. "Guggenheim Museum, New York City, NY”. 2015. http://www.street-urban.com/galleria_it_1. htm\#.Vs94Lkb-11A

Fig. 45: Bednar, M.J. "Greek and Roman Domus" The New Atrium. New York: McGraw-Hill, 1986. Print, p. 06

Fig. 46: Image created by author.

Fig. 47: Image created by author.

Fig. 48: Drawing series created by author

Fig. 49: Treasure-box artefact from Te Papa Tongarewa collections. Tongarewa, Te Papa. "Wakahuia (Treasure Box)." Museum of New Zealand Te Papa Tongarewa Circa 2000. Web. 03 May 2015.

Fig. 50: Image created by author.

Fig. 51: Image created by author.
Fig. 52: Drawing series created by author.

Fig. 53: Image created by author.

Fig. 54: Vase artefact from Te Papa Tongarewa collections. Tongarewa, Te Papa. "Vase." Museum of New Zealand Te Papa Tongarewa Circa 2000. Web. 03 May 2015.

Fig. 55: Image created by author.

Fig. 56: Image created by author.

Fig. 57: Image created by author.

Fig. 58: Drawing series. Exploration of placement for cannon atrium. Created by author

Fig. 59: Cannon artefact from Te Papa Tongarewa collections. Tongarewa, Te Papa. "The Endeavor Cannon." Museum of New Zealand Te Papa Tongarewa Circa 2000. Web. 03 May 2015.

Fig. 60: Image created by author.

Fig. 61: Image created by author.

Fig. 62: Image created by author.

Fig. 63: Image created by author.

Fig. 64: Image created by author.

Fig. 65: Image created by author. 
Fig. 66: Sketch series created by author.

Fig. 67: Image created by author.

Fig. 68: Sketch series created by author.

Fig. 69: Image created by author.

Fig. 70: Sketch series created by author.

Fig. 71: Render series created by author.

Fig. 72: Line drawing series created by author.

Fig. 73: Image rendered by author.

Fig. 74: Image rendered by author.

Fig. 75: Image rendered by author.

Fig. 76: Image rendered by author.

Fig. 77: Image rendered by author.

Fig. 78: Image rendered by author.

Fig. 79: Image rendered by author.

Fig. 80: Image rendered by author.

Fig. 81: Image rendered by author.

Fig. 82: Image rendered by author.
Fig. 83: Image rendered by author.

Fig. 84: Image rendered by author.

Fig. 85: Image rendered by author.

Fig. 86: Image rendered by author.

Fig. 87: Image rendered by author.

Fig. 88: Image rendered by author.

Fig. 89: Image rendered by author.

Fig. 90: Image rendered by author.

Fig. 91: Image rendered by author.

Fig. 92: Image rendered by author.

Fig. 94: Image rendered by author.

Fig. 95: Image rendered by author.

Fig. 96: Image rendered by author. 


\section{BIBLIOGRAPHY}

Abraham, Raimund. Unbuilt. Trans. Maria E. clay, Camilla Nielsen. Slovenia: Springer-Verlag/Wien, 1996. Print. Bednar, M.J. The New Atrium. New York: McGraw-Hill, 1986. Print.

Bloomer, Kent C. and Charles W. Moore. Body, Memory and Architecture. London: New Haven and London Yale University, 1935. Print.

Bradwell, Simon \& Tom Hunt. "Renowned Architect Sir Ian Athfield Dies, Aged 74." 16 January 2015. Web. 26 May 2015

Chametzky, Peter. "Not What We Expected: The Jewish Museum Berlin in Practice." Museum and Society Vol. 06.No. 03 (2008): 216-45. Print.

Corbusier, Le. Towards a New Architecture. 1927. Trans. Etchells, Frederick. London: The Architectural Press, 1946. Print.

Fitzgerald, Lawrence. "Building on Victorian Ideas." Reshaping Museum Space: Architecture, Design, Exhibitions. Ed. Macleod, Suzanne. London and New York: Routledge Taylor \& Francis Group 2005. 133-45. Print.

Fleming, David. "Creative Space." Reshaping Museum Space: Architecture, Design, Exhibitions. Ed. MacLeod, Suzanne. London and New York: Routledge Taylor \& Francis Group, 2005. 53-61. Print.

Foundation, Guggenheim. “Guggenheim: Press Release Archive.” 12 Jan 2016 2016. Web. 13 Jan 2016.

Foundation”, “Guggenheim. “Bilbao History.” Guggenheim Date Unknown. Web. 06 May 20152015.

Gehry, Ian Athfield and Frank O. Museum of New Zealand Proposal. 1989.

Goldberger, Paul. Why Architecture Matters. Connecticut: Yale University Press, 2009. Print. 
Gorbey, Ken. "Landmark Architecture Serves Museums - the Example of the Jewish Museum Berlin.” Museum Autearoa Conference. 2007. Print.

Group, Jasmax. “Te Papa Tongarewa - Museum of New Zealand.” Architecture New Zealand July/Aug 1990: 30-34. Print.

Hoberman, Ruth. "Museum Dreams." Museum Trouble: Edwardian Fiction and the Emergence of Modernism. United States: University of Virginia Press, 2011. 256. Print.

Holtschneider, Hannah K. The Holocaust and Representations of Jews: History and Identity in the Museum. Routledge Jewish Studies Series. London: Taylor \& Francis, 2011. Print.

Hunt, John. "Process of Selection.” Architecture New Zealand Feb. 1998: 14-16. Print.

Hutchison, AJH. "Reclamations in Wellington Harbour with Special Reference to Recent Developments " New Zealand Engineering Vol. 28.No.8 (1973): 217-24. Print.

Jameson, Fredric. Postmodernism, or, the Cultural Logic of Late Capitalism. Duke University Press, 1991. Print.

Kelly, Michael. “Old Shoreline - Heritage Trail.” 1996. Ed. Council, Wellington City. 2nd ed. Wellington: Absolutely Positively Wellington, 2005. Print.

Kumar, Jatishbag. "The Architectural Spaces and Their Psychological Impacts." National Conference on Cognitive Research on Human Perception of Built Environment for Health and Wellbeing. 2012. Print.

Lake-Hammond, Alice \& Noel Waite. "Exhibition Design: Bridging the Knowledge Gap." The Design Journal 13.01 (2010): 77-98. Print. 
Leach, Neil. Rethinking Architecture: A Reader in Cultural Theory. Psychology Press, 1997. Print.

Leahy, Helen Rees. "Producing a Public for Art." Reshaping Museum Space: Architecture, Design, Exhibitions. Ed. Macleod, Suzanne. London and New York: Routledge Taylore and Frances Group, 2005. 108-17. Print.

Lederer, Arno. "Circulation Areas - Places for Interaction or an El Dorado for Building Regulations?" Trans.

Aichele-Platen, Antoinette. Designing Circulation Areas : Staged Paths and Innovative Floorplan Concepts. Ed.

Schittich, Christian. Germany: Institut Für Internationale Architektur-Dokumentation GmbH \& Col. KG, 2013. 1421. Print.

Lewis, Michael J. “The Guggenheim in Bilbao.[Critical Essay]." New Criterion 17 (1999): 52-54. Print.

Linzey, Michael. "A Fault-Line at Te Papa - the Use of a Metaphor." The Journal of the Society of Architectural Historians 17.1 (2007): 68-81. Print.

MacCannell, Dean. "The Ethics of Sightseeing." The Ethics of Siteseeing. 1 ed. United States: University of California Press, 2011. 288. Print.

MacLeod, Suzanne. Reshaping Museum Space. Ed. Macleod, Suzanne. London and New York: Routledge Taylor \& Francis Group, 2005. Print.

---. "Rethinking Museum Architecture: Towards a Site Specific History of Production and Use." Reshaping Museum Space: Architecture, Design Exhibitions. Ed. Macleod, Suzanne. London and New York: Routledge Taylor \& Frances Group, 2005. 09-25. Print.

Marriage, Guy. "Significant Social Space: Connecting Circulation in Atrium Design." Victoria University of Wellington, 2012. Print. 
Milojevic, Michael. “An Architecture of Difference." Australian-Canadian Studies Vol. $15 . N o .1$ (1997): 75-104. Print. Parkinson, Robin. "Design in Exhibits." Architecture New Zealand February 1998: 61-62. Print.

Pine, Joseph and James Gilmore. The Experience Economy. Boston, Massachusettes: Harvard Business Review Press, 1999. Print

Rasmussen, S.E. Experiencing Architecture. M.I.T. Press, 1964. Print.

Saxon, Richard. Atrium Buildings: Development and Design. Second ed. London: Architectural Press Limited, 1989. Print.

Shiner, Larry. "On Aesthetics and Function in Architecture: The Case of the "Spectacle" Art Museum." The Journal of Aesthetics and Art Criticism 69.1 (2011): 31-41. Print.

Shum, Katrina. “A Place for Space: Atrium.” Victoria University of Wellington, 1990. Print.

Sully, Anthony. "Circulation Concept." Interior Design: Conceptual Basis. Switzerland: Springer International Publishing, 2015. 37-51. Print.

Tongarewa, Te Papa. “The Endeavor Cannon.” Museum of New Zealand Te Papa Tongarewa Circa 2000. Web. 03 May 2015.

---. Museum of New Zealand Te Papa Tongarewa Te Pürongo Ā Tau / Annual Report 2013/14 Wellington, NZ2014. Print.

---. "Our History." Web.

---. "Vase." Circa 2000. Web. 03 May 2015. 
--. "Wakahuia (Treasure Box)." Circa 2000. Web. 03 May 2015.

Wannan, Olivia. "Training All Eyes on Shifting a Hotel." Dominion Post (17 Aug 2003). Web. 09 Feb 2016.

Young, James E. "Daniel Libeskind's Jewish Museum in Berlin: The Uncanny Arts of Memorial Architecture.” Jewish Social Studies 6.2 (2000): 1-23. Print.

Zealand, Museum of New. Briefing to the Incoming MinisterDecember 2011. Print. 

